Development of novel electrode materials for the electrocatalysis of oxygen-transfer and hydrogentransfer reactions.

by

\title{
Brett Kimball Simpson
}

A dissertation submitted to the graduate faculty

in partial fulfillment of the requirements for the degree of

DOCTOR OF PHLOSOPHY

Major: Analytical Chemistry

Program of Study Committee:

Dennis C. Johnson, Major Professor

David Cann

R. Sam Houk

Marc Porter

L. Keith Woo

Iowa State University

Ames, lowa 


\section{Graduate College}

Iowa State University

This is to certify that the doctoral dissertation of

Brett Kimball Simpson

has met the dissertation requirements of Iowa State University

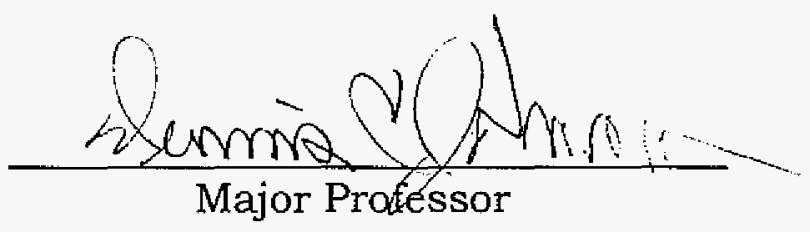

For the Major Program 


\section{TABLE OF CONTENTS}

CHAPTER 1. INTRODUCTION

General Introduction

Thesis Organization 9

References 11

CHAPTER 2. ELECTROCATALYTIC ACTIVITY FOR OXYGENTRANSFER REACTIONS AT IRON(III)-DOPED MANGANESE DIOXIDE FILMS

$\begin{array}{ll}\text { Abstract } & 15 \\ \text { Introduction } & 15 \\ \text { Experimental } & 18 \\ \text { Results and Discussion } & 20 \\ \text { Conclusions } & 32 \\ \text { Acknowledgements } & 33 \\ \text { References } & 33 \\ \text { Figures } & 36\end{array}$

CHAPTER 3. ENHANCEMENT OF ANODIC RESPONSE FOR DMSO AT RUTHENIUM OXIDE FILM ELECTRODES AS A RESULT OF DOPING WITH IRON(III)

Abstract

Introduction 
$\begin{array}{ll}\text { Conclusions } & 60\end{array}$

Acknowledgements $\quad 61$

References $\quad 62$

$\begin{array}{ll}\text { Figures } & 64\end{array}$

CHAPTER 4. ELECTROCATALYSIS OF NITRATE REDUCTION 69 REACTIONS AT VARIOUS PURE METAL AND ALLOY ELECTRODES

\begin{tabular}{lr} 
Abstract & 69 \\
Introduction & 69 \\
Experimental & 73 \\
Results and Discussion & 74 \\
Conclusions & 81 \\
Acknowledgements & 82 \\
References & 83 \\
Tables & 86 \\
Figures & 88 \\
$\quad$ REACTIONS IN ACIDIC MEDIA AT COPPER-NICKEL & \\
CHAPTER 5. ELECTROCATALYSIS OF NITRATE REDUCTION & 95 \\
& \\
Abstract & \\
Introduction & 95 \\
Experimental & 96 \\
Results and Discussion & 99 \\
Conclusions & 101 \\
Acknowledgements & 111 \\
References & 113 \\
\hline
\end{tabular}


Table

116

Figures

117

CHAPTER 6. CONCLUSIONS

General Conclusions

126

Future Research

127

ACKNOWLEDGEMENTS

128 


\section{CHAPTER 1. INTRODUCTION}

\section{General Introduction}

The main focus of research in our group has been to increase our knowledge of the fundamental aspects of processes involved in the mechanisms for the electrocatalysis of oxygen-transfer (O-transfer) and hydrogen-transfer (H-transfer) reactions. Based upon the knowledge obtained, novel electrode materials have been developed with improved electrocatalytic properties for the transfer reactions. The novel electrode materials have practical applications in electrochemical detection, environmental remediation, and electrosynthesis.

An overall equation for the electrocatalysis of an anodic $\mathrm{O}$-transfer reaction can be shown by

$$
\mathrm{R}+\mathrm{H}_{2} \mathrm{O} \rightarrow \mathrm{RO}+2 \mathrm{H}^{+}+2 \mathrm{e}^{--}
$$

where $\mathrm{R}$ represents a generic organic molecule and RO represents the oxidation product of a single O-transfer from $\mathrm{H}_{2} \mathrm{O}$ to $\mathrm{R}$. Equation 1 is a simplified version of the processes involved in O-transfer reactions. The actual transfer occurs at the electrode surface by the interaction of $\mathrm{R}$ with a labile species such as $\mathrm{OH}$. Therefore, interaction of the reactant species $\mathrm{R}$ with the electrode surface is pertinent for Eqn. 1. In addition, the potential at the electrode must be sufficiently positive to facilitate the formation of adsorbed $\mathrm{OH}$ species through the anodic discharge of $\mathrm{H}_{2} \mathrm{O}$. 
An overall reaction for the electrocatalysis of cathodic $\mathrm{H}$-transfer reactions in acidic media can be represented by

$$
\mathrm{RO}+2 \mathrm{H}^{+}+2 \mathrm{e}^{-} \rightarrow \mathrm{R}+\mathrm{H}_{2} \mathrm{O}
$$

where RO represents a generic molecule with at least one oxygen moeity and $\mathrm{R}$ represents the reduction product of transfer of two $\mathrm{H}$-atoms to the $\mathrm{O}$-atom on $\mathrm{RO}$. As was seen for $\mathrm{O}$-transfer reactions, the transfer of $\mathrm{H}$-atoms occurs at the electrode surface. Thus the target molecule, $\mathrm{RO}$, must interact with the electrode surface. Additionally, the potential at the electrode must be sufficiently negative to allow formation of adsorbed H-atoms, through the reduction of $\mathrm{H}^{+}$in solution.

While at different ends of the electrochemical spectrum, i.e. $\mathrm{O}_{2}$ and $\mathrm{H}_{2}$ evolution, Eqns. 1 and 2 share similar properties. Both have a prerequisite step of adsorption of reactant species. Benefits of adsorption of reactant species include partial desolvation of reactant, which aids the O-transfer and $\mathrm{H}$-transfer processes at the electrode surface, and increased lifetime of the reactant species at the electrode surface, which increases current efficiency for the transfer reactions. The transfer reactions also share the requirement of formation of an additional adsorbed reaction species $(\mathrm{O}-$ atoms, $\mathrm{H}$-atoms) at the electrode surface. The potentials at which Eqns. 1 and 2 occur depend upon their corresponding overpotentials (n) for $\mathrm{O}_{2}(\mathrm{~g})$ evolution and $\mathrm{H}_{2}(\mathrm{~g})$ evolution at a particular electrode material. 
The above has been an extreme simplification of complex mechanisms. However, the principles behind the choice of electrode materials for said reactions are similar. While electrode materials will generally not exhibit electrocatalytic properties for both reactions, the determination of electrode materials that exhibit electrocatalytic properties for the desired reaction is similar. In both instances, the electrode material must exhibit bifunctional properties for catalysis of two separate adsorption processes, one of which must be the absorption of the reactant species. For Eqn. 1, reactant adsorption must occur concurrently with the formation of adsorbed O-atoms while with Eqn. 2, the adsorption must occur concurrently with the formation of adsorbed H-atoms.

The research in this thesis pertains to the search of novel electrode materials specific to Eqns. 1 and 2. Doped metal oxide films are appropriate electrode materials for anodic O-transfer reactions (Eqn. 1). Quite often, metal oxide films suffer from cathodic stripping, resulting in loss of film, at potentials significantly more positive than those required for Eqn. 2 to occur. Therefore, alloy electrode materials were studied for cathodic $\mathrm{H}-$ transfer reactions (Eqn. 2).

Anodic O-transfer Reactions - Based on thermodynamic information, anodic $\mathrm{O}$-transfer reactions of polar aliphatic organic compounds are expected to be achieved easily using noble metal electrodes, e.g., Au and Pt. However, noble metal electrodes often exhibit loss in activity, which is 
attributed to the adsorption of intermediate and oxidation product species at the electrode surface. Because traditional noble electrode materials are incapable of facilitating anodic O-transfer reactions, metal oxide electrodes have been studied to provide alternative materials for use in anodic $\mathrm{O}$ transfer reactions.

A thorough discussion of the literature of electrocatalysis at metal oxide films is beyond the scope of this introduction. Therefore, only specific cases pertinent to this research will be discussed. Various structures are seen for the metal oxide film electrodes used in electrocatalysis. The reader is directed to the following reviews for in depth discussion of experimental techniques and theory for spinel-type[1], perovskite-type[2], and rutiletype[3] oxides.

Lead dioxide film electrodes have maintained major interest in industry and academia due to their activity for O-transfer reactions. [4-6] Extensive research has been carried out in our group with regards to the aand $\beta-\mathrm{PbO}_{2}$ film electrodes. Incorporation of $\mathrm{Bi}(\mathrm{V})$ within the nonstoichiometric lattice of the $\beta-\mathrm{PbO}_{2}$ film electrodes increased electrocatalytic activity for anodic O-transfer reactions as compared to the undoped film.[712] Popovic and Johnson found that the $\mathrm{Bi}(\mathrm{V})$ sites acted as adsorption sites for target reactant molecules such as DMSO. The improvement of activity was explained by the provision at the electrode surface of separate catalytic sites for DMSO and OH adsorption in the film. [11] 
Treimer and Johnson found that doping of the $\beta-\mathrm{PbO}_{2}$ films with $\mathrm{Fe}(\mathrm{III})$ improved catalytic response with respect to anodic O-transfer reactions involving toluene, xylene and phenol. $[13,14]$ Extensive research of various other electrocatalytic properties of doped and undoped $\mathrm{PbO}_{2}$ film electrodes indicates that the films exhibit good mechanical stability, are reproducibly electrodeposited and support a large number of O-transfer reactions. [15-28]

Although the $\mathrm{PbO}_{2}$ films show good mechanical stability, the development of electrode materials of a less toxic and more environmentally friendly matrix is desired. The knowledge obtained from the study of the $\mathrm{PbO}_{2}$ films that pertain to the principal processes involved in anodic $\mathrm{O}$ transfer reactions, i.e. reaction mechanisms and dopant effects, is expected to be applicable to the development of other metal oxide film electrodes such as $\mathrm{MnO}_{2}$ and $\mathrm{RuO}_{2}, \mathrm{MnO}_{2}$ and $\mathrm{RuO}_{2}$ have been selected for further study based upon their electrocatalytic properties for $\mathrm{O}_{2}(\mathrm{~g})$ evolution in acidic media and simple deposition techniques.

Boron-doped diamond (BDD) electrodes have gained much attention for use in electrocatalysis due to their remarkable properties. The BDD electrodes exhibit stable voltammetric background currents, large working potential windows, and long-term response stability.[29, 30] The electrodes have displayed electrocatalytic activity for oxidation of polyamines[31, 32], histamine and serotonin[33, 34], organic acids[35] and various sulfur- 
containing compounds[36]. The BDD electrodes show great promise for future applications, however, study of said films was decided against due to the difficulties and instrumentation requirements involved in the deposition procedures.

Cathodic H-transfer Reactions - As stated previously, the principles governing anodic $\mathrm{O}$-transfer reactions can also be correlated to cathodic $\mathrm{H}$ transfer reactions. A requisite step for these reactions is the formation of adsorbed $\mathrm{H}$-atoms at the electrode surface which occurs by the Vollmer reaction.[37] A great deal of interest has been shown for the electrocatalytic hydrogenation $(\mathrm{ECH})$ of various organic compounds. A recent review discussed a general mechanism (similar to the one proposed for cathodic $\mathrm{H}$ transfer reactions in this introduction) for $\mathrm{ECH}$ of numerous organic compounds at various electrode materials which included Pt, Pd, conducting polymers and Raney-type materials. It was concluded that the study of ECH has allowed the development of electrode materials that exhibit properties of high selectivity and efficiency, yet, ECH is rarely seen on the industrial scale.[38]

The reduction of oxygen at various electrode materials has also received much attention due to its role in many important electrochemical processes. A recent review discussed oxygen reduction reactions at noble and nonnoble metal electrodes, various metal oxides, such as leadruthenate pyrochlores, and Au electrodes modified by metal adatoms. [39] 
The deposition of metal adatoms of $\mathrm{Pb}, \mathrm{Bi}$ and $\mathrm{Tl}$ increased catalytic activity with the mechanism for oxygen reduction changing from a two-electron process $\left(\mathrm{H}_{2} \mathrm{O}_{2}\right.$ formation), seen for $\mathrm{Au}$, to a four-electron process $\left(\mathrm{H}_{2} \mathrm{O}\right.$ formation).[39]

The target analyte of interest in our studies of cathodic $\mathrm{H}$-transfer reactions was $\mathrm{NO}_{3}{ }^{-}$. The cathodic $\mathrm{H}$-transfer reaction involving $\mathrm{NO}_{3}{ }^{-}$ reduction in acidic media can be represented by

$$
\mathrm{NO}_{3}{ }^{-}+2 \mathrm{H}^{+}+2 \mathrm{e}^{-} \rightarrow \mathrm{NO}_{2}^{-} \text {ads }+\mathrm{H}_{2} \mathrm{O}
$$

Based upon research for anodic O-transfer reactions, the development of a material with separate sites for adsorption of reactant species and adsorption of $\mathrm{H}$-atoms is expected to show improved electrocatalytic properties.

An initial study of $\mathrm{NO}_{3}^{-}$reduction at various pure metal electrodes was carried out by Khomutov and Stamkulov. They observed that the reduction potential for $\mathrm{NO}_{3}-$ in nitric acid solutions showed a dependence upon the atomic number of the cathode material.[40] Vijh decided to * reinterpret the data with respect to metal hydrogen $(\mathrm{M}-\mathrm{H})$ and metal oxygen (M-O) bonding energies. Transition metals showed volcano type plots with respect to $\mathrm{NO}_{3}{ }^{-}$reduction potential vs. $\mathrm{M}-\mathrm{H}$ and $\mathrm{M}-\mathrm{O}$ interaction energies. Metals with moderate values of bonding energies showed optimum activity.[41] 
Because of the prerequisite step of $\mathrm{NO}_{3}{ }^{-}$adsorption at the electrode surface, blocking of surface sites by adsorbed $\mathrm{H}$-atoms can result in loss of electrocatalytic activity for $\mathrm{NO}_{3}^{-}$reduction. The reduction of $\mathrm{NO}_{3}^{-}$on platinized Pt was found by Horanyi et al. to be adversely affected by surface saturation of the electrode by adsorbed $\mathrm{H}$-atoms. [42] Supporting evidence was seen by Bockris et al.[43] and Ohmori et al.[44] The loss of activity indicates the necessity for electrode materials that maintain separate sites for the adsorption processes occurring at the electrode surface.

A possible means for producing the desired electrode materials is by deposition of foreign metal adatoms upon metal electrodes. The electrodeposition of copper on cadmium was shown by Sherwood and Johnson to enhance $\mathrm{NO}_{3}{ }^{-}$reduction activity.[45, 46] Gootzen et al. also demonstrated the feasibility of adatom deposition for improvement in $\mathrm{NO}_{3}{ }^{-}$ response with a study of underpotential deposition of $\mathrm{Ge}$ at $\mathrm{Pt}, \mathrm{Pd}$ and $\mathrm{Pt}-\mathrm{Pd}$ alloy electrodes.[47]

Another possibility is the use of alloy electrode materials. Alloy combinations of $\mathrm{Cu}-\mathrm{Pd}[48,49], \mathrm{Cu}-\mathrm{Ni}[50]$ and $\mathrm{Pt}-\mathrm{Ir}[51]$ were studied to determine electrocatalytic activity for $\mathrm{NO}_{3}^{-}$reduction. A final interesting note is that boron-doped diamond electrodes exhibit enhanced response for nitrate reduction as well.[52-54] As stated in the beginning, very few electrode materials are expected to exhibit capabilities for both anodic Otransfer reactions and cathodic $\mathrm{H}$-transfer reactions. Thus, the use of alloy 
electrodes was investigated in this thesis for cathodic $\mathrm{H}$-transfer reactions in nitrate reduction.

\section{Thesis Organization}

The research described in this dissertation was conducted under the supervision of Dennis C. Johnson beginning in August of 1996. This dissertation consists of four main chapters which are preceded by this introduction and followed by conclusions. Two of the four main chapters are papers that have been submitted for publication or are in preparation for submission to peer-reviewed electrochemical journals. The papers are all written according to the same journal format.

Chapter 2 presents research involving the study of the electrocatalysis of anodic O-transfer reactions at undoped and $\mathrm{Fe}(\mathrm{III})$-doped $\mathrm{MnO}_{2}$ films electrodeposited upon Au. We attempted to find an electrode material that would demonstrate similar activity and stability for anodic O-transfer reactions as compared to the $\mathrm{PbO}_{2}$ film electrodes. Various deposition techniques for the $\mathrm{MnO}_{2}$ films were investigated to determine conditions required for maximum response for dimethyl sulfoxide (DMSO) oxidation. A new deposition technique, involving potential cycling, was considered and determined to provide adequate $\mathrm{MnO}_{2}$ films. Doping of the $\mathrm{MnO}_{2}$ films with Fe(III) improved the film properties. 
Chapter 3 is a paper that examines anodic $\mathrm{O}$-transfer reactions at $\mathrm{RuO}_{2}$ and $\mathrm{Fe}(\mathrm{III})$-doped $\mathrm{RuO}_{2}$ film electrodes deposited on Ti substrates. Further attempts were made to find films of similar activity and stability as compared to the $\mathrm{PbO}_{2}$ films. Various thermal deposition techniques were explored for determination of optimal film deposition conditions. The effect of doping the $\mathrm{RuO}_{2}$ films with $\mathrm{Fe}$ (III) was studied with respect to DMSO oxidation. Flow injection analysis was carried out to determine the feasibility of electrochemical detection using $\mathrm{Fe}$ (III)-doped $\mathrm{RuO}_{2}$ film electrodes.

Chapter 4 discusses an initial study of the electrocatalysis of cathodic $\mathrm{H}$-transfer reactions involving $\mathrm{NO}_{3}-$ reduction at various pure metal and alloy electrodes. The pure metals were studied to examine the effects of $\mathrm{H}_{2}$ (g) evolution upon their response for $\mathrm{NO}_{3}-$ reduction. The incorporation of metals with varying electrocatalytic properties for $\mathrm{NO}_{3}{ }^{-}$reduction was shown to improve response for electrodes vs. the pure component metals. Alloys studied consisted of combinations (atomic \%) of $\mathrm{Cu}$ and $\mathrm{Ni}\left(\mathrm{Cu}_{25} \mathrm{Ni}_{75}\right), \mathrm{Cu}$

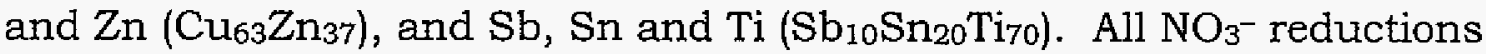
were perceived to occur through an anodic $\mathrm{H}$-transfer mechanism.

Chapter 5 consists of a paper in which the response for $\mathrm{NO}_{3}^{-}$ reduction is studied at varying compositions (atomic \%) of $\mathrm{Cu}-\mathrm{Ni}$ alloy electrodes. The pure component metals, $\mathrm{Cu}$ and $\mathrm{Ni}$, were studied to determine their response for $\mathrm{NO}_{3}^{-}$reduction. Various alloys consisting of 
$\mathrm{Cu}_{75} \mathrm{Ni}_{25}, \mathrm{Cu}_{50} \mathrm{Ni}_{50}$, and $\mathrm{Cu}_{25} \mathrm{Ni}_{75}$ were also studied to establish optimum alloy composition with respect to $\mathrm{NO}_{3}-$ reduction. Flow injection analysis was carried out to show the application of the $\mathrm{Cu}-\mathrm{Ni}$ alloy electrodes to electrochemical detection.

\section{References}

1. Tarasevich, M.R. and B.N. Efremov, Electrodes of Conductive Metallic Oxides, ed. S. Trasatti. Ch. 5. 1980, Amsterdam: Elsevier.

2. Tamura, M.R., H. Yoneyama, and Y. Matsumoto, Electrodes of Conductive Metallic Oxides, ed. S. Trasatti. Ch. 6. 1980, Amsterdam: Elsevier.

3. Trasatti, S. and G. Lodi, Electrodes of Conductive Metallic Oxides, ed. S. Trasatti. Ch. 7. 1980, Amsterdam: Elsevier.

4. Kuhn, A.T., The Electrochemistry of Lead. 1979, London: Academic Press.

5. Pletcher, D. and F. Walsh, Industrial Electrochemistry. 2nd ed. 1990, New York: Chapman and Hall.

6. Conway, B.E., Electrodes of Conductive Metal Oxides, ed. S. Trasatti. 1981, New York: Elsevier.

7. Chang, H. and D.C. Johnson, Anal. Chim. Acta, 1991. 248, 85.

8. Yeo, I.H., et al., J. Electrochem. Soc., 1989. 136, 1395.

9. Popovic, N.D. and D.C. Johnson, Electroanalysis, 1999. 11, 934. 
10. Popovic, N.D., J.A. Cox, and D.C. Johnson, J. Electroanal. Chem., 1998. $456,203$.

11. Popovic, N.D., J.A. Cox, and D.C. Johnson, J. Electroanal. Chem., 1998. $455,153$.

12. Pamplin, K.L. and D.C. Johnson, J. Electrochem. Soc., 1996. 143, 2119.

13. Treimer, S.E. and D.C. Johnson, Electrochemical and Solid-State Letters, 2001. 4, D13.

14. Treimer, S.E., et al., J. Electrochem. Soc., 2001. 148, E459.

15. Chang, H. and D.C. Johnson, J. Electrochem. Soc.; 1990. 137, 3108.

16. Chang, H. and D.C. Johnson, J. Electrochem. Soc., 1990. 137, 2452.

17. Feng, J. and D.C. Johnson, J. Electrochem. Soc., 1990. 137, 507.

18. Feng, J. and D.C. Johnson, J. Electrochem. Soc., 1991. 138, 3328.

19. Feng, J., et al., J. Electrochem. Soc., 1995. 142, 3626.

20. Ge, J. and D.C. Johnson, J. Electrochem. Soc., 1995. 142, 1525.

21. Hsiao, Y.L. and D.C. Johnson, J. Electrochem. Soc., 1989. 136, 3704.

22. Kawagoe, K.T. and D.C. Johnson, J. Electrochem. Soc., 1994. 141, 3404.

23. LaCourse, W.R., Y.L. Hsiao, and D.C. Johnson, J. Electrochem. Soc., 1989. 136,3714 .

24. Popovic, N.D. and D.C. Johnson, Anal. Chem., 1998. 70, 468. 
25. Treimer, S.E., J. Feng, and D.C. Johnson, J. Electrochem. Soc., 2001. 148, E321.

26. Treimer, S., A. Tang, and D.C. Johnson, Electroanalysis, 2002. 14, 165.

27. Velichenko, A.B., et al., J. Electroanal. Chem., 1998. 454, 203.

28. Yeo, I.H. and D.C. Johnson, J. Electrochem. Soc., 1987. 134, 1973.

29. Swain, G.M., A. Anderson, and J.C. Angus, Mater. Res. Bull., 1998. 23,56 .

30. Xu, J., et al., Anal. Chem., 1997. 69, 591A.

31. Koppang, M.D., et al., Anal. Chem., 1999. 71, 1188.

32. Witek, M.A. and G.M. Swain, Anal. Chim. Acta, 2001. 440, 119.

33. Sarada, B.V., et al., Proc. - Electrochem. Soc., 2000. 99-32, 502.

34. Sarada, B.V., et al., Anal. Chem., 2000. 72, 1632.

35. Chailapakul, O., et al., Electrochem. Comm., 2000. 2, 422.

36. Chailapakul, O., et al., Sensors and Actuators B: Chemical, 2001. 80, 193.

37. Christman, K., Electrocatalysis, ed. J. Lipkowski and P. Ross. Ch. 1. 1998, New York: John Wiley \& Sons.

38. Chapuzet, J.M., A. Lasia, and J. Lessard, Electrocatalysis, ed. J. Lipkowski and P. Ross. Ch. 4. 1998, New York: John Wiley \& Sons.

39. Adzic, R., Electrocatalysis, ed. J. Lipkowski and P. Ross. Ch. 5. 1998, New York: John Wiley \& Sons. 
40. Khomutov, N.E. and U.S. Stamkulov, Sov. Electrochem., 1971. 7, 312.

41. Vijh, A.K., J. Catal., 1974, 230.

42. Horanyi, G. and E.M. Rizmayer, J. Electroanal. Chem., 1985. 188, 265.

43. Bockris, J.O.M. and J. Kim, J. Electrochem. Soc., 1996. 143, 3801.

44. Ohmori, T., M.S. El-Deab, and M. Osawa, J. Electroanal. Chem., 1999. 470,46 .

45. Sherwood, G.A., A copperized cadmium flow-through detector for the amperometric determination of nitrate in aqueous samples based on electrocatalytic reduction. 1979, Thesis: Iowa State University.

46. Sherwood, J., Glenn A. and D.C. Johnson, Anal. Chim. Acta, 1981. $129,87$.

47. Gootzen, J.F.E., et al., J. Electroanal. Chem., 1997. 434, 171.

48. de Vooys, A.C.A., R.A. van Santen, and J.A.R. van Veen, J. Molec. Catal. A: Chem., 2000. 154, 203.

49. Deganello, F., et al., Appl. Catal. B: Environ., 2000. 24, 265.

50. Moorcroft, M.J., et al., Anal. Lett., 2000. 33, 3127.

51. Ureta-Zanrtu, S. and C. Yanez, Electrochim. Acta, 1997. 42, 1725.

52. Bouamrane, F., et al., J. Electroanal. Chem., 1996. 405, 95.

53. Reuben, C., et al., J. Electroanal. Chem., 1995. 396, 233.

54. Tenne, R., et al., J. Electroanal. Chem., 1993. 347, 409. 


\section{CHAPTER 2, ELECTROCATALYTIC ACTIVITY FOR OXYGEN-TRANSFER REACTIONS AT IRON(III)-DOPED MANGANESE DIOXIDE FILMS}

\section{Abstract}

The oxidation of DMSO to the corresponding sulfone is representative of numerous anodic oxygen transfer reactions that suffer from slow kinetics at noble metal electrodes. Voltammetric data for oxidation of DMSO show that an increase in reaction rate for DMSO oxidation can be obtained by the use of manganese dioxide $\left(\mathrm{MnO}_{2}\right)$ thin films electrodeposited upon gold electrodes. Iron(III)-doped manganese dioxide (Fe(III)- $\mathrm{MnO}_{2}$ ) films show a further increase in catalytic activity over the $\mathrm{MnO}_{2}$ films. $\mathrm{MnO}_{2}$ and $\mathrm{Fe}$ (III)doped $\mathrm{MnO}_{2}$ film deposition is not done by conventional constant current or constant potential, but rather by a cyclic voltammetry deposition. An additional step for the deposition was found to be stripping of the film at $0.8 \mathrm{~V}$ in electrolyte solution prior to addition of an analyte of interest. The thin films are active for DMSO oxidation even after stripping of the Au substrate oxide layer. Chemical stripping of the $\mathrm{MnO}_{2}$ films is seen with the detection of cysteine.

\section{Introduction}

Anodic O-transfer reactions often suffer from slow kinetics, resulting in diminished detection capabilities, at noble metal electrodes, which has 
led to intensive research on metal oxide film electrodes. Metal oxide film electrodes have been of academic interest based upon their ability for use in electrocatalysis of reactions involving transfer of oxygen and hydrogen atoms. Electrocatalysis of anodic O-transfer reactions at metal oxide film electrodes can be described by a general mechanism, proposed by Johnson and coworkers, in which oxygen from $\mathrm{H}_{2} \mathrm{O}$ is transferred to the reactant (R).[1]

The anodic discharge of water to form adsorbed hydroxyl species [OH] at the electrode surface is seen as a prerequisite step for anodic O-transfer. The discharge of water can be represented by

$$
\mathrm{S}[]+\mathrm{H}_{2} \mathrm{O} \rightarrow \mathrm{S}[\mathrm{OH}]+\mathrm{H}^{+}(a g)+\mathrm{e}^{-}
$$

where $\mathrm{S}[\mathrm{OH}]$ represents an adsorbed $\mathrm{OH}$ species and $\mathrm{S}[\mathrm{]}$ represents empty surface catalytic sites. Adsorption of the reactant $\mathrm{R}$ can be represented by

$$
\mathrm{S}^{\prime}[\mathrm{]}+\mathrm{R} \rightarrow \mathrm{S}[\mathrm{R}]
$$

where $S^{2}[]$ represents a surface catalytic site at which discharge of water is not occurring. $S^{\prime}[R]$ represents adsorption of the reactant to an $S^{\prime}$ catalytic site. Reactant adsorption can occur concurrently with water discharge at the different catalytic sites, $\mathrm{S}$ and $\mathrm{S}$ '. Actual oxygen transfer from an adsorbed $\mathrm{OH}$ radical to an adsorbed reactant can be expressed by

$$
\mathrm{S}[\mathrm{OH}]+\mathrm{S}^{\prime}[\mathrm{R}] \rightarrow \mathrm{S}[]+\mathrm{S}^{\prime}[]+\mathrm{RO}+\mathrm{H}^{+}(a q)+\mathrm{e}^{-}
$$

where RO is the oxidation product of $\mathrm{R}$. The overall mechanism for the 
anodic oxygen transfer reaction can be obtained by combining reactions $1-3$ to give a net reaction of

$$
\mathrm{R}+\mathrm{H}_{2} \mathrm{O} \rightarrow \mathrm{RO}+2 \mathrm{H}^{+}(a q)+2 \mathrm{e}^{-}
$$

which presents the overall equation for anodic O-transfer.

A competitive reaction with the O-transfer reaction is the evolution of $\mathrm{O}_{2}(\mathrm{~g})$ which is represented by

$$
2 \mathrm{~S}[\mathrm{OH}] \rightarrow 2 \mathrm{~S}[]+\mathrm{O}_{2}(g)+2 \mathrm{H}^{+}(a q)+2 \mathrm{e}^{-}
$$

This reaction consumes surface $\mathrm{OH}$ radicals thus decreasing current efficiency for O-transfer reactions.

Chang and Johnson found that enhancement of anodic O-transfer reactions, involving dimethyl sulfoxide (DMSO) oxidation, at undoped $\mathrm{PbO}_{2}$ film electrodes could be achieved by the addition of small amounts of Bi(III) into solution.[2] Doping of the $\mathrm{PbO}_{2}$ films directly with $\mathrm{Bi}[1,3-8], \mathrm{Fe}$ [9-13] and $\mathrm{Cl}^{-}[14]$ ions increased activity for many anodic $\mathrm{O}$-transfer reactions as compared to the undoped films. It was suggested that the dopant in the films could have various roles with respect to the anodic O-transfer mechanism. Anodic discharge of water could occur at dopant sites thus assisting in the formation of $\mathrm{OH}$ radicals. Another possible function of the dopant was to promote adsorption.[6] Adsorption allows desolvation and increased residence time of the analyte, both of which enable O-transfer to occur more readily. Recent efforts have been made to find new films with similar electrocatalytic activity to the $\mathrm{PbO}_{2}$ films without the possible toxic 
effects of the $\mathrm{Pb}$.

Manganese dioxide $\left(\mathrm{MnO}_{2}\right)$ exists in many forms in nature. However, not all forms are electroactive. The formation of electroactive forms of $\mathrm{MnO}_{2}$, e.g. $\beta-\mathrm{MnO}_{2}, \gamma-\mathrm{MnO}_{2}$ and $\varepsilon-\mathrm{MnO}_{2}$, is required for use as a sensor and therefore selective and reproducible electrodeposition techniques are needed. All electroactive forms of $\mathrm{MnO}_{2}$ incorporate some structural water into the lattice. The amount of structural water incorporated into the $\mathrm{MnO}_{2}$ can affect porosity and activity. $\beta-\mathrm{MnO}_{2}$ incorporates little structural water, is the least porous and battery active of the three.[15]

Izumiya et al. found that incorporation of molybdenum and tungsten in the manganese oxides enhanced current efficiency for $\mathrm{O}_{2}(\mathrm{~g})$ evolution in $\mathrm{Cl}^{-}$solutions. [16] The evolution of $\mathrm{O}_{2}(\mathrm{~g})$ and anodic O-transfer reactions are both dependent upon the formation of adsorbed surface $\mathrm{OH}$ species. Therefore, manganese dioxide $\left(\mathrm{MnO}_{2}\right)$ films can provide an alternative to using $\mathrm{Pb}$ containing films. In the present study, we examined the electrocatalytic activity for anodic O-transfer reactions at $\mathrm{MnO}_{2}$ film electrodes and also further enhanced the activity by incorporation of Fe(III) into the $\mathrm{MnO}_{2}$ films.

\section{Experimental}

Instrumentation and Data Collection - Voltammetric experiments were performed at rotating disk electrodes (RDE) under potentiometric control by 
a Model RDE4 potentiostat (Pine Instrument Company). A Model MSR rotator (Pine Instrument Company) was used for rotation of RDE's. A three compartment cell was used to separate the working, auxiliary and reference electrodes. All electrode potentials were measured and are reported $v$ s. the saturated calomel electrode reference (SCE). Data were collected using an IBM-compatible computer equipped with an AT-MIO-16XE-50 data aquisition board (National Instruments) and Labview (National Instruments) data acquisition software.

Preparation of Electrodes - Au disk electrodes were constructed in house by embedding $4.1 \mathrm{~mm}$ diameter gold rods into the center of teflon plugs with dimensions of $12.5 \mathrm{~mm}$ diameter and $5.5 \mathrm{~mm}$ height. The gold was sealed into the center of the teflon plugs with an epoxy resin to prevent leakage around the gold-teflon interface. Prior to deposition of fresh films, the electrode substrates were cleaned with oxalic acid, washed with distilled water and polished using 1 micron alumina powder. All films were electrodeposited from $\mathrm{MnSO}_{4}$ and $\mathrm{Fe}\left(\mathrm{ClO}_{4}\right)_{2}$ salt solutions of various concentrations under quiescent conditions. Constant current depositions required application of $1 \mathrm{~mA} \mathrm{~cm}-2$ current density for 10 minutes, with intermittent rotation of the electrode to remove $\mathrm{O}_{2}$ bubbles on the electrode surface. Constant potential depositions involved applying a potential of $1.75 \mathrm{~V}$ (vs SCE) for 30 seconds followed by $1.65 \mathrm{~V}$ (vs SCE) for 14.5 minutes. Cycling potential depositions entailed scanning the potential from $0.7 \mathrm{~V}$ to 
$1.7 \mathrm{~V}$ (vs SCE) at a scan rate of $40 \mathrm{mV} \mathrm{s}^{-1}$ under quiescent conditions for 10 total cycles followed by an additional step of scanning the potential to $0.4 \mathrm{~V}$ (vs SCE) prior to detection of analyte of interest.

Chemicals - All chemicals used were of reagent grade. Perchloric acid (1 M) was used as the electrolyte in all voltammetric experiments as well as for all film deposition solutions. Distilled water was obtained by use of a NANO-pure-II system (SYBRON/Barnstead). The $\mathrm{MnSO}_{4}$ (Fisher) and $\mathrm{Fe}\left(\mathrm{ClO}_{4}\right)_{2}$ (Fisher) were used as received to prepare fresh solutions prior to film deposition. The DMSO (Fisher) and cysteine (Sigma) were used as received.

\section{Results and Discussion}

Preparation of Films - The response of Au in $1 \mathrm{M} \mathrm{HClO}_{4}$ supporting electrolyte (-- $)$ with the presence of $50 \mathrm{mM} \mathrm{MnSO}_{4}(-)$ is shown in Figure 1. Formation of $\mathrm{Au}$ oxide begins at $\mathrm{A}(\sim 1.20 \mathrm{~V})$ with the stripping of said oxide occurring at $\mathrm{D}(\sim 0.8 \mathrm{~V})$. The formation of $\mathrm{MnOOH}$ is speculated to also occur at A by the following reaction. $[17,18]$

$$
\mathrm{Mn}^{2+}(a q)+2 \mathrm{H}_{2} \mathrm{O} \rightarrow \mathrm{MnOOH}(\mathrm{s})+3 \mathrm{H}+(a q)+\mathrm{e}^{-}
$$

Initially, the $\mathrm{MnOOH}$ is formed, with further oxidation taking place at higher potentials, at $\mathrm{B}$, by the following reaction. $[17,18]$

$$
\mathrm{MnOOH}(\mathrm{s}) \rightarrow \mathrm{MnO}_{2}(\mathrm{~s})+\mathrm{H}^{+}(a q)+\mathrm{e}^{-}
$$

At $\mathrm{C}(\sim 1.2 \mathrm{~V})$, reduction of the $\mathrm{MnO}_{2}$ film to $\mathrm{Mn}^{+2}$ goes through a stepwise 
process involving reduction to $\mathrm{MnOOH}$ followed by conversion to $\mathrm{Mn}^{+2}$. Incomplete voltammetric stripping of the $\mathrm{MnO}_{2}$ film at $\mathrm{C}$ allows a thin film layer, thought to be $\mathrm{MnOOH}$, to remain. Scanning the potential further negative, reduction of $\mathrm{Au}$ oxide at $\mathrm{D}(\sim 0.8 \mathrm{~V})$ has no adverse effect upon the remaining thin film. Stripping of the remaining manganese oxide film occurs at $\mathrm{E}(\sim 0.0 \mathrm{~V})$. Cycling potential deposition takes advantage of this incomplete stripping to form thin films. After each cycle of deposition and stripping, a thin film remains, thus allowing repetitive deposition of film layers. The total thickness of each layer is unknown but is speculated to be more than a monolayer. Mechanical stability of the $\mathrm{MnO}_{2}$ film is adversely affected by the reduction of the Au oxide and subsequent formation of $\mathrm{Au}$ oxide on the positive scan.

Electrodeposition of metal oxide films is carried out by various techniques including constant current deposition. Constant current deposition, for our research, involves the application of a $1 \mathrm{~mA} \mathrm{~cm}-2$ current density to the electrode in a deposition solution. For numerous metal oxide film depositions, constant current deposition is a simple and efficient procedure. Various problems arise with the constant current deposition of $\mathrm{MnO}_{2}$ films. As the $\mathrm{MnO}_{2}$ film is deposited, formation of a porous layer of $\mathrm{MnOOH}$ causes current decay requiring a positive shift in potential to maintain desired current density. As potential increases, competing reactions, such as the evolution of $\mathrm{O}_{2}(\mathrm{~g})$, become predominant over the 
formation of the $\mathrm{MnO}_{2}$ film. The evolution of $\mathrm{O}_{2}(\mathrm{~g})$ can diminish current efficiency for $\mathrm{MnO}_{2}$ film deposition sufficiently enough to slow and possibly stop formation of the $\mathrm{MnO}_{2}$ films. The $\mathrm{O}_{2}(\mathrm{~g})$ evolution current can vary between film depositions causing problems with reproducibility between depositions. The formation of $\mathrm{O}_{2}(\mathrm{~g})$ bubbles on the surface of the electrode causes the film to crack and separate from the electrode surface. Pitting may occur in the film where these bubbles sit causing additional problems with uniformity and activity of the $\mathrm{MnO}_{2}$ films.

Another problem encountered during constant current deposition is the formation of $\mathrm{Mn}^{3+}$ at the electrode followed by formation of $\mathrm{MnO}_{2}$ (s) in solution as shown in the following equation.[15]

$$
2 \mathrm{Mn}^{3+}(a q)+2 \mathrm{H}_{2} \mathrm{O} \rightarrow \mathrm{Mn}^{2+}(a q)+\mathrm{MnO}_{2}(\mathrm{~s})+4 \mathrm{H}^{+}(a q)
$$

The formation of the $\mathrm{MnO}_{2}$ (s) causes particulate matter to appear in the deposition solution. In the bulk solution, the $\mathrm{MnO}_{2}$ precipitate is not a concern. At the electrode surface, however, precipitation of the $\mathrm{MnO}_{2}$ will cause variations between films. Due to the various problems intrinsic to constant current deposition, this deposition procedure was not a viable technique for preparation of the $\mathrm{MnO}_{2}$ films.

Constant potential deposition allows electrodeposition of films at potentials low enough to avoid $\mathrm{O}_{2}(\mathrm{~g})$ evolution, however, formation of $\mathrm{Mn}^{3+}$ can still occur. A drawback to constant potential deposition is that the procedure suffers from current decay to such minimal current values that 
little film deposition takes place after a short period of time. Two possible processes may cause this phenomenon. One reason may involve the formation of a porous layer of $\mathrm{MnO}_{2}$. Initially, a compact layer is formed, but as more $\mathrm{Mn}^{2+}$ is oxidized, a porous intermediate layer, possibly $\mathrm{MnOOH}$, develops. Diffusion of $\mathrm{Mn}^{2+}$ to the surface becomes limited by diffusion through the porous layer of $\mathrm{MnOOH}$ and a decrease in deposition current is seen.[15] The porous layer may be less conductive than the compact layer which may also cause the decrease in current seen. Another possible source of current loss is due to the formation of a $\mathrm{MnO}_{2}$ film which is less electrocatalytic towards oxidation of $\mathrm{Mn}^{+2}$ than the initial substrate.

A different method of forming the $\mathrm{MnO}_{2}$ films is by a cyclic voltammetric deposition. To deposit the $\mathrm{MnO}_{2}$ films, the potential is cycled between the oxidation of $\mathrm{Mn}^{2+}$ and the reduction of $\mathrm{MnO}_{2}$. As stated before, stripping of the $\mathrm{MnO}_{2}$ film does not fully remove the film from the substrate thus allowing continuous removal of the porous layer of $\mathrm{MnOOH}$ and providing a fresh surface upon which deposition can be carried out.

A comparison of $\mathrm{MnO}_{2}$ films prepared by constant potential and cycling potential deposition techniques with respect to electrocatalytic properties towards DMSO oxidation is shown in Figure 2. The response of an undoped $\mathrm{MnO}_{2}$ film, prepared by constant potential deposition, in the absence (Fig. 2A) and the presence of $5 \mathrm{mM} \mathrm{DMSO}$ (Fig. 2C) in $1 \mathrm{M} \mathrm{HClO}_{4}$ is shown in Figure 2. The response of an undoped $\mathrm{MnO}_{2}$ film, prepared by 
cycling potential deposition, in the absence (Fig. 2B) and the presence of $5 \mathrm{mM}$ DMSO (Fig. 2D) in $1 \mathrm{M} \mathrm{HClO}_{4}$ is shown in Figure 2. As can be seen from Figure 2, the response for DMSO oxidation is significantly larger at the cycling potential deposited film.

Based upon deposition technique, various forms of $\mathrm{MnO}_{2}$ can be formed, some of which have better catalytic properties than others. This is one example of a possible reason for the large difference between the two films. The structural difference between the two films was undeterminable. Regardless, the cycling potential deposition created a better film with respect to electrocatalytic properties and thus this technique was employed for the rest of the study.

An additional step, after transfer from deposition solution to a fresh solution of electrolyte, was found to be necessary in order to obtain a masstransport limited response. In a fresh solution, without any analyte, a large stripping peak was seen for the film at approximately $0.8 \mathrm{~V}$ on the initial scan but not on consecutive scans. A stripping peak for the $\mathrm{MnO}_{2}$ film such as that of $\mathrm{C}$ from Figure 1 was not seen. Upon removal of the electrode from solution, exposing the electrode to air and reinsertion of electrode into solution, the reduction peak at $0.8 \mathrm{~V}$ was again seen.

The effect of stripping the film prior to detection of the DMSO is shown in Figure 3. DMSO was chosen as a model for detection for two reasons: 1) the compound follows a single oxidation transfer process and 2) 
DMSO shows minimal oxidation response on Au. The detection of DMSO at various rotation rates (Fig. 3B) shows a maximum current of $\sim 120 \mu \mathrm{A}$ at $1.70 \mathrm{~V}$. Upon stripping of the film, rotation rate dependence can be seen by looking at plots $\mathrm{B}, \mathrm{C}, \mathrm{D}$ and $\mathrm{E}$ in Figure 3 which correspond to rotation rates of $6.47 \mathrm{rads} \mathrm{s}^{-1}, 9.70$ rads s $\mathrm{s}^{-1}, 12.94 \mathrm{rads} \mathrm{s}^{-1}$, and 16.17 rads $\mathrm{s}^{-1}$, respectively.

Even at the lowest rotation rate, the current after stripping is greater than prior to stripping. The reason for this phenomenon is speculated to involve the formation of $\mathrm{MnOOH}$. The porous $\mathrm{MnOOH}$ causes problems with the formation of the $\mathrm{MnO}_{2}$ films by creating a diffusion layer for the $\mathrm{Mn}^{2+}$ to overcome. A similar problem may occur with DMSO. The stripping peak at $0.8 \mathrm{~V}$ discussed previously is believed to be from the reduction of the surface $\mathrm{MnOOH}$ which then alleviates the diffusion problem. However, the cause for this increase is not due to possible $\mathrm{Mn}^{2+}$ in solution due to film reduction. Calculations based upon reduction current show that $\mathrm{Mn}^{2+}$ concentration in the solution would be minimal. Also, in the presence of electrolyte only, no significant change in current is seen after electrochemical stripping of the film. The addition of this stripping step prior to detection was thus added to the deposition procedure for the rest of the film preparations.

Detection capabilities of undoped $\mathrm{MnO}_{2}$ films - The rotation dependence of DMSO at undoped $\mathrm{MnO}_{2}$ films prepared by a cycling 
potential deposition technique, followed by a stripping step prior to detection, are shown in plots $\mathrm{C}, \mathrm{D}$ and $\mathrm{E}$ in Figure 3. Determination of the number of electrons transferred in the anodic reaction of DMSO is important for further understanding of the mechanism involved. Levich plots of $i$ vs $\omega^{1 / 2}$, where $i$ is current $(\mu \mathrm{A})$ and $\omega$ is rotational velocity (rads s" $\left.{ }^{1}\right)$, were constructed for $5.0 \mathrm{mM}$ DMSO. For a mass transport limited mechanism, the Levich plot is linear with an intercept of 0 . However, negative deviation from linearity was seen in these plots which is indicative of a kinetic controlled parameter in the mechanism.

Koutecky-Levich plots of $1 / \mathrm{i}$ vs $1 / \omega^{1 / 2}$ were constructed and a representative plot is shown in Figure 4. In Koutecky-Levich plots, the slope is equal to $1 / 0.62 n \mathrm{FAD}^{2 / 3} v^{1 / 6} \mathrm{C}^{\mathrm{b}}$, where $n$ is the number of electrons (eq $\left.\mathrm{mol}^{-1}\right), \mathrm{F}$ is the Faraday constant $\left(\mathrm{C} \mathrm{eq}^{-1}\right), \mathrm{A}$ is the geometric electrode area $\left(\mathrm{cm}^{2}\right), \mathrm{D}$ is the diffusion coefficient $\left(\mathrm{cm}^{2} \mathrm{~s}^{-1}\right), v$ is the kinematic viscosity of the solution $\left(\mathrm{cm}^{2} \mathrm{~s}^{-1}\right)$ and $\mathrm{C}^{\mathrm{b}}$ is the bulk concentration of the reactant (mM). Using $D=1.1 \times 10^{-5} \mathrm{~cm}^{2} \mathrm{~s}^{-1}$ for DMSO, an $\mathrm{n}$ value of 1.50 is obtained from the slope of the line in Figure 4A. The expected product of the oxidation of DMSO is $\mathrm{DMSO}_{2}$, which is a 2 electron process.

As stated above, stripping of the Au oxide layer does not dislocate the $\mathrm{MnO}_{2}$ films thus permitting study of an increased potential range for various catalytic properties. The effect of an increase in potential range upon the detection capabilities of thin $\mathrm{MnO}_{2}$ films for DMSO oxidation is 
shown in Figure 5. As can be seen from comparing plot D in Figure 3 and plot B in Figure 5, increase in potential range for DMSO oxidation does not significantly improve detection current. However, an improvement is seen in the shape of the voltammograms. The larger potential range shows an improved plateau shaped response. Scan rate dependence is seen for the stripping of the Au oxide layer $(\sim 0.9 \mathrm{~V})$ as well as with the formation of the oxide layer on the positive scan at $1.1 \mathrm{~V}$. Detection of the DMSO also shows scan rate dependence which is believed to involve the further oxidation of the thin $\mathrm{MnO}_{2}$ film.

Effect of $\mathrm{Fe}(\mathrm{II})$ Upon $\mathrm{MnO}_{2}$ Films - The effect of $\mathrm{Fe}(\mathrm{II})$ in the deposition solution upon the electrodeposition of the $\mathrm{MnO}_{2}$ films is shown in Figure 6. Similar peaks are seen that correspond to the same reactions discussed for Figure 1. However, we see an additional stripping peak, peak e in Figure $6 \mathrm{~A}$, for what is assumed to involve the $\mathrm{Fe}(\mathrm{III})$-doped $\mathrm{MnO}_{2}$ film. As the amount of $\mathrm{Fe}(\mathrm{II})$ in the deposition solution is increased, a shift in the $\mathrm{E}_{1 / 2}$ value for the new stripping peak is seen. As concentration increases further, anodic and cathodic peaks for the $\mathrm{Fe}(\mathrm{II})-\mathrm{Fe}$ (III) redox couple begin to appear. The reduction of Fe(III) overlaps with the stripping of the Fe(III)doped $\mathrm{MnO}_{2}$ film. The stripping peak continues to move more positive as $\mathrm{Fe}$ (II) concentration increases while the only change seen in the $\mathrm{Fe}$ (II)-Fe(III) couple peaks is an expected increase in current. The increase in current supports the theory that the peak at the more negative potential on the 
reverse scan is due to the Fe(III)-Fe(II) couple.

Doping of the $\mathrm{MnO}_{2}$ films with $\mathrm{Fe}(\mathrm{III})$ is expected to improve the film's response to DMSO. As with the undoped $\mathrm{MnO}_{2}$ films, the doped films must go through a stripping step in order to obtain rotation rate dependence and an increase in signal. The potential of the stripping peak does shift positive as you go to higher concentrations of $\mathrm{Fe}(\mathrm{II})$ in the deposition solution. The effect of doping $\mathrm{MnO}_{2}$ films with $\mathrm{Fe}(\mathrm{III})$ is shown in Figure 7. The ratios do not reflect amount of $\mathrm{Mn}$ to $\mathrm{Fe}$ in the film but rather $\mathrm{mM}$ concentrations of $\mathrm{MnSO}_{4}$ and $\mathrm{Fe}\left(\mathrm{ClO}_{4}\right)_{2}$, respectively, in the deposition solution. Au (Fig. 7A) shows very little response to the DMSO, but electrodeposition of an undoped $\mathrm{MnO}_{2}$ film onto the Au substrate increases the signal by $\sim 200 \mu \mathrm{A}$ (Fig. 7B).

The $\mathrm{Fe}(\mathrm{III})$-doped $\mathrm{MnO}_{2}$ film, prepared by cycling potential deposition in a deposition solution containing $1 \mathrm{mM} \mathrm{Fe}(\mathrm{II})$, shows no improvement in electrocatalytic oxidation of DMSO (Fig. 7C) as compared to the undoped $\mathrm{MnO}_{2}$ film (Fig. 7B). Further addition of $\mathrm{Fe}(\mathrm{II})$ to a concentration of $2 \mathrm{mM}$ improves the response of the film up to a maximum value of $\sim 450 \mu \mathrm{A}$ at $1.70 \mathrm{~V}$ (Fig. 7D). Additional increase in Fe(II) concentration creates an $\mathrm{Fe}(\mathrm{III})$-doped $\mathrm{MnO}_{2}$ film that shows lower current values as compared to not only the previously doped film but the undoped $\mathrm{MnO}_{2}$ film as well.

The Fe(III) dopant sites are believed to be sites for adsorption of the DMSO molecule, which increases residence time of DMSO thus increasing the chance for O-transfer to occur. Excessive amounts of Fe(III) in the film 
can have an adverse effect. The film from a 50:3 (Fig. 7E) deposition solution shows a decrease in signal from the undoped $\mathrm{MnO}_{2}$ film (Fig. 7B). Response from films of further increased doping tend to show the same response as that of the 50:3. As the number of Fe adsorption sites increases, the number of $\mathrm{Mn}$ sites, at which formation of the surface $\mathrm{OH}$ radicals occurs, decreases. Eventually one would expect to have insufficient formation of $\mathrm{OH}$ as compared to available reactant species resulting in loss of O-transfer capabilities. Data from Figure 7 indicates that the best ratio of $\mathrm{Mn}$ to $\mathrm{Fe}$ in the film deposition solution is $50 \mathrm{mM}$ to $2 \mathrm{mM}$. These concentrations will be used to produce the films used to collect the remaining data presented when dealing with $\mathrm{Fe}(\mathrm{III})$-doped $\mathrm{MnO}_{2}$ films.

The rotational velocity dependence of $5 \mathrm{mM}$ DMSO at the 50:2 $\mathrm{Fe}$ (III)doped $\mathrm{MnO}_{2}$ film is shown in Figure 8. The residual response of said film in $1 \mathrm{M} \mathrm{HClO}_{4}$ is shown by plot $\mathrm{A}$, while plots $\mathrm{B}-\mathrm{E}$ show the response of $5 \mathrm{mM}$ DMSO at rotational velocities of 6.47 rads $\mathrm{s}^{-1}, 9.70$ rads $\mathrm{s}^{-1}, 12.94$ rads $\mathrm{s}^{-1}$, and 16.17 rads s$^{-1}$, respectively. The data obtained were used to construct Koutecky-Levich plots, an example of which is shown in Figure 4B. Analysis reveals that the $n$ value is 2.0 with an $r^{2}$ value of 0.999 .

Ultra-thin film Fe-doped and undoped $\mathrm{MnO}_{2}$ films - Stripping of the Au oxide layer prior to detection of DMSO was shown to improve detection response. However, mechanical stability of the film is greatly decreased by the process. The remaining film is easily removed from the electrode 
surface. Upon reinsertion into a fresh solution of $1 \mathrm{M} \mathrm{HClO}_{4}$ and subsequent detection of DMSO, the electrocatalytic properties of the electrode showed remarkably improved response. The improvement in response is speculated to involve a remaining layer of $\mathrm{MnO}_{2}$ film that is deemed an ultra-thin film.

The residual response in $1 \mathrm{M} \mathrm{HClO}_{4}$ on the thin $\mathrm{MnO}_{2}$ film and ultrathin $\mathrm{MnO}_{2}$ film are shown in Figure 9 as plots $\mathrm{A}$ and $\mathrm{B}$, respectively with the oxidation of $5.0 \mathrm{mM}$ DMSO for said films shown as plots $\mathrm{C}$ and $\mathrm{D}$, respectively. Comparing the maximum response of the two films, the ultrathin film shows a maximum of $\sim 1000 \mu \mathrm{A}$ at $1.7 \mathrm{~V}$ whereas the thin film shows a maximum of $\sim 225 \mu \mathrm{A}$ at $1.7 \mathrm{~V}$. A similar effect is seen in the $\mathrm{Fe}(\mathrm{III})$-doped $\mathrm{MnO}_{2}$ films.

Shown in Figure 10 are the residual responses in $1 \mathrm{M} \mathrm{HClO}_{4}$ at the thin $\mathrm{Fe}$ (III)-doped $\mathrm{MnO}_{2}$ film (Fig. 10A) and ultra-thin Fe(III)-doped $\mathrm{MnO}_{2}$ film (Fig. 10B) with the oxidation of $5 \mathrm{mM}$ DMSO at the two film electrodes shown in Figure 10C and 10D, respectively. The ultra-thin film shows a maximum response of $\sim 1400 \mu \mathrm{A}$ at $1.7 \mathrm{~V}$ whereas the thin film shows a response of $\sim 400 \mu \mathrm{A}$ at $1.7 \mathrm{~V}$. Looking at Figure 9D and 10D, it can be seen that $\mathrm{Fe}$ doping of the $\mathrm{MnO}_{2}$ film improves the catalytic response to DMSO by $\sim 400 \mu \mathrm{A}$ at $1.7 \mathrm{~V}$. This dissimilarity helps support the presence of an ultrathin film as opposed to some modification of the Au surface of the electrode. Although the ultra-thin films showed improved response over the thin films, 
reproducibility of the ultra-thin films is mediocre, making them a poor candidate for use in constant potential detection.

Detection of cysteine at films - DMSO is a model compound for detection of sulfur containing compounds. Therefore, because the films discussed above showed excellent response to DMSO, they were expected to show response to sulfur containing amino acids. The response of cysteine at the $\mathrm{Fe}$ (III)-doped and undoped $\mathrm{MnO}_{2}$ thin films is shown in Figure 11. Plots $\mathrm{A}$ and $\mathrm{B}$ in Figure 11 show the residual response in $1 \mathrm{M} \mathrm{HClO} 4$ on the thin undoped and $\mathrm{Fe}(\mathrm{III})$-doped $\mathrm{MnO}_{2}$ films, respectively. Response to $100 \mu \mathrm{M}$ cysteine in $1 \mathrm{M} \mathrm{HClO}_{4}$ at the thin undoped and $\mathrm{Fe}(\mathrm{III})$-doped $\mathrm{MnO}_{2}$ films is shown in plots $C$ and $D$ in Figure 11, respectively. As expected, the Fe(III)-doped film shows improved response as compared to the undoped.

Cysteine is believed to allow a maximum transfer of 3-4 oxygen atoms, which would be a $6-8 \mathrm{e}^{-}$process, as opposed to DMSO which involves transfer of 1 oxgyen, which is a $2 \mathrm{e}^{-}$process. Thus, we would expect currents to be higher than seen for cysteine. Comparative data for concentration dependence and rotational velocity dependence for cysteine oxidation could not be obtained as chemical stripping of prepared films occurred with addition of minimal amounts of cysteine. Data shown in Figure 11 is the first scan collected upon addition of cysteine to solution. 


\section{Conclusions}

$\mathrm{MnO}_{2}$ and $\mathrm{Fe}(\mathrm{III})$-doped $\mathrm{MnO}_{2}$ films show improved response for electrocatalytic anodic O-transfer reactions involving DMSO as compared to Au. Constant potential and constant current deposition techniques are inadequate to produce desired films and so a cycling potential deposition is used. An additional stripping step was found necessary to get rotation dependence for DMSO in a solution. Reasons for this are speculated involve the removal of a porous layer of $\mathrm{MnOOH}$ at the surface of the film. The stripping step also has an apparent positive effect upon the electrocatalytic properties of the film. The ability of the film to withstand stripping of the Au oxide allows for the possibility of a large potential window to look for various reactants. However, mechanical stability of the film suffers.

Doping of the $\mathrm{MnO}_{2}$ films with $\mathrm{Fe}$, up to $2 \mathrm{mM} \mathrm{Fe}$ (II) in the deposition solution, creates a significant improvement in the catalytic properties of the film. However, additional $\mathrm{Fe}$ in the deposition solution has adverse effects upon the desired film properties. Reasons for the initial increase in response, followed by subsequent decrease, are speculated to involve the function of $\mathrm{Fe}$ (III) sites in the $\mathrm{Fe}(\mathrm{III})$-doped $\mathrm{MnO}_{2}$ film. Adsorption of DMSO is occurring at the Fe(III) sites. Increasing the number of DMSO adsorption sites reduces sites for $\mathrm{OH}$ adsorption to occur resulting in insufficient supply of $\mathrm{OH}$ to allow for anodic O-transfer to occur.

The films show good stability upon exposure to DMSO, however, 
stripping of the oxide films occurs when examining cysteine detection. Based upon the stripping problem seen, further studies, such as flow injection analysis, to determine feasibility of using of the doped and undoped $\mathrm{MnO}_{2}$ film electrodes for electrochemical detection were not carried out. The use of both the undoped and $\mathrm{Fe}$ (III)-doped $\mathrm{MnO}_{2}$ films for electrochemical detection is not a viable option due to the instability of the films.

\section{Acknowledgments}

This report has been authored by the Iowa State University of Science and Technology under Contract No. W-7405-ENG-82 with the U.S.

Department of Energy. The U. S. Government retains and the publisher, by accepting the article for publication, acknowledges that the U. S.

Government retains a non-exclusive, paid-up, irrevocable, world-wide license to publish or reproduce the published form of this manuscript, or allow others to do so, for U. S. Government purposes.

\section{References}

1. Popovic, N.D., J.A. Cox, and D.C. Johnson, J. Electroanal. Chem., 1998. 456, 203-209.

2. Chang, H. and D.C. Johnson, J. Electrochem. Soc., 1990. 137, 24527. 
3. LaCourse, W.R., Y.L. Hsiao, and D.C. Johnson, J. Electrochem. Soc., 1989. 136, 3714-9.

4. Pamplin, K.L. and D.C. Johnson, J. Electrochem. Soc., 1996. 143, $2119-2125$.

5. Popovic, N.D. and D.C. Johnson, Anal. Chem., 1998. 70, 468-472.

6. Popovic, N.D., J.A. Cox, and D.C. Johnson, J. Electroanal. Chem., 1998. $455,153-160$.

7. Popovic, N.D. and D.C. Johnson, Electroanalysis, 1999. 11, 934-939.

8. Yeo, I.H., et al., J. Electrochem. Soc., 1989. 136, 1395-401.

9. Feng, J. and D.C. Johnson, J. Electrochem. Soc., 1990, 137, 507-10.

10. Feng, J., et a1., J. Electrochem. Soc., 1995. 142, 3626-32.

11. Treimer, S.E., et al., J. Electrochem. Soc., 2001. 148, E459-E463.

12. Treimer, S.E., J. Feng, and D.C. Johnson, J. Electrochem. Soc., 2001. 148, E321-E325.

13. Treimer, S.E. and D.C. Johnson, Electrochemical and Solid-State Letters, 2001. 4, D13-D15.

14. Hsiao, Y.L. and D.C. Johnson, J. Electrochem. Soc., 1989. 136, 370411.

15. Anderson, T.N., Modern Aspects of Electrochemistry, ed. R.E. White. 1996, New York: Plenum Press.

16. Izumiya, K., et al., Electrochim. Acta, 1998. 43, 3303-3312. 


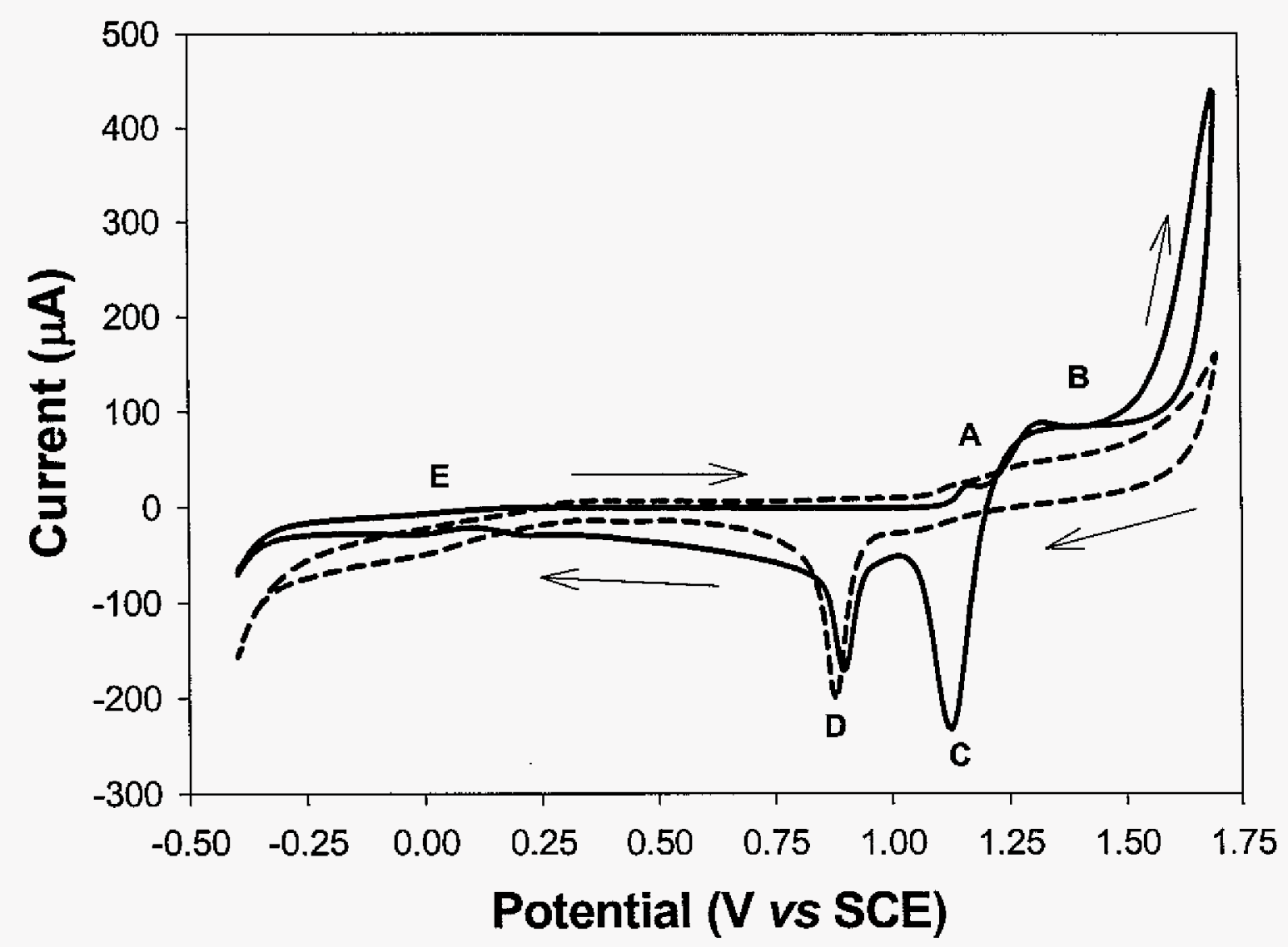

Figure 1. Voltammetric response of gold to $50 \mathrm{mM} \mathrm{MnSO}_{4}$ in quiescent solution of $1 \mathrm{M} \mathrm{HClO}_{4}$. Scan: $40 \mathrm{mV} / \mathrm{s}$. (--- ) $1 \mathrm{M} \mathrm{HClO}_{4}(-) 50 \mathrm{mM}$ $\mathrm{MnSO}_{4}$ (A)-Formation of Au oxide and $\mathrm{MnOOH},(\mathrm{B})$-Further oxidation of $\mathrm{MnOOH}$ to $\mathrm{MnO}_{2}$, (C)-Cathodic stripping of $\mathrm{MnO}_{2}$, (D)-Reduction of $\mathrm{Au}$ oxide, $(\mathrm{E})$-Cathodic stripping of remaining $\mathrm{MnO}_{2}$ film. 


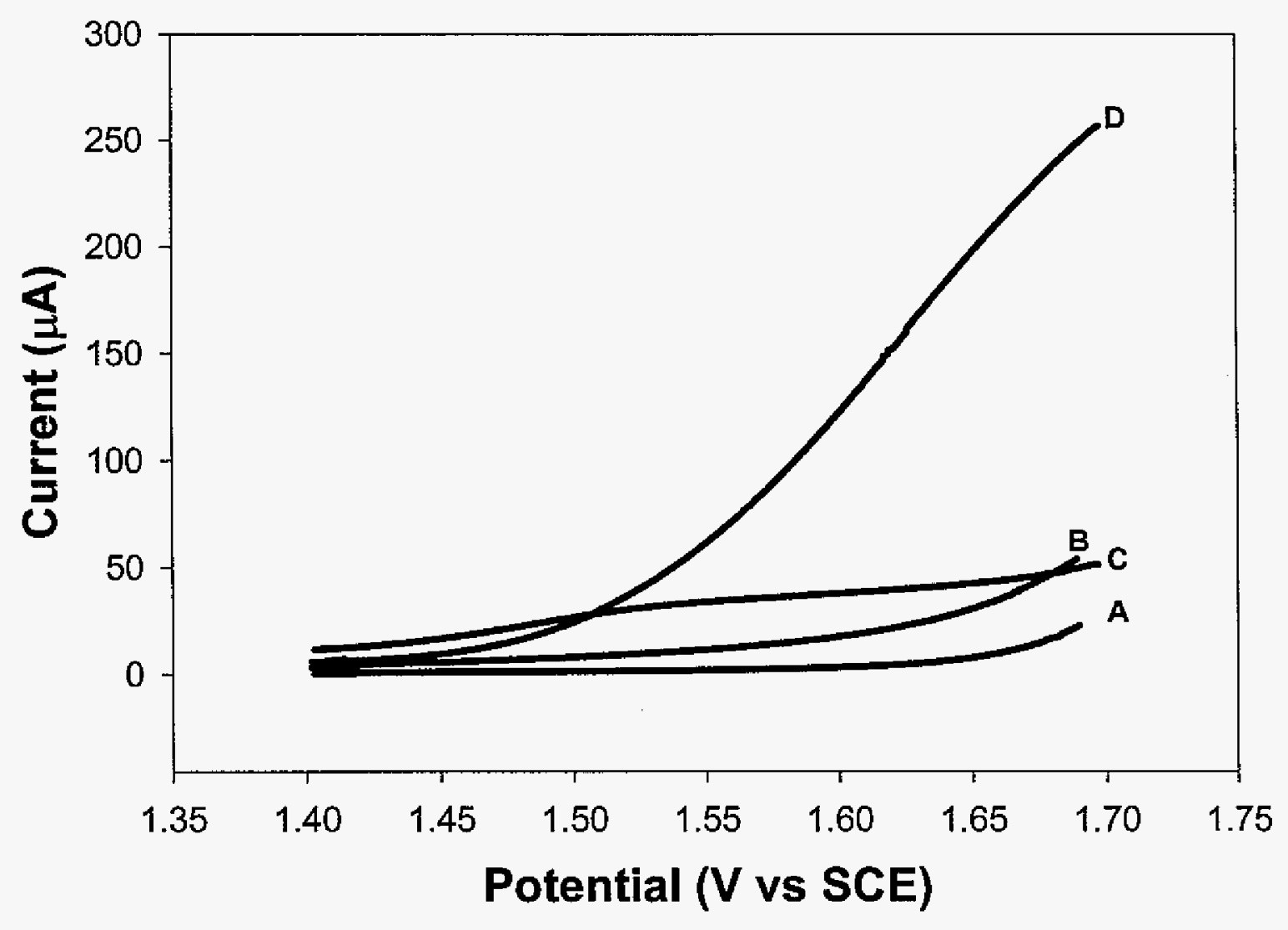

Figure 2. Comparison of electrocatalytic properties of thin $\mathrm{MnO}_{2}$ films prepared by constant potential and cycling potential deposition techniques. Scan rate: $40 \mathrm{mV} / \mathrm{s}$ Rotational velocity: 9.7 rads s$^{-1}$. (A) Residual (Constant Potential Deposition), (B) Residual (Cycling Potential Deposition), (C) $5 \mathrm{mM}$ DMSO (Constant Potential Deposition), (D) $5 \mathrm{mM}$ DMSO (Cycling Potential Deposition). 


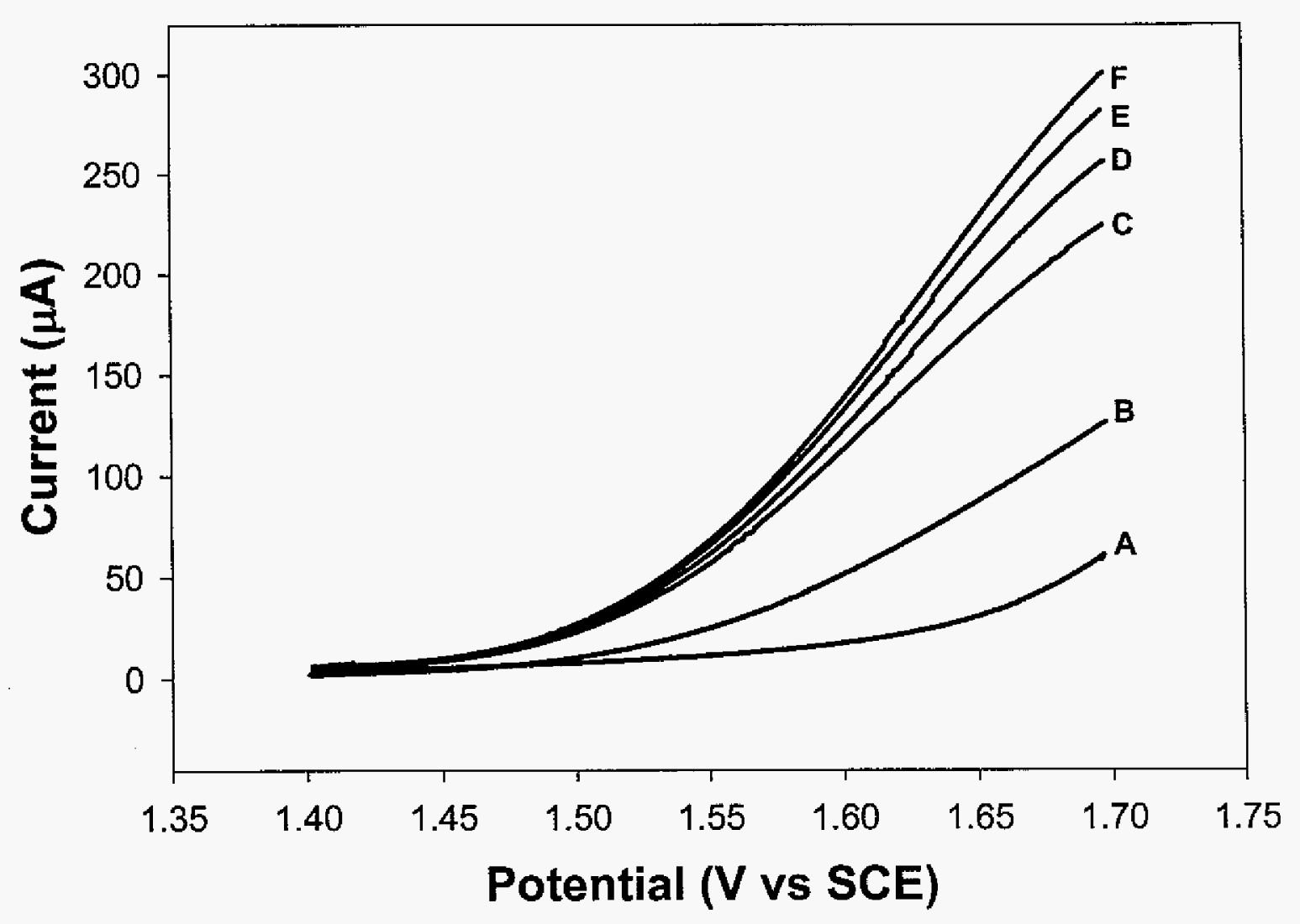

Figure 3. Effect of stripping $\mathrm{MnO}_{2}$ film after cyclic voltammetric deposition but prior to detection of $5 \mathrm{mM}$ DMSO in $1 \mathrm{M} \mathrm{HClO}_{4}$. Scan: $40 \mathrm{mV} / \mathrm{s}$. (A) Residual (B)- All rotation rates prior to stripping, $(\mathrm{C})-(\mathrm{F})$ rotation rates after film stripping at $6.47,9.70,12.94$, and 16.17 rads s $^{-1}$, respectively. 


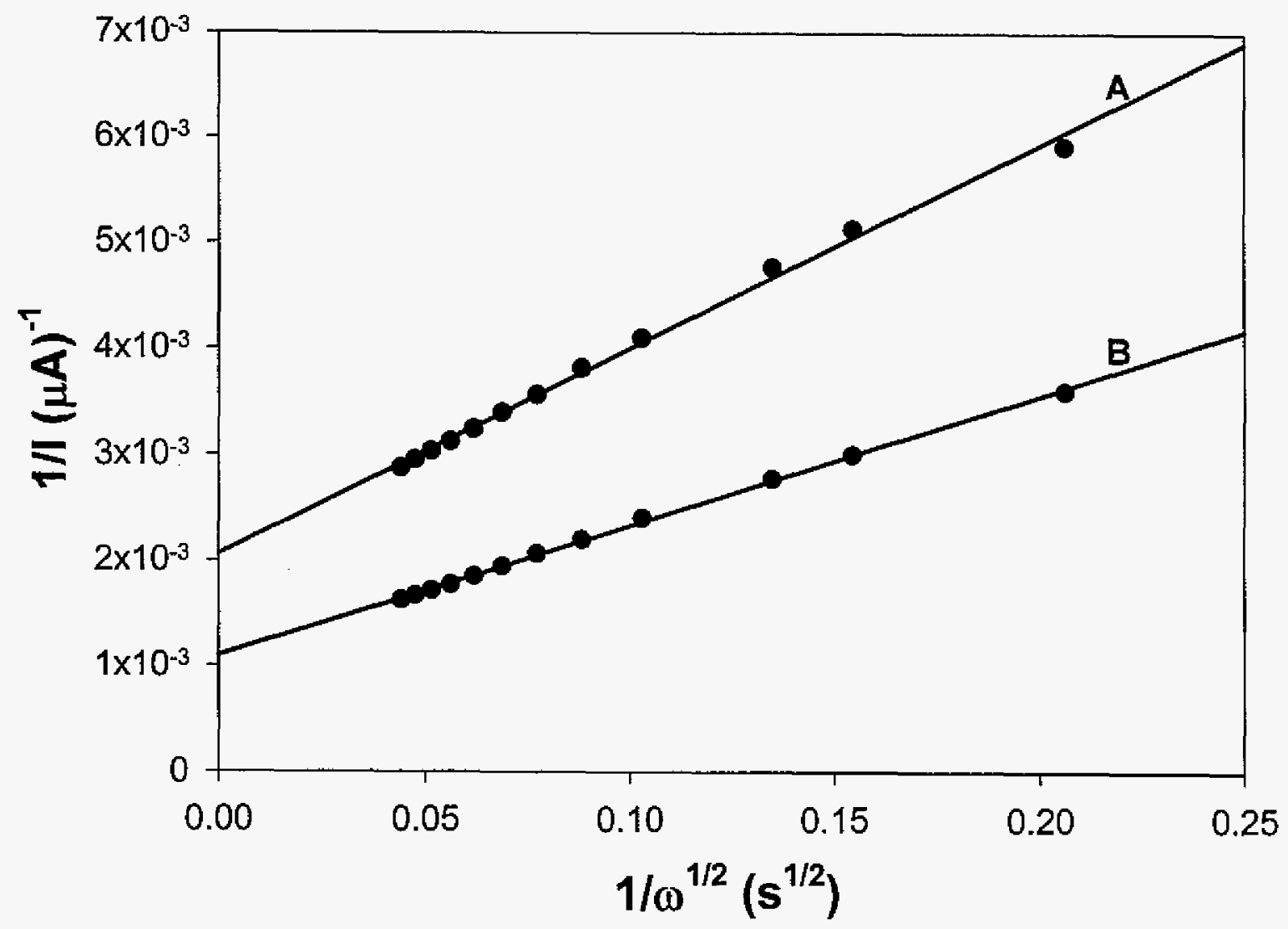

Figure 4. Koutecky-Levich plot for $5.0 \mathrm{mM} \mathrm{DMSO}$ in $1 \mathrm{M} \mathrm{HClO}_{4}$ at (A) undoped $\mathrm{MnO}_{2}$ film Detection potential: $1.65 \mathrm{~V}$. (B) 50:2 doped $\mathrm{Fe}-\mathrm{MnO}_{2}$ thin films. Detection potential: $1.65 \mathrm{~V}$. 


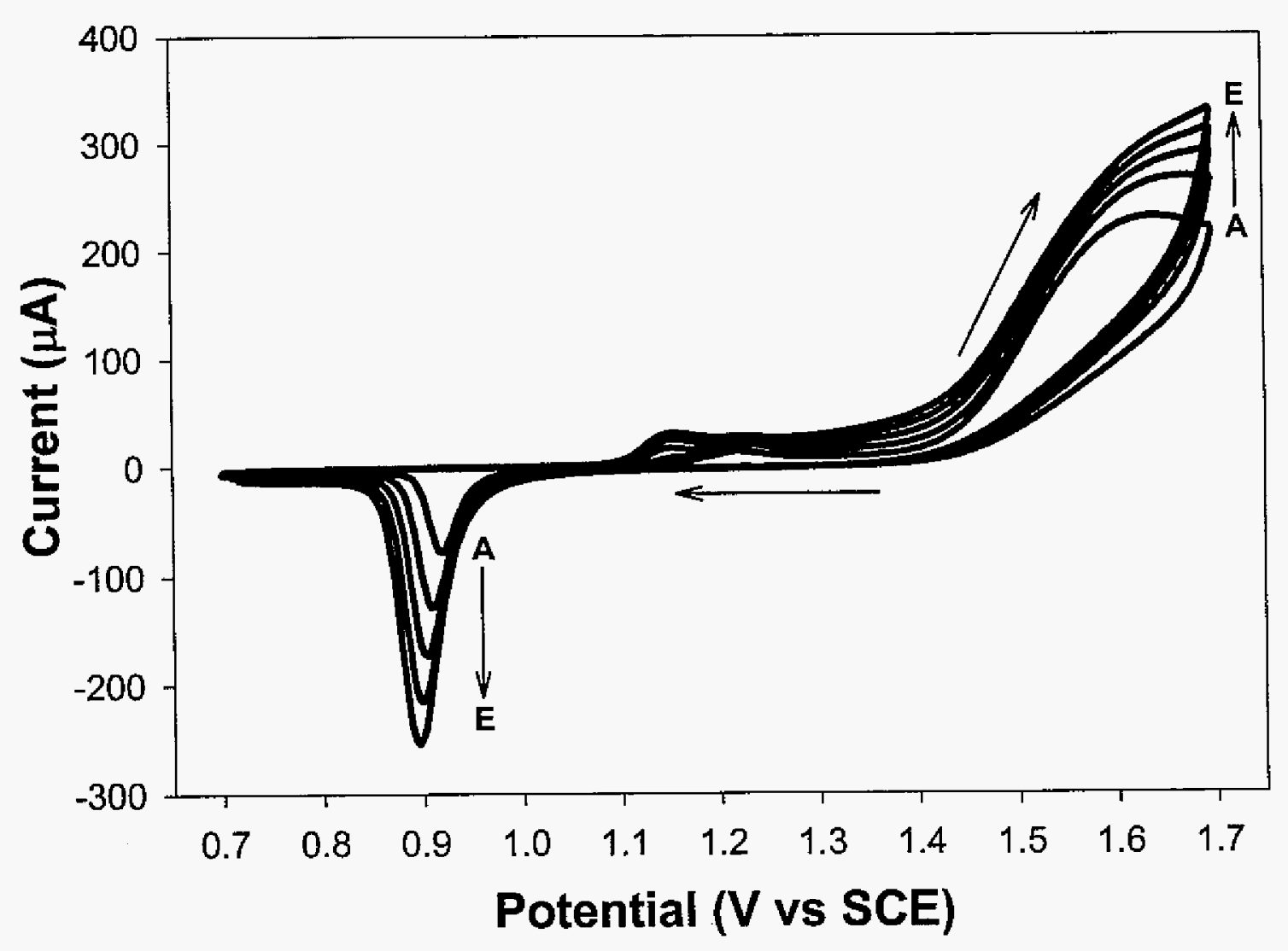

Figure 5. Scan rate dependence of $5 \mathrm{mM}$ DMSO oxidation at thin $\mathrm{MnO}_{2}$ films. Rotational velocity: 9.7 rads s ${ }^{-1}$. Scan rates: (A) $20 \mathrm{mV} / \mathrm{s}$, (B) 40 $\mathrm{mV} / \mathrm{s},(\mathrm{C}) 60 \mathrm{mV} / \mathrm{s}$, (D) $80 \mathrm{mV} / \mathrm{s}$, (E) $100 \mathrm{mV} / \mathrm{s}$. 


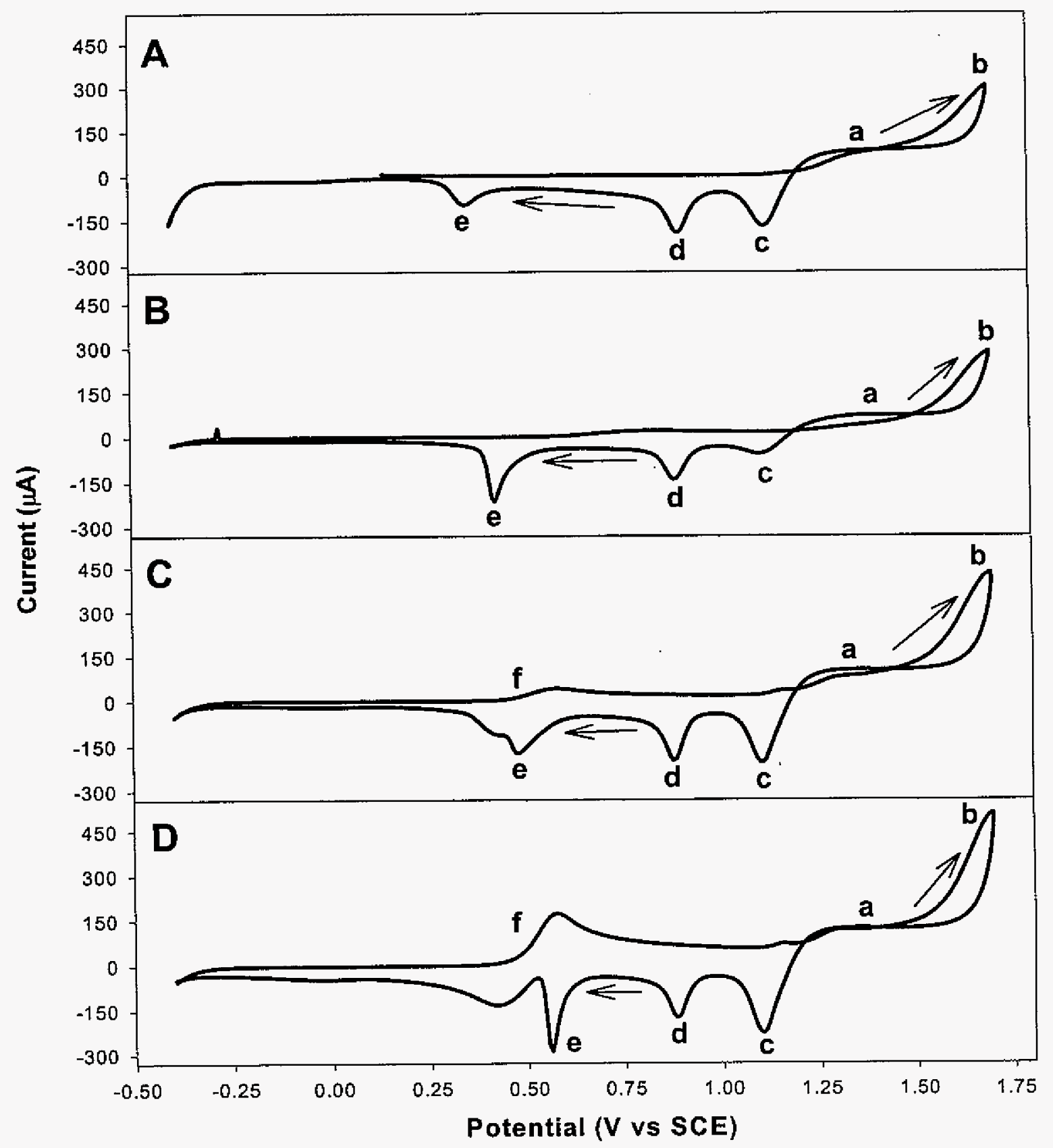

Figure 6. Voltammetric response of $\mathrm{Au}$ to $50 \mathrm{mM} \mathrm{MnSO}_{4}$ with varying concentrations of $\mathrm{Fe}\left(\mathrm{ClO}_{4}\right)_{2}$ in quiescent solution of $1 \mathrm{M} \mathrm{HClO}_{4}$. Scan rate: $40 \mathrm{mV} / \mathrm{s}$. Concentrations of $\mathrm{Fe}\left(\mathrm{ClO}_{4}\right)_{2}:(\mathrm{A}) 1 \mathrm{mM},(\mathrm{B}) 2 \mathrm{mM}$, (C) $3 \mathrm{mM}$, (D)9 mM. 


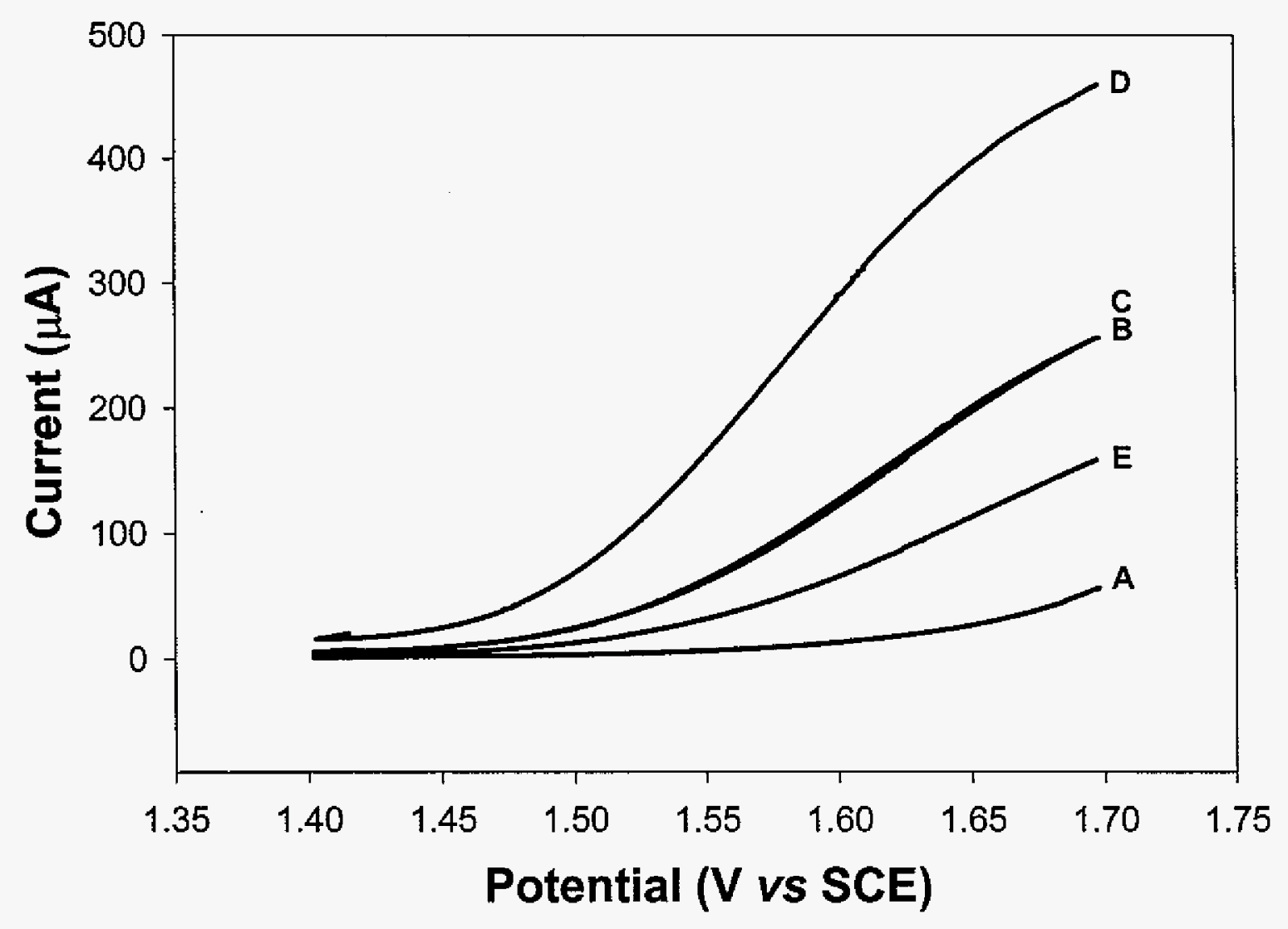

Figure 7. Effect of $\mathrm{Fe}(\mathrm{II})$ concentration upon catalytic properties of $\mathrm{MnO}_{2}$ films to $5 \mathrm{mM}$ DMSO in $1 \mathrm{M} \mathrm{HClO}_{4}$. Scan rate: $40 \mathrm{mV} / \mathrm{s}$ Rotational velocity: 9.7 rads s$^{-1}$. Responses shown are due to films made from varying ratios of $\mathrm{mM} \mathrm{Mn(II):mM} \mathrm{Fe(II)} \mathrm{in} \mathrm{deposition} \mathrm{solution.} \mathrm{(A)} \mathrm{-} \mathrm{Au,} \mathrm{(B)} \mathrm{-} \mathrm{50:0,} \mathrm{(C)} \mathrm{-}$ $50: 1,(\mathrm{D})-50: 2,(\mathrm{E})-50: 3$. 


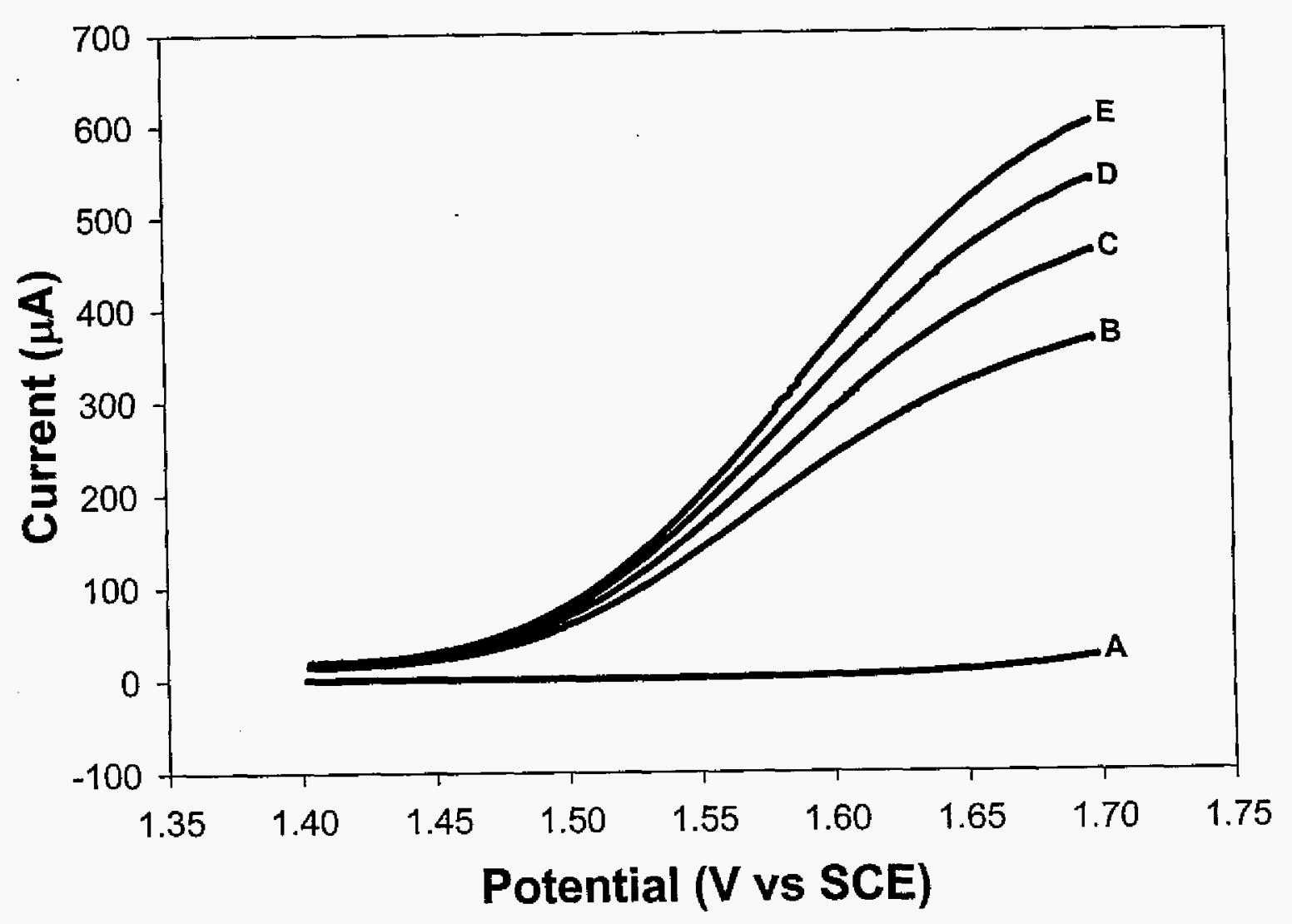

Figure 8. Rotational velocity dependence of $5.0 \mathrm{mM}$ DMSO oxidation at 50:2 doped $\mathrm{Fe}-\mathrm{MnO}_{2}$ thin films in $1 \mathrm{M} \mathrm{HClO}_{4}$. Scan rate: $40 \mathrm{mV} / \mathrm{s}$ Rotational velocity: (A) Residual, (B) $6.47 \mathrm{rads} \mathrm{s}^{-1}$, (C) $9.70 \mathrm{rads}^{-1}$, (D) 12.94 rads $\mathrm{s}^{-1},(\mathrm{E}) 16.17$ rads s$^{-1}$. 


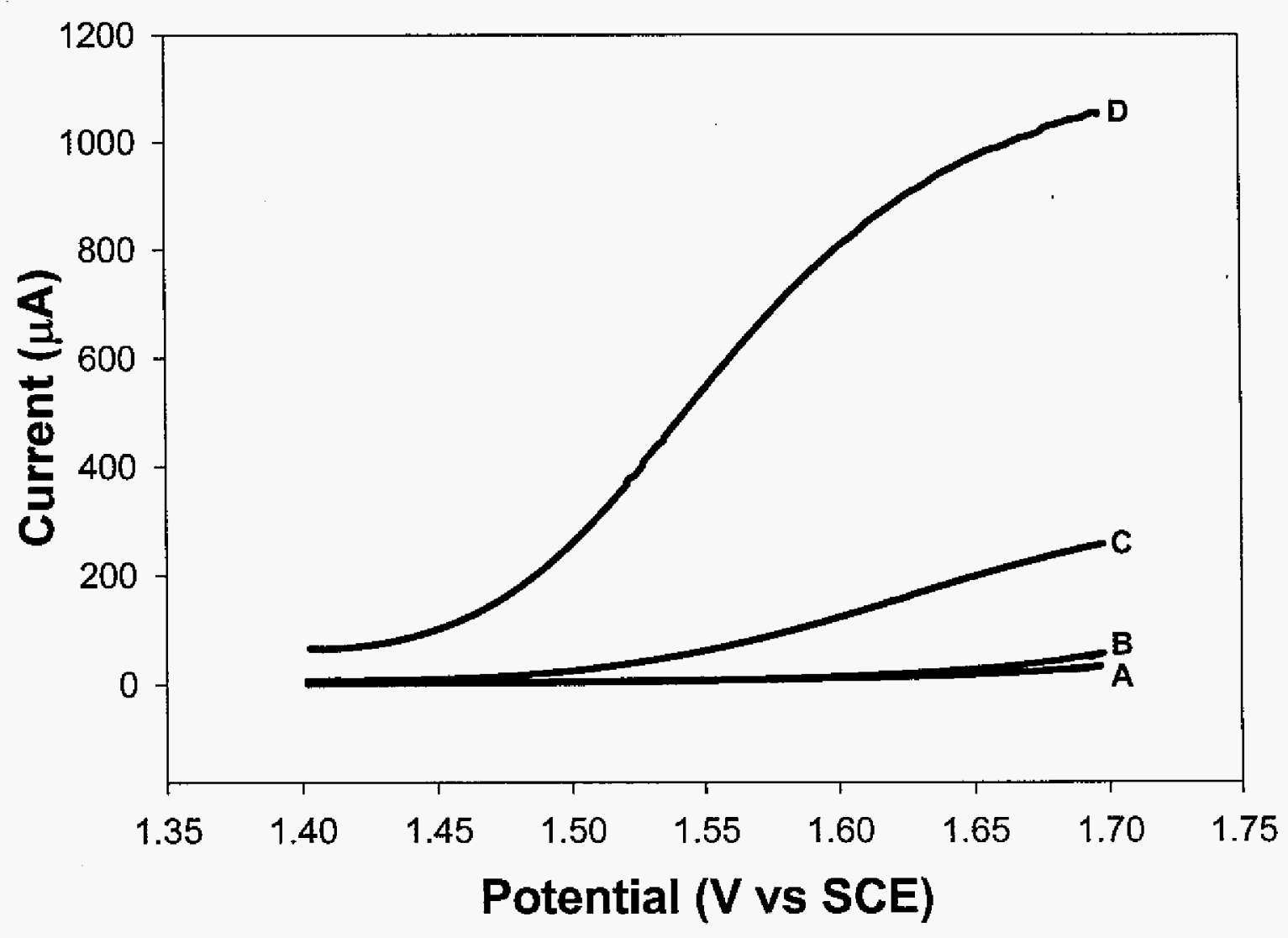

Figure 9. Comparison of electrocatalytic properties of ultra-thin $\mathrm{MnO}_{2}$ films and thin $\mathrm{MnO}_{2}$ films to $5 \mathrm{mM}$ DMSO. Scan rate: $40 \mathrm{mV} / \mathrm{s}$ Rotational velocity: 9.7 rads s ${ }^{-1}$ (A) Residual, (B) pure $\mathrm{Au}$, (C) thin $\mathrm{MnO}_{2}$ film, (D) ultra-thin $\mathrm{MnO}_{2}$ film. 


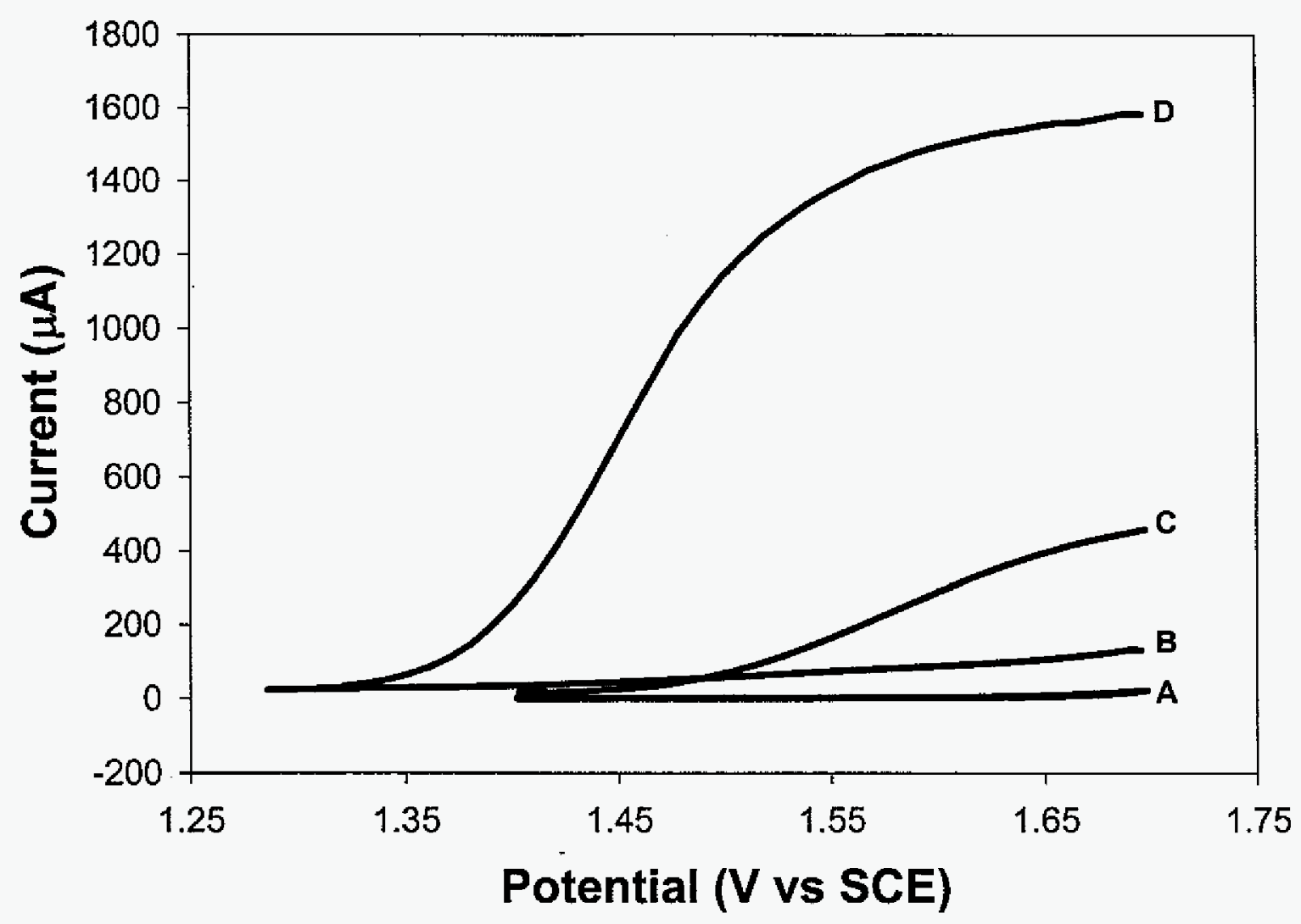

Figure 10. Comparison of electrocatalytic properties of ultra-thin 50:2 doped $\mathrm{Fe}-\mathrm{MnO}_{2}$ films and thin 50:2 doped $\mathrm{Fe}-\mathrm{MnO}_{2}$ films to $5 \mathrm{mM}$ DMSO in $1 \mathrm{M} \mathrm{HClO}_{4}$. Scan rate: $40 \mathrm{mV} / \mathrm{s}$ Rotational velocity: 9.7 rads s$^{-1}$ (A) thin film residual, (B) ultra-thin film residual, (C) thin film 5.0 mM DMSO, (D) ultra-thin film 5.0 mM DMSO. 


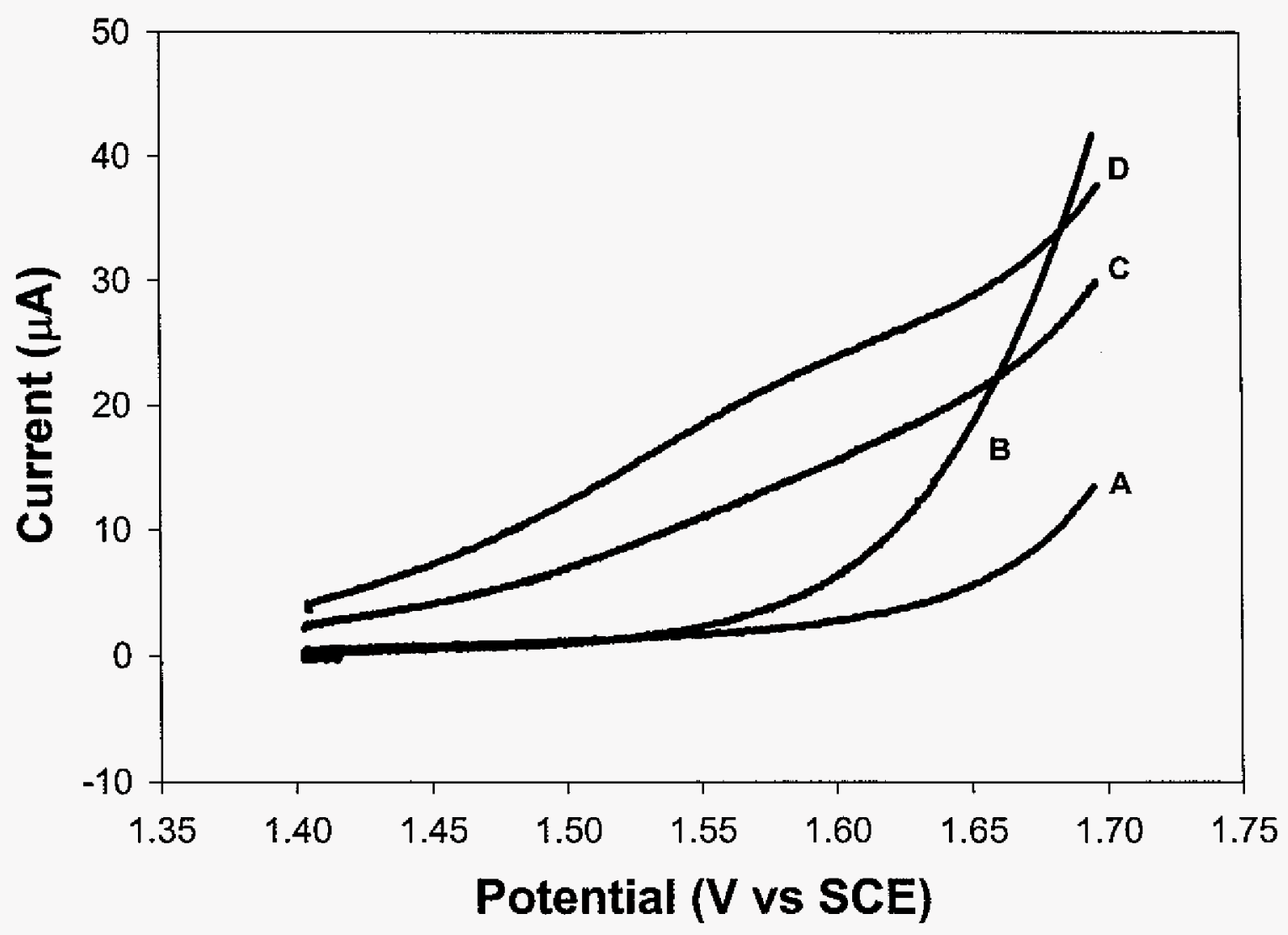

Figure 11. Electrocatalysis of cysteine oxidation in $1 \mathrm{M} \mathrm{HClO}_{4}$. Scan rate: $40 \mathrm{mV} / \mathrm{s}$ Rotational velocity: 9.70 rads s-1 $\mathrm{MnO}_{2}$ thin films: (B) Residual $\begin{array}{lll}\text { (C) } 100 \mu \mathrm{M} \text { cysteine } \quad 50: 2 \text { doped } \mathrm{Fe}-\mathrm{MnO}_{2} \text { thin films: (A) Residual } & \text { (D) } 100\end{array}$ $\mu \mathrm{M}$ cysteine. 


\section{CHAPTER 3. ENHANCEMENT OF ANODIC RESPONSE FOR DMSO AT RUTHENIUM OXIDE FILM ELECTRODES AS A RESULT OF DOPING WITH IRON(III)}

A paper accepted for publication in Electroanalysis.

Brett K. Simpson and Dennis C. Johnson

\section{Abstract}

The oxidation of dimethyl sulfoxide (DMSO) to dimethyl sulfone $\left(\mathrm{DMSO}_{2}\right)$ is representative of numerous anodic oxygen-transfer reactions of organosulfur compounds that suffer from slow kinetics at noble metal electrodes. Anodic voltammetric data for DMSO are examined at various $\mathrm{RuO}_{2}$-film electrodes prepared by thermal deposition on titanium substrates. The response for DMSO is slightly larger at $\mathrm{RuO}_{2}$ films prepared in a flame as compared with films prepared in a furnace; however, temperature is more easily controlled in the furnace. Doping of the $\mathrm{RuO}_{2}$ films with $\mathrm{Fe}(\mathrm{III})$ further improves the sensitivity of anodic response for DMSO. Optimal response is obtained at an $\mathrm{Fe}(\mathrm{III})$-doped $\mathrm{RuO}_{2}$-film electrode prepared using a deposition solution of $50 \mathrm{mM} \mathrm{RuCl}_{3}$ and $10 \mathrm{mM}$ $\mathrm{FeCl}_{3}$ in a $1: 1$ mixture of isopropanol and $12 \mathrm{M} \mathrm{HCl}$ at an annealing temperature of $450^{\circ} \mathrm{C}$. The Levich plot ( $i$ vs. $\omega^{1 / 2}$ ) and Koutecky-Levich plot $\left(1 / i\right.$ vs. $\left.1 / \omega^{1 / 2}\right)$ of amperometric data for the oxidation of DMSO at an Fe(III)doped $\mathrm{RuO}_{2}$-film electrode configured as a rotated disk are consistent with 
an anodic response controlled by mass-transport processes at low totational velocities. Flow injection data demonstrate that $\mathrm{Fe}(\mathrm{III})$-doped $\mathrm{RuO}_{2}$-film electrodes exhibit detection capability for methionine and cysteine in addition to DMSO. Detection limits for $100-\mu \mathrm{L}$ injections of the three compounds are ca. $3.2 \times 10^{-4} \mathrm{mM}$, i.e., ca. $32 \mathrm{pmol}$.

\section{Introduction}

Based on thermodynamic information, anodic oxygen-transfer reactions of polar aliphatic organic compounds are expected to be achieved easily using noble metal electrodes, e.g., Au and Pt. However, noble metal electrodes generally exhibit only short-lived response for these reactions because of loss of electrode activity. Loss of activity of noble metal anodes is frequently attributed to adsorption of carbonaceous intermediate and/or final reaction products that mask surface sites needed to promote the corresponding electrocatalytic response mechanisms. Because traditional noble electrode materials are incapable of detecting organic compounds under constant-potential operation, alternative novel electrodes are desired that exhibit stable electrocatalytic activity for the desired anodic reactions. Various metal oxide film electrodes are being examined in this laboratory for their electrocatalytic response for a variety of polar aliphatic compounds.

Electrocatalysis of anodic oxygen-transfer reactions is presumed to 
follow the general mechanism described by Reactions (1) - (4) for a twoelectron process. According to this mechanism, proposed by

$$
\begin{aligned}
\mathrm{H}_{2} \mathrm{O} & \rightarrow \mathrm{OH}_{\mathrm{ads}}+\mathrm{H}^{+}+\mathrm{e}^{-} \\
\mathrm{R} & \rightarrow \mathrm{R}_{\mathrm{ads}} \\
\mathrm{R}_{\mathrm{ads}}+\mathrm{OH}_{\mathrm{ads}} & \rightarrow \mathrm{RO}+\mathrm{H}^{+}+\mathrm{e}^{-} \\
\text {net: } \mathrm{R}+\mathrm{H}_{2} \mathrm{O} & \rightarrow \mathrm{RO}+2 \mathrm{H}^{+}+2 \mathrm{e}^{-}
\end{aligned}
$$

Popović et al. [1], an oxygen atom from an adsorbed hydroxyl radical $\left(\mathrm{OH}_{\text {ads }}\right)$ generated by anodic discharge of $\mathrm{H}_{2} \mathrm{O}$ is transferred to an adsorbed reactant species ( $\left.R_{\text {ads }}\right)$ to achieve the net two-electron reaction with transfer of a single oxygen atom. Based on this mechanism, desirable co-requisite properties of electrocatalytic electrode materials include existence of sites for adsorption of reactant species ( $\left.\mathrm{R}_{\mathrm{ads}}\right)$ and sites for anodic discharge of $\mathrm{H}_{2} \mathrm{O}$ with adsorption of $\mathrm{OH}$ species $\left(\mathrm{OH}_{\text {ads }}\right)$. The primary benefit of adsorption of reactant species is concluded to be the result of partial desolvation of reactant species to facilitate transfer of the oxygen atom from $\mathrm{OH}_{\mathrm{ads}}$ species to $R_{\text {ads. }}$ The benefit of desolvation in anodic oxygen-transfer mechanisms is speculated to result because the oxygen-transfer step cannot occur readily by tunneling through the solvent sphere of the fully solvated R species. A secondary benefit of reactant adsorption is the increased lifetime for the adsorbed species within the applied interfacial potential field. The current efficiency for the desired anodic oxygen-transfer reaction can be diminished 
for increasing values of applied potential because anodic evolution of $\mathrm{O}_{2}$ results in consumption of the $\mathrm{OH}_{\text {ads }}$ species, as indicated by Reaction (5). Furthermore, co-evolution of

$$
\mathrm{H}_{2} \mathrm{O}+\mathrm{OH}_{\mathrm{ads}} \rightarrow \mathrm{O}_{2}+3 \mathrm{H}^{+}+3 \mathrm{e}^{-}
$$

$\mathrm{O}_{2}$ increases the background current with undesirable consequences when anodic oxygen-transfer reactions are applied for analytical purposes.

Desirable electrocatalytic electrodes will possess surface sites at which anodic generation of $\mathrm{OH}_{\text {ads }}$ by Reaction (1) can occur at low applied overpotential whereas anodic generation of $\mathrm{O}_{2}$ by Reaction (5) requires large values of applied overpotential. Accordingly, a potential region exists in which the electrode surface is well populated with $\mathrm{OH}_{\text {ads }}$ and, provided surface sites exist for adsorption of $\mathrm{R}$ and the potential is sufficient for oxidation of $\mathrm{R}$ to $\mathrm{RO}$, the anodic detection of $\mathrm{R}$ can occur by the proposed electrocatalytic mechanism without excessive $\mathrm{O}_{2}$ evolution.

Electrocatalysis of anodic oxygen-transfer reactions at $\beta-\mathrm{PbO}_{2}(\mathrm{~s})$-film electrodes doped with altervalent metallic ions has been the subject of extensive attention in this laboratory [1-7]. Recently, attention has turned to doped oxide films at noble metal electrodes. Ruthenium oxide films have been shown to offer desirable stability and electrocatalytic ability for both hydrogen evolution $[8,9]$ and, more importantly for our research, anodic evolution of $\mathrm{O}_{2}[10-12]$. The stability of the ruthenium oxide films and the low overpotential observed for anodic discharge of $\mathrm{H}_{2} \mathrm{O}$ make the ruthenium 
oxide films good candidates for application to anodic oxygen-transfer reactions. Cox et al. demonstrated that ruthenium oxide films containing cyanide with ruthenium in two valences, when coated on glassy carbon electrodes, would yield convective-diffusional controlled anodic response for cysteine and glutathione [13]. Zen et al. reported on the electrocatalytic properties of Nafion/ruthenium oxide pyrochlore and Nafion/lead ruthenate pyrochlore chemically modified electrodes with respect to oxidation of various compounds including cysteine $[14,15]$, guanine and adenine [16] hydrazine [17], hypoxanthine [18], and dopamine [19]. They reported a detection limit for cysteine of $1.9 \mu \mathrm{M}$ using square-wave voltammetry and $1.70 \mathrm{nM}$ using flow injection analysis [14]. Here we describe evidence for the electrocatalytic effect of $\mathrm{Fe}(\mathrm{III})$ sites in $\mathrm{Fe}(\mathrm{III})$-doped $\mathrm{RuO}_{2}$ film electrodes for oxidation of DMSO, methionine and cysteine.

\section{Experimental}

Instrumentation and Data Collection - Voltammetric experiments were performed at rotated disk electrodes (RDEs) under control by a Model MSR rotator (Pine Instrument) with potentiometric control of RDEs by a Model RDE4 potentiostat (Pine Instrument). A three-compartment cell was used to separate the working, auxiliary and reference electrodes. Electrode potentials used in voltammetric experiments were measured and reported vs. the saturated calomel electrode (SCE). Voltammetric data were collected 
using an IBM-compatible computer equipped with an AT-MIO-16XE-50 data acquisition board (National Instruments) and Labview data acquisition software (National Instruments).

Flow injection data were performed using a FIA-2500 system (FIAlab Instruments), a Flexcell flow-through electrochemical cell (ANTEC Leyden) and an ED40 electrochemical detector (Dionex). All electrode potentials applied in the flow cell were controlled $v$ s. a silver-silver chloride electrode (SSCE); however, these potential values are reported here vs. SCE. Flow injection data were collected using an IBM-compatible computer equipped with Peaknet data acquisition software (Dionex).

All data were obtained at ambient temperature $\left(24 \pm 2{ }^{\circ} \mathrm{C}\right)$ Statistical analyses of linear segments of Levich, Koutecky-Levich and calibration plots were performed using Sigmaplot for Windows (SPSS).

Preparation of Electrodes - Titanium (Ti) electrodes with areas of 0.314 and $0.448 \mathrm{~cm}^{2}$ were used as substrates for construction of electrodes used in voltammetric and flow injection experiments, respectively. Prior to . deposition of the $\mathrm{RuO}_{2}$ films, the Ti electrodes were sanded with 600-grit sandpaper and rinsed with deionized water. Films were thermally deposited from solutions containing $\mathrm{RuCl}_{3}$ and $\mathrm{FeCl}_{3}$ using a Bunsen burner or an electrical furnace. The thermal procedures consisted of alternate applications of drops of the appropriate solution to the titanium substrate followed by heating for approximately $10 \mathrm{~min}$. The furnace temperature was 
maintained at $450^{\circ} \mathrm{C}$. After the desired number of repeated applications of solution, a final annealing step involved heating in the furnace at $450{ }^{\circ} \mathrm{C}$ for $4 \mathrm{hr}$.

Chemicals - All chemicals were Reagent Grade. The electrolyte used in all voltammetric and FIA experiments was $1.0 \mathrm{M}$ perchloric acid (Fisher). A 1:1 mixture of isopropanol (Fisher) to $12 \mathrm{M}$ hydrochloric acid (Fisher) was used as the solvent for all deposition solutions. All water had been distilled followed by further purification in a NANO-Pure-II system (SYBRON/Barnstead). The $\mathrm{RuCl}_{3}$ (Strem) and $\mathrm{FeCl}_{3}$ (Fisher) were used as received to prepare fresh solutions immediately prior to each film deposition procedure. The DMSO (Fisher), methionine (Fisher) and cysteine (Sigma) were used as received.

\section{Results and Discussion}

Voltammetric comparison of $\mathrm{RuO}_{2}$ films - Figures $1 \mathrm{~A}$ and $1 \mathrm{~B}$ show typical voltammetric response $(i-E)$ for the positive potential scan obtained in the absence (-) and presence (- - ) of $1.0 \mathrm{mM} \mathrm{DMSO}$ in $1.0 \mathrm{M} \mathrm{HClO}_{4}$ at $\mathrm{RuO}_{2}$-film electrodes prepared by the flame and furnace techniques, respectively. The residual curves $(-$ ) for both electrodes are without defining features in the region $E=0.80-1.15 \mathrm{~V}$ with anodic evolution of $\mathrm{O}_{2}$ beginning at $E>$ ca. $1.15 \mathrm{~V}$. A modest anodic response is shown for DMSO $(---)$ in the region $E=1.05-1.15 \mathrm{~V}$ with a slightly larger response at the 
electrode produced by the flame technique (Fig. 1A). We speculate that this might be the result of the presence of a greater density of $\mathrm{Ru}$ sites in high oxidation states for the film generated in the higher temperature in the flame. Whereas the $\mathrm{RuO}_{2}$ film deposited in the flame exhibited a slightly larger DMSO signal, the furnace technique has the advantage of better temperature control and, therefore, the furnace was used to prepare all films used in succeeding studies.

Figure $1 \mathrm{C}$ shows the $i-E$ response for $1.0 \mathrm{mM}$ DMSO in $1.0 \mathrm{M} \mathrm{HClO}_{4}$ at an $\mathrm{Fe}$ (III)-doped $\mathrm{RuO}_{2}$ film (" $\mathrm{Fe}-\mathrm{RuO}_{2}$ ") produced by the furnace technique using a deposition solution containing $10 \mathrm{mM} \mathrm{FeCl}_{3}$ with $50 \mathrm{mM} \mathrm{RuCl} 3$. The background response (-) shows a small positive potential shift for onset of $\mathrm{O}_{2}$ evolution and we speculate that the $\mathrm{Fe}$ (III) sites are not active for anodic discharge of $\mathrm{H}_{2} \mathrm{O}$ with subsequent evolution of $\mathrm{O}_{2}$. However, the anodic response for DMSO (- - -) is substantially larger for this electrode in comparison to that for the undoped films (Fig. 1A and 1B) and approaches a current plateau in the approximate region $E=$ ca. $1.12-1.18 \mathrm{~V}$. We speculate that the enhanced DMSO response at the $\mathrm{Fe}-\mathrm{RuO}_{2}$ electrode is the direct result of $\mathrm{Fe}(\mathrm{III})$ sites in the electrode surface that function for adsorption of the DMSO molecules within the response mechanism represented above by Reactions (1) - (4).

Figure 2 depicts the maximum voltammetric current for DMSO as a function of the $\mathrm{FeCl}_{3}$ concentration in the deposition solution containing 50 
$\mathrm{mM} \mathrm{RuCl}$. As shown, the maximum response is obtained for a concentration of $10 \mathrm{mM} \mathrm{FeCl}_{3}$, indicating that the film composition might correspond to an approximate Fe-to-Ru ratio of 1:5. Energy dispersive spectroscopy (EDS) indicated the film contained, by atomic percent, $5.2 \% \mathrm{Fe}$ and $26 \%$ Ru which are in satisfactory agreement with the expected ratio. The observation that the anodic response for DMSO is larger at the $\mathrm{Fe}-\mathrm{RuO}_{2}$ electrode, in comparison to the $\mathrm{RuO}_{2}$ electrodes, is evidence for a synergistic function of the $\mathrm{Fe}(\mathrm{III})$ and $\mathrm{Ru}(\mathrm{IV})$ sites in this oxide. The decrease in DMSO response for Fe(III)-to-Ru(IV) ratios larger than 1:5 is believed to occur because of a decrease in the flux of $\mathrm{OH}$ species generated at the specified potential as a result of the low density of Ru(IV) sites. This speculation is supported by the observation of smaller current for $\mathrm{O}_{2}$ evolution at $E=1.2 \mathrm{~V}$ for the $\mathrm{Fe}-\mathrm{RuO}_{2}$ electrode (Fig. $1 \mathrm{C}$ ) as compared with that for the pure $\mathrm{RuO}_{2}$ electrode (Fig. 1B).

Hydrodynamic response at a rotated disk electrode - The hydrodynamic chronoamperometric response was obtained for $1.0 \mathrm{mM}$ DMSO in $1.0 \mathrm{M} \mathrm{HClO}_{4}$ at the rotated $\mathrm{Fe}-\mathrm{RuO}_{2}$ electrode (data not shown). Chronoamperometric response at a RDE is considered to be an effective simulation of the response expected under potentiostatic conditions in a flow-through cell. Furthermore, data is obtained at constant applied potential thereby removing from current values any contribution from double-1ayer charging. The anodic evolution of $\mathrm{O}_{2}$ at the rotated $\mathrm{Fe}-\mathrm{RuO}_{2}$ 
electrode was observed to occur at measurable rates for $E \geq 1.17 \mathrm{~V}$ in the 1.0 $\mathrm{M} \mathrm{HClO}_{4}$ whereas, following addition of $1.0 \mathrm{mM} \mathrm{DMSO}$, the current corresponding to $\mathrm{O}_{2}$ evolution was significant only for $E \geq 1.20 \mathrm{~V}$. This difference between potential values for onset of significant $\mathrm{O}_{2}$ evolution is understood on the basis of the explanation by Popovic et al. of observations made for use of a rotated ring-disc electrode [7]. In their experiment, the Au ring electrode was used for cathodic detection of $\mathrm{O}_{2}$ generated under voltammetric conditions at the $\mathrm{Bi}-\mathrm{PbO}_{2}$ disc electrode as a function of added DMSO. The rate of $\mathrm{O}_{2}$ evolution at the disc electrode was observed to decrease as a function of added DMSO. The decreased $\mathrm{O}_{2}$ evolution was explained on the basis of the "harvesting" of $\mathrm{OH}_{\text {ads }}$ species by the DMSO oxidation reaction before the $\mathrm{OH}_{\text {ads }}$ could be utilized within the $\mathrm{O}_{2}$-evolution reaction. Therefore, the net DMSO signal in the flow-injection procedure estimated by subtraction of the baseline current from the total peak current represents an inappropriate over correction for the contribution of $\mathrm{O}_{2}$ evolution to the total peak current. Based on the chronoamperometric data, the DMSO response at potentials in the range $1.15-1.17 \mathrm{~V}$ is judged to yield maximum DMSO response with minimal background current from $\mathrm{O}_{2}$ evolution.

Characterization of amperometric response mechanisms frequently involves examinations of so-called Levich plots of current $(i, \mu \mathrm{A})$ at RDEs vs. square root of rotational velocity $\left(\omega^{1 / 2}, \mathrm{~s}^{-1 / 2}\right)$. For mass transport-limited 
response, i.e., fast heterogeneous kinetics, the Levich plot is predicted to be linear with a zero intercept [20]. The slope of a linear Levich plot corresponds to $0.62 n \mathrm{FA} D^{2 / 3} \bar{\nu}^{-1 / 6} \mathrm{C}^{\mathrm{b}}$ where $n$ is the apparent number of electrons transferred in the electrode reaction (eq $\mathrm{mol}^{-1}$ ), $\mathrm{F}$ is the Faraday constant $\left(9.65 \times 10^{4} \mathrm{C} \mathrm{eq}^{-1}\right), \mathrm{A}$ is the geometric electrode area $\left(\mathrm{cm}^{2}\right), D$ is the diffusion coefficient $\left(\mathrm{cm}^{2} \mathrm{~s}^{-1}\right), v$ is the kinematic viscosity of the solution $\left(\mathrm{cm}^{2} \mathrm{~s}^{-1}\right)$ and $C^{b}$ is the bulk concentration of reactant $(\mathrm{mM})$. Negative curvature from linearity in a Levich plot is characteristic of slow heterogeneous kinetics resulting in an electrode response that is under mixed kinetic-mass transport control. These data can be plotted according to the so-called Koutecky-Levich equation as reciprocal current $\left(1 / i, \mu \mathrm{A}^{-1}\right)$ vs. reciprocal square root of rotational velocity $\left(1 / \omega^{1 / 2}, s^{1 / 2}\right)[21]$. The slope of a linear Koutecky-Levich plot is $1 / 0.62 n F A D^{2 / 3} v^{-1 / 6} C^{b}$ and the intercept is $1 / n \mathrm{FA} k_{\mathrm{app}} C^{\text {b}}$, where $k_{\mathrm{app}}$ is the apparent heterogeneous rate constant $(\mathrm{cm}$ $\left.\mathrm{s}^{-1}\right)$.

Levich and Koutecky-Levich plots for the DMSO response at a Fe$\mathrm{RuO}_{2} \mathrm{RDE}$ under potentiostatic conditions are shown in Figure 3. The Levich plot shows the type of curvature characteristic of a transition from transport-controlled response at low rotational velocities to mixed kinetictransport control at high rotational velocities. The Koutecky-Levich plot is linear with a slope of $2.67 \times 10^{-2} \mathrm{rad}^{1 / 2} \mathrm{\mu A}^{-1} \mathrm{~s}^{-1 / 2}$ (std. error $=7 \times 10^{-5} \mathrm{rad}^{1 / 2}$ $\mu \mathrm{A}^{-1} \mathrm{~s}^{-1 / 2}$ ) and a non-zero intercept of $8.69 \times 10^{-4} \mu \mathrm{A}^{-1}$ (std. error $=9 \times 10^{-6} \mu \mathrm{A}^{-}$ 
1). The value $n=1.8 \mathrm{eq}^{-1} \mathrm{~mol}^{-1}$ was calculated from the slope of the Koutecky-Levich plot using the values $D=1.1 \times 10^{-5} \mathrm{~cm}^{2} \mathrm{~s}^{-1}$ obtained from Figure 12 of Ref. [22] for $25^{\circ} \mathrm{C}$ and $\nu=8.8 \times 10^{-3} \mathrm{~cm}^{2} \mathrm{~s}^{-1}$. This result is considered to be in satisfactory agreement with the expected value $n=2$ eq $\mathrm{mol}^{-1}$ for anodic conversion of DMSO to $\mathrm{DMSO}_{2}$. The value $k_{\text {app }}=2.9 \times 10^{-2}$ $\mathrm{cm} \mathrm{s}^{-1}$ was calculated from the intercept of the Koutecky-Levich plot in Figure 4 using $n=2.0 \mathrm{eq}^{\mathrm{mol}}{ }^{-1}$.

Flow-injection detection - Figure 4 shows peaks for DMSO obtained using the flow-injection system with detection at the $\mathrm{Fe}-\mathrm{RuO}_{2}$ film electrode in the flow-through detection cell. Shown are the first five and the last five peaks obtained for a series of 60 injections of $(100 \mu \mathrm{L})$ of $0.010 \mathrm{mM}$ DMSO in $1.0 \mathrm{M} \mathrm{HClO}_{4}$. The detection potential used was $1.15 \mathrm{~V}$ and the flow rate of the solvent was $1.0 \mathrm{~mL} \mathrm{~min}^{-1}$. The injections were made at intervals of 1.5 min. Minor peak variations in a chromatogram are expected and can be seen in Figure 4. For the first five injections, the average deviation of peak heights was $1.9 \%$ while that of the peak area was $3.6 \%$. For the last five injections, the average deviation was $3.2 \%$ for peak height and $2.6 \%$ for peak area. Peak height showed a loss of $9.8 \%$ between the average of the first five injections and the last five injections. The corresponding average of peak areas showed a loss of $5.0 \%$. As can be seen from these data, there was some loss in electrode response over the period of 60 injections. The effect of this signal loss on detection capabilities when injections are not 
continuous is uncertain. Therefore, use of these film electrodes is predicted to require periodic recalibrations.

Figure 5 shows calibration data, based on peak-height data; for DMSO, methionine and cysteine using a flow-injection system with the Fe$\mathrm{RuO}_{2}$ film electrode. The amino acids were included to test activity of Fe$\mathrm{RuO}_{2}$ electrodes for biologically significant sulfur-containing compounds. The error bars shown represent the standard deviation for all injections. The straight line shown in Figure 5 corresponds to the linear regression for methionine $\left(r^{2}=0.9999\right)$ that exhibits linearity over the largest concentration range. A linear response is observed for methionine over the concentration

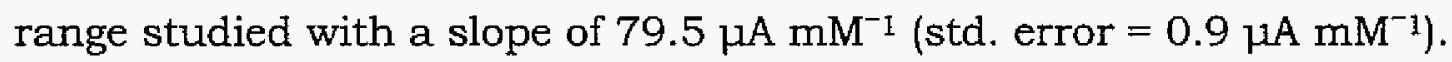
Using the slope for the methionine response and $3 \mathrm{X}$ the average peak-topeak variation in baseline signal represented in Figure $4\left(8.6 \times 10^{-3} \mu \mathrm{A}\right)$, the limit of detection is estimated by:

$$
\frac{3\left(8.6 \times 10^{-3} \mu \mathrm{A}\right)}{\left(79.5 \mu \mathrm{Am}^{-1}\right)}=3.2 \times 10^{-4} \mathrm{mM}=0.32 \mu \mathrm{M}
$$

This estimated detection limit corresponds to $32 \mathrm{pmol}$ in a $100-\mu \mathrm{L}$ injection.

Whereas the plot of methionine data in Figure 5 exhibits satisfactory linearity $\left(r^{2}=0.9999\right)$ over the concentration range studied, the DMSO and cysteine plots exhibit significant deviation from linearity for concentrations larger than ca. $0.02 \mathrm{mM}$. This deviation from linearity is evidence of slow heterogeneous kinetics for the anodic oxidations of DMSO and cysteine in 
comparison that for methionine. However, at first thought, such a conclusion is suspect in view of the large value of $k_{\text {app }}$ calculated for DMSO based on data in Figure 3. For the response mechanism invoked here, the response is predicted to be dependent on both the adsorption equilibrium constant for the reactant and the rate of the anodic generation of $\mathrm{OH}_{\text {ads }}$ [1]. Accordingly, linearity of calibration curves can be expected only for low concentrations and, furthermore, the concentration at which negative deviation from linearity is observed will be dependent on the identify of the reactant.

\section{Conclusions}

Based on the preliminary results described here, the Fe(III)-doped $\mathrm{RuO}_{2}$-film electrodes are projected to be applicable for anodic detection of sulfur compounds as illustrated here by DMSO, methionine and cysteine. Use of this electrode can have an advantage of simple instrumentation as compared to pulsed electrochemical detection of sulfur compounds at $\mathrm{Au}$ electrodes [23]. Based on experimental evidence, the $\mathrm{Fe}(\mathrm{III})$ sites in the $\mathrm{Fe}-$ $\mathrm{RuO}_{2}$ films are speculated to act as adsorption sites for the DMSO whereas the $\mathrm{Ru}(\mathrm{IV})$ sites function for anodic discharge of $\mathrm{H}_{2} \mathrm{O}$ to generate the adsorbed $\mathrm{OH}$ species. Adsorption of DMSO is believed to occur at $\mathrm{Fe}(\mathrm{III})$ sites via the nonbonded electron pair on the S-atom. Our conclusion that reactant adsorption is important in the electrocatalytic response mechanism 
is based on the considerations that (i) adsorption of DMSO results in an increased lifetime of this reactant within the applied interfacial potential field and (ii) adsorption of DMSO via the sulfur atom promotes desolvation of the atomic orbital to which the oxygen atom is transferred from the $\mathrm{OH}_{\text {ads }}$ species generated at neighboring Ru(IV) sites.

The sulfur moiety of methionine had been expected to undergo a fourelectron process with transfer of two oxygen atoms to produce the corresponding sulfone whereas the sulfur moiety of cysteine had been expected to undergo a six-electron process with transfer of three oxygen atoms to produce the corresponding sulfonate. However, the nearly equivalent response for DMSO, methionine and cysteine at concentrations < $0.03 \mathrm{mM}$ (Figure 6) is consistent with the conclusion that the anodic responses of these three compounds correspond to transfer of an equivalent number of electrons, i.e., $n=2$ eq $\mathrm{mol}^{-1}$.

\section{Acknowledgments}

This report has been authored by the Iowa State University of Science and Technology under Contract No. W-7405-ENG-82 with the U.S.

Department of Energy. The U. S. Government retains and the publisher, by accepting the article for publication, acknowledges that the U.S. Government retains a non-exclusive, paid-up, irrevocable, world-wide license to publish or reproduce the published form of this manuscript, or 
allow others to do so, for U. S. Government purposes. The authors gratefully acknowledge Warren E. Strazheim for EDS data.

\section{References}

1. N. D. Popović, J. A. Cox, D. C. Johnson, J. Electroanal. Chem. 1998, 455,$153 ; 1998,456,203$.

2. I-H. Yeo, D. C. Johnson, J. Electrochem Soc. 1987, 134, 1973.

3. I-H. Yeo, S. Kim, R. Jacobsen, D. C. Johnson, J. Electrochem Soc. $1989,136,1395$.

4. J. Ge, D. C. Johnson, J. Electrochem Soc. 1995, 137, 1525.

5. H. Chang, D. C. Johnson, Analytica Chimica Acta 1991, 248, 85.

6. H. Chang, D. C. Johnson, J. Electrochem Soc. 1990, 137, 3108.

7. N. D. Popović, D. C.; Johnson, Anal. Chem., 1998, 70, 468.

8. N. Spataru, J. G. Le Helloco, R. Durand, J. Appl. Electrochem., 1996, $26,397$.

9. L. L. Chen, D. Guay, A. Lasia, J. Electrochem. Soc., 1996, 143, 3576.

10. D. Burke, M. M. McCarthy, Electrochim. Acta., 1984, 29, 211.

11. R. Kotz, S. Stucki, S. Electrochim. Acta, 1986, 31, 1311.

12. D. T. Shieh, B. J. Hwang, J. Electroanal. Chem., 1995, 391, 77.

13. J. A. Cox; T. J. Gray, Anal. Chem., 1990, 62, 2742.

14. J.-M. Zen, A. S. Kumar, et al., Anal. Chem., 2001, 73, 1169.

15. J.-M. Zen, A. S. Kumar, et al., Chem. Lett., 1999, 8, 743. 
16. J.-M. Zen, M.-R. Chang, et al., Analyst, 1999, 124, 679.

17. J.-M. Zen and J.-S. Tang, Anal. Chem., 1995, 67, 208.

18. J.-M. Zen, Y.-Y. Lai, et al., Electroanalysis, 2000, 12, 280.

19. J.-M. Zen, A. S. Kumar, et al., J. Mol. Cat. A: Chem., 2001, 165, 177.

20. V. G. Levich, Physicochemical Hydrodynamics, Prentice-Hall, Englewood Cliffs, NJ 1962, 345-57.

21. J. Koutecky and V. G. Levich, Zh. Fiz. Khim., 1958, 32, 1565.

22. C. O. Lobdell, Diffusion of Dimethyl Sulfoxide in Aqueous Mixtures and Polyelectrolyte Gels" Ph.D. Dissertation, State University of New York at Binghamton (1975).

23. W. R. LaCourse, Pulsed Electrochemical Detection in High-Performance Liquid Chromatography, J. Wiley: New York 1997. 


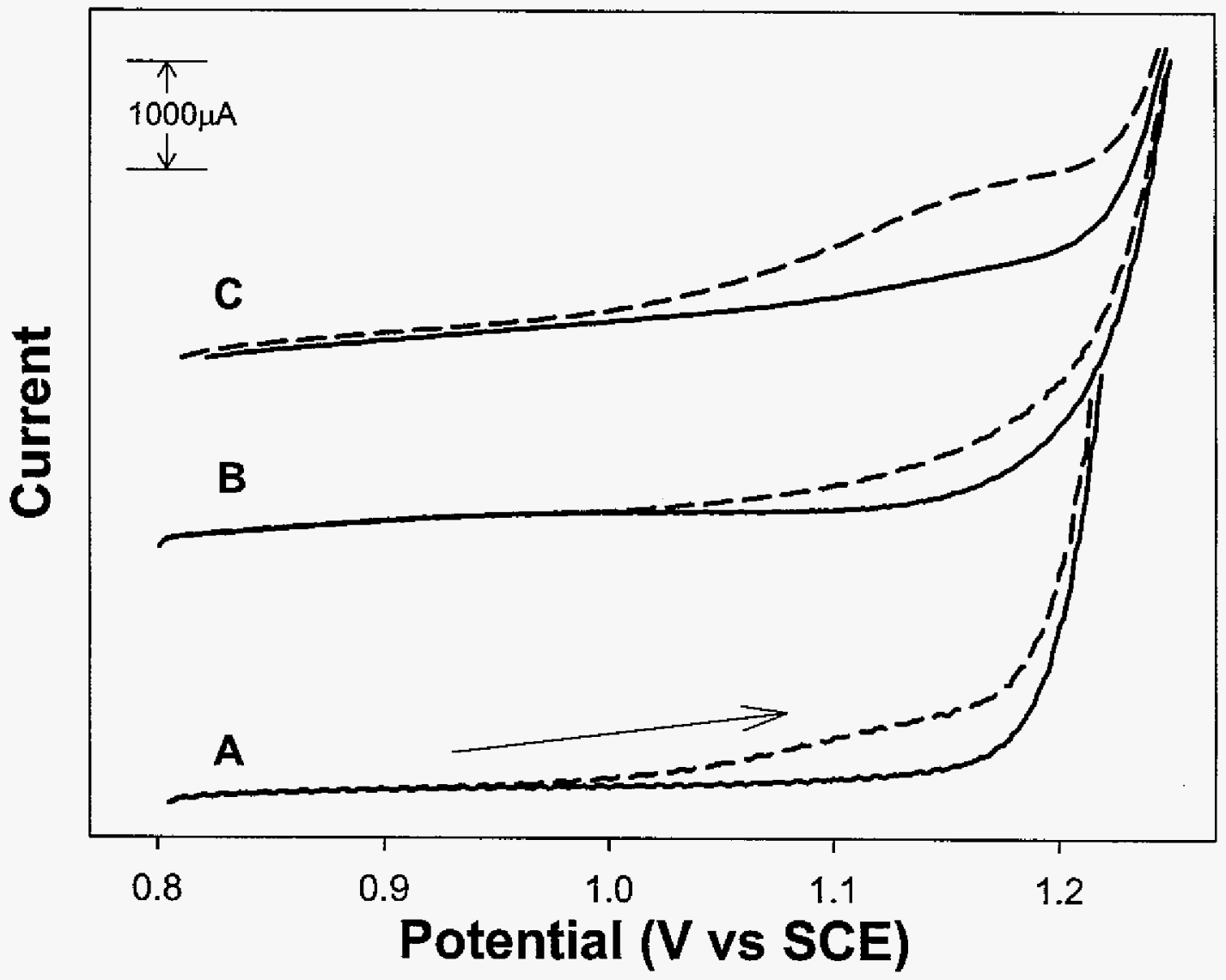

Figure 1. Comparison of voltammetric response (positive scan) for DMSO at $\mathrm{RuO}_{2}$ film electrodes prepared by the flame (A) and furnace (B) techniques, and a $\mathrm{Fe}-\mathrm{RuO}_{2}$ film electrode (C) prepared by the furnace technique. Electrolyte: $1.0 \mathrm{M} \mathrm{HClO}_{4}$. DMSO concentration (mM): (-) 0 , (--) 1.0. Scan rate: $100 \mathrm{mV} \mathrm{s}^{-1}$. Rotational velocity: $9.7 \mathrm{~s}^{-1}$. 


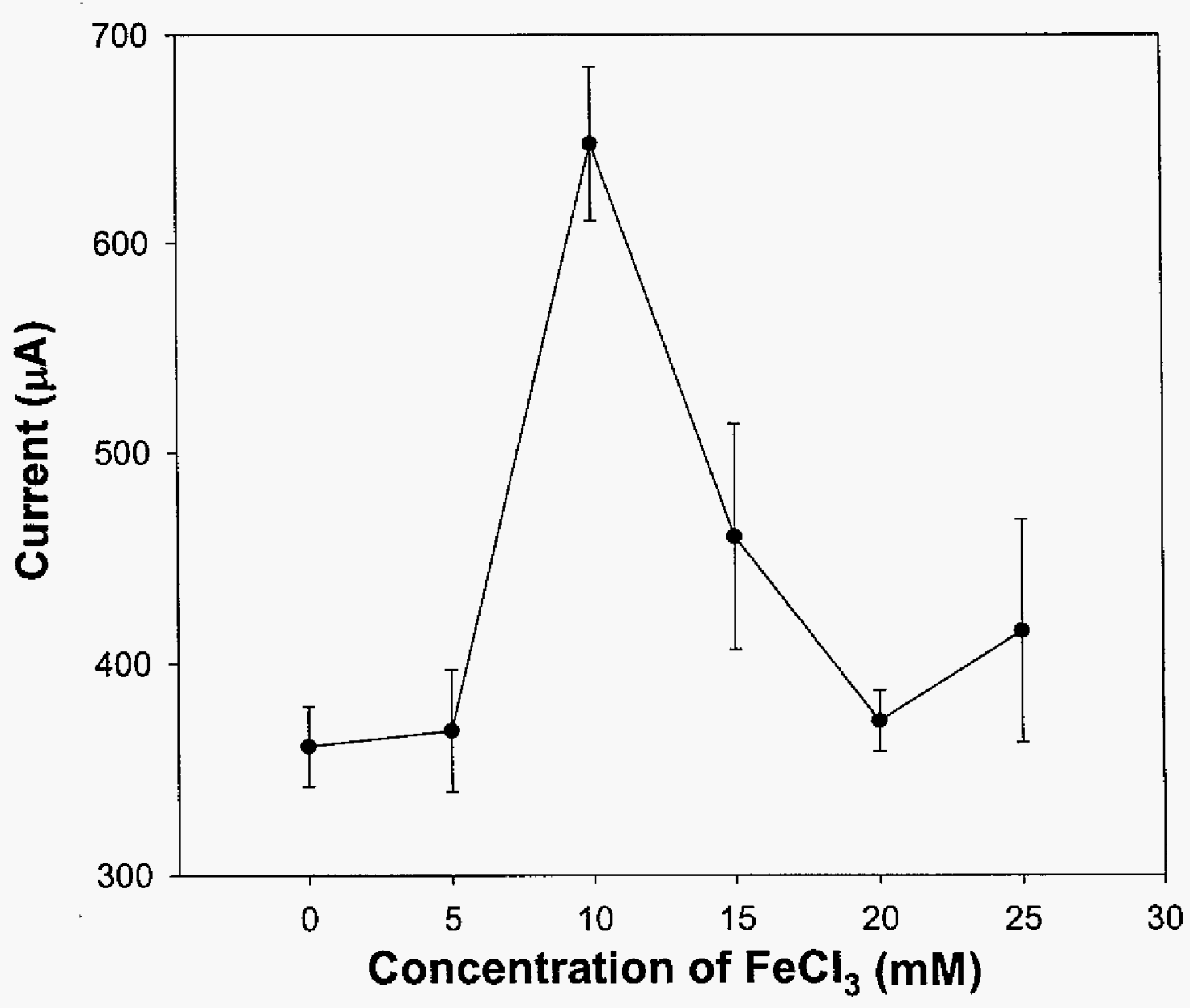

Figure 2. Maximum response for $1.0 \mathrm{mM}$ DMSO in $1.0 \mathrm{M} \mathrm{HClO}_{4}$ at $\mathrm{Fe}-$ $\mathrm{RuO}_{2}$ electrodes prepared by the furnace technique as a function of concentration of $\mathrm{FeCl}_{3}$ in the deposition solution. Deposition solution: designated concentration of $\mathrm{FeCl}_{3}$ in a $1: 1$ mixture of isopropanol and $12 \mathrm{M}$ $\mathrm{HCl}$ containing $50 \mathrm{mM} \mathrm{RuCl}_{4}$. Annealing temperature: $450^{\circ} \mathrm{C}$. Rotational velocity: $9.7 \mathrm{~s}^{-1}$. 


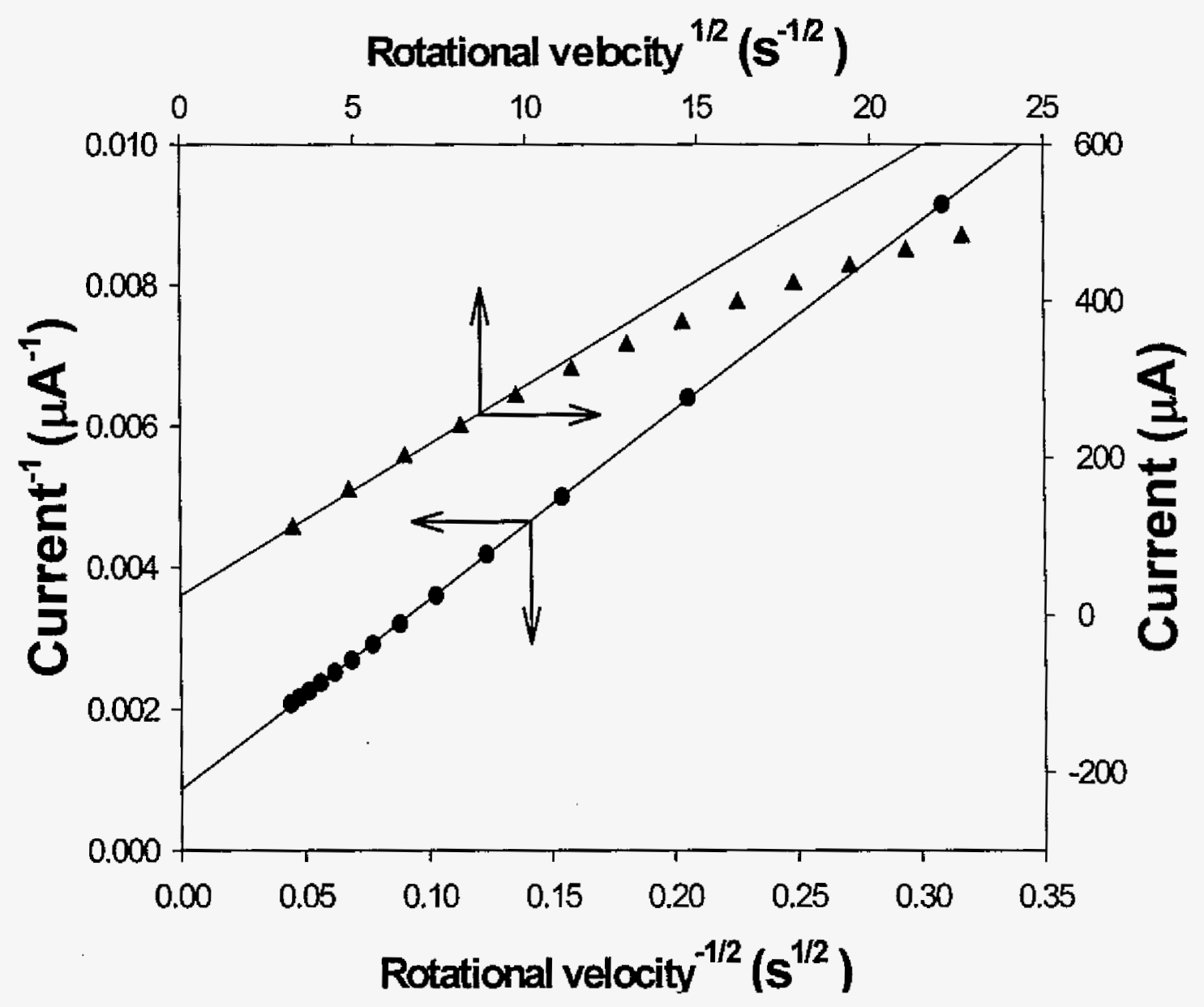

Figure 3. Levich (A) and Koutecky-Levich () plots for $1.0 \mathrm{mM}$ DMSO in $1.0 \mathrm{M} \mathrm{HClO}_{4}$ at a $1: 5 \mathrm{Fe}$-doped $\mathrm{RuO}_{2}$ film electrode prepared by the furnace technique. Detection potential: $1.16 \mathrm{~V}$ vs. SCE. 


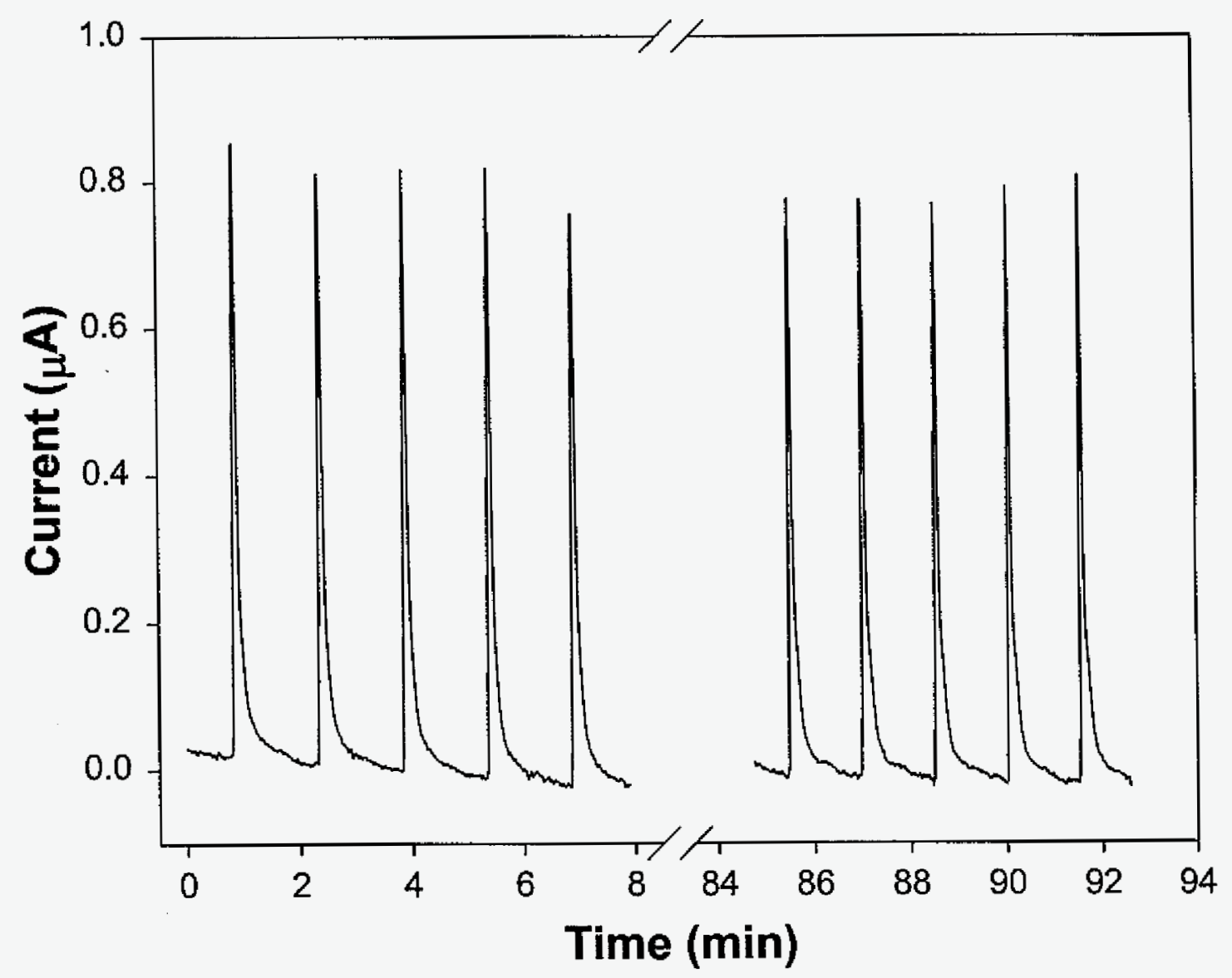

Figure 4. Stability of response for injections of $100-\mu \mathrm{L}$ samples of 0.010 $\mathrm{mM}$ DMSO in $1.0 \mathrm{M} \mathrm{HClO}_{4}$ at 1.5-minute intervals in a flow-injection system with detection at a $1: 5 \mathrm{Fe}$-doped $\mathrm{RuO}_{2}$ film electrode prepared by the furnace technique. Peaks shown correspond to the first five and last five of 60 injections. Detection potential: $1.15 \mathrm{~V}$ vs. SCE. Flow rate: $1.0 \mathrm{~mL}$ $\min ^{-1}$. 


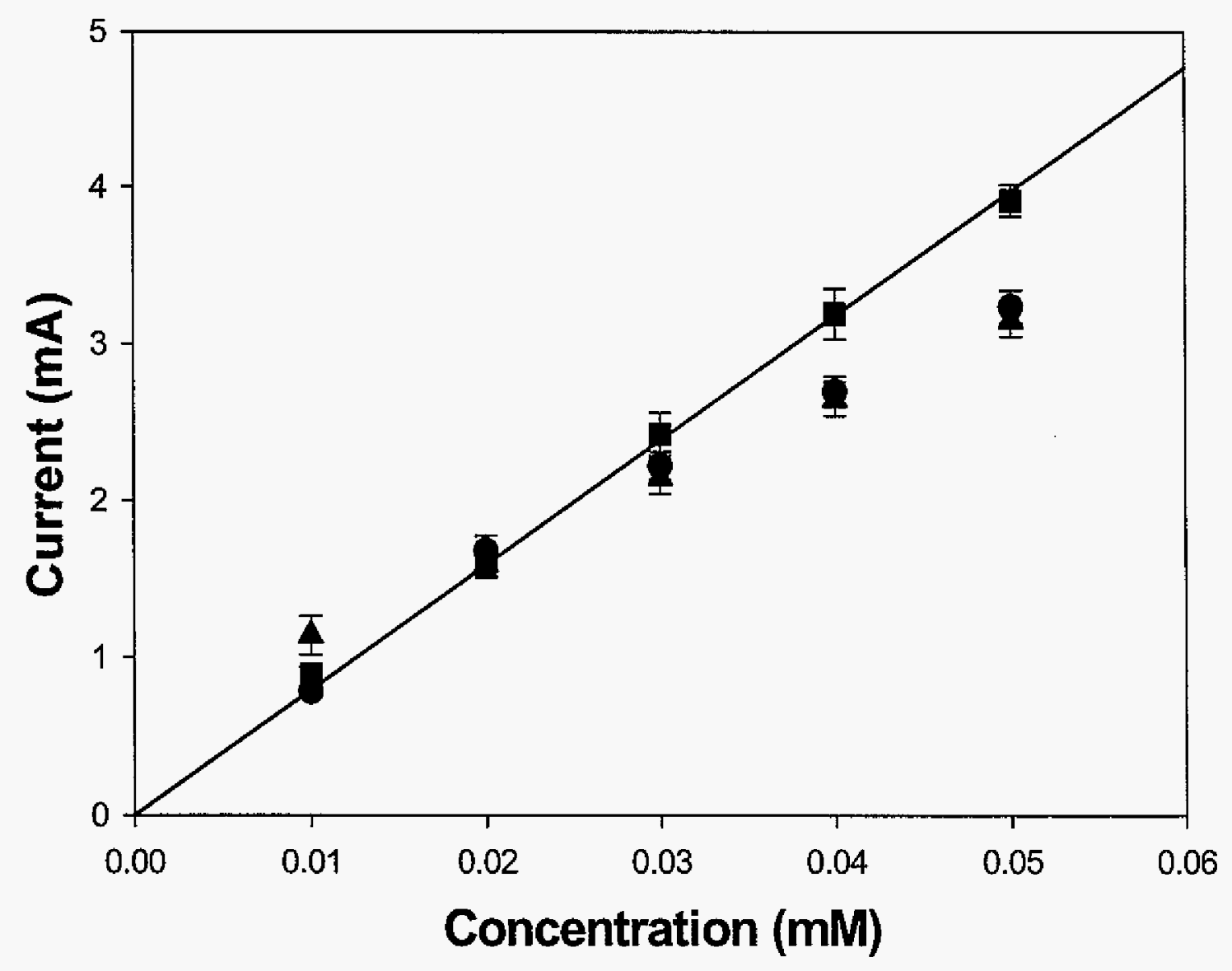

Figure 5. Peak currents by flow injection detection vs. concentration of sulfur-containing compounds in $1.0 \mathrm{M} \mathrm{HClO}_{4}$ using a 1:5 Fe-doped $\mathrm{RuO}_{2}$ film electrode prepared by the furnace technique. All points include a minimum of 50 injection peaks with standard deviation shown. Data: (๑) dimethyl sulfoxide, $(\square)$ methionine, (A) cysteine. $(-)$ linear regression line for methionine data. 


\title{
CHAPTER 4. ELECTROCATALYSIS OF NITRATE REDUCTION REACTIONS AT VARIOUS PURE METAL AND ALLOY ELECTRODES
}

\begin{abstract}
Various metals are studied with respect to the $\mathrm{H}_{2}(\mathrm{~g})$ evolution potentials in $1 \mathrm{M} \mathrm{HClO}_{4}$. In addition, the reduction of $5.0 \mathrm{mM} \mathrm{NO}_{3}^{-}$in $1 \mathrm{M}$ $\mathrm{HClO}_{4}$ is studied at the various metals. The initial studies are carried out to determine candidates for combination into alloy electrodes with a homogeneous mixture of discrete surface sites for adsorption of $\mathrm{NO}_{3}^{-}$and $\mathrm{H}-$ atoms which is expected to increase electrocatalytic response for $\mathrm{NO}_{3}^{-}$ reduction. Voltammetric data for the reduction of $\mathrm{NO}_{3}{ }^{-}$in $1 \mathrm{M} \mathrm{HClO}_{4}$ is presented for the $\mathrm{Sb}_{10} \mathrm{Sn}_{20} \mathrm{Ti}_{70}, \mathrm{Cu}_{63} \mathrm{Zn}_{37}$ and $\mathrm{Cu}_{25} \mathrm{Ni}_{75}$ alloy electrodes along with their corresponding pure component metals. Improvement in electrocatalytic properties for nitrate reduction is seen for all alloys as compared to the pure metals.
\end{abstract}

\section{Introduction}

Nitrates in the environment have long been studied due to the concern of possible health effects on humans. Runoff from various areas where large use of manure and pesticides occurs, i.e. farms and industry, can lead to increased nitrate levels in the surrounding ground water. 
Nitrate itself is relatively non-toxic, however, conversion of $\mathrm{NO}_{3}{ }^{-}$to $\mathrm{NO}_{2}{ }^{-}$is conducted by bacteria in the intestinal tract of the human body. [1] Nitrite in the body can lead to the development of methemoglobinemia, a disease in which hemoglobin in the blood is prevented from carrying oxygen.[2] Additionally, nitrites in the body can lead to the formation of $N$-nitroso compounds, which are precursors to cancer causing agents. $[1,3,4]$

The reduction of $\mathrm{NO}_{3}{ }^{-}$has been studied using various techniques such as solution based metal macrocycles[5-8], porphyrins[9], and nitrate reductase biocatalysts $[10,11]$. Heterogeous catalysts have been studied as well. The half-wave potential for $\mathrm{NO}_{3}{ }^{-}$reduction was investigated at various metal electrodes by Khomutov and Stamkulov and observed to have a dependence on the atomic number of the cathode material.[12] The data were later reinterpreted with regards to metal hydrogen (M-H) and metal oxygen (M-O) bonding energies. Vijh determined that transition metals showed volcano type plots with respect to $\mathrm{NO}_{3}{ }^{-}$reduction activity compared to $\mathrm{M}-\mathrm{H}$ and $\mathrm{M}-\mathrm{O}$ interaction energies, with moderate values of bonding energies showing the optimum activity.[13]

Whereas Khomutov and Stamkulov did a broad study for various metals in nitric acid, extensive research has been carried out for more detailed information of $\mathrm{NO}_{3}{ }^{-}$reduction at various metals electrodes such as $\mathrm{Cu}[14-22], \mathrm{Cd}[17,20,23,24], \mathrm{Pb}[5,25]$ and $\mathrm{Ag}[15,26]$. Boron-doped diamond electrodes have shown electrocatalytic properties for $\mathrm{NO}_{3}{ }^{-}$ 
reduction as well[27-29]. The study of $\mathrm{NO}_{3}{ }^{-}$reduction at various platinized platinum electrodes[30-33] by Horanyi et al. revealed that $\mathrm{NO}_{3}{ }^{-}$reduction is inhibited at potentials more negative than the reference hydrogen electrode (RHE) potential. Reasons for this were speculated to involve surface saturation by adsorbed $\mathrm{H}$-atoms resulting in loss of catalytic sites for $\mathrm{NO}_{3}{ }^{-}$ adsorption.[33] Studies by Ohmori et al.[34] and Bockris et al.[35] also showed suppression of nitrate reduction with onset of $\mathrm{H}_{2}(\mathrm{~g})$ evolution.

The $\mathrm{NO}_{3}{ }^{-}$reduction mechanism at a metal electrode requires the adsorption of $\mathrm{H}$-atoms, which, in acidic media, can occur via two different reaction mechanism represented by

$$
\begin{aligned}
2 \mathrm{H}^{+}+2 \mathrm{e}^{-} & \rightarrow 2 \mathrm{H}_{\text {ads }} \\
\mathrm{H}_{2} \mathrm{O}+\mathrm{e}^{-} & \rightarrow \mathrm{H}_{\text {ads }}+\mathrm{OH}^{-}
\end{aligned}
$$

with Eqn. 1 being the predominant reaction in acidic media.

Additionally, concurrently with adsorption of $\mathrm{H}$-atoms, $\mathrm{NO}_{3}{ }^{-}$must adsorb at the electrode surface which can be represented by the following reaction

$$
\mathrm{NO}_{3}{ }^{-} \rightarrow \mathrm{NO}_{3}{ }^{-} \text {ads }
$$

Upon adsorption of both $\mathrm{NO}_{3}{ }^{-}$and $\mathrm{H}$-atoms, cathodic $\mathrm{H}$-transfer can occur and is represented by the following reaction

$$
2 \mathrm{H}_{\text {ads }}+\mathrm{NO}_{3}^{-}{ }^{-} \text {ads } \rightarrow \mathrm{NO}_{2}{ }^{-} \text {ads }+\mathrm{H}_{2} \mathrm{O}
$$

A combination of reactions 1,3 and 4 gives us the net overall reaction for $\mathrm{NO}_{3}{ }^{-}$reduction

$$
\mathrm{NO}_{3}{ }^{-}+2 \mathrm{H}^{+}+2 \mathrm{e}^{-} \rightarrow \mathrm{NO}_{2}^{-} \text {ads }+\mathrm{H}_{2} \mathrm{O}
$$


As can be seen from reaction 5 , the final product of $\mathrm{NO}_{3}{ }^{-}$reduction is adsorbed $\mathrm{NO}_{2}{ }^{-}$. The $\mathrm{NO}_{2}{ }^{-}$can then either desorb from the electrode surface or undergo further $\mathrm{H}$-transfer to produce various products. Because the mechanism is dependent upon adsorbed $\mathrm{H}$-atoms, the $\mathrm{NO}_{3}{ }^{-}$reduction efficiency is affected by formation of $\mathrm{H}_{2}(\mathrm{~g})$ through combination of two surface adsorbed $\mathrm{H}$-atoms represented by

$$
2 \mathrm{H}_{\mathrm{ads}} \rightarrow \mathrm{H}_{2} \text { (g) }
$$

Development of electrode materials that have separate catalytic sites for $\mathrm{H}$-atom adsorption and $\mathrm{NO}_{3}{ }^{-}$adsorption has been the subject of numerous studies. The electrodeposition of $\mathrm{Cu}$ at various substrates[14, $17,21]$ and Ge at $\mathrm{Pt}$ and $\mathrm{Pt}$ alloy electrodes[36] improve electrocatalytic response for nitrate reduction. Combinations of $\mathrm{Cu}$ with $\mathrm{Pd}[19,37-39]$ and Pt with Ir [40] provided materials that exhibited improvement of nitrate reduction response as compared to the pure component metals.

The purpose of this research was to ascertain the effects of $\mathrm{H}_{2}(\mathrm{~g})$ evolution upon the electrocatalysis of the nitrate reduction process and to study the nitrate reduction at alloys composed of pure metal components that exhibited either nitrate adsorption capabilities and/or differing potentials for $\mathrm{H}_{2}(\mathrm{~g})$ evolution in $1 \mathrm{M} \mathrm{HClO}_{4}$. Separation of catalytic sites for $\mathrm{NO}_{3}{ }^{-}$and $\mathrm{H}$-atom adsorption is achieved by combination of metals into alloy electrodes. This separation of reactions at the electrode surface is expected to improve electrocatalytic activity for $\mathrm{NO}_{3}{ }^{-}$reduction. 


\section{Experimental}

Instrumentation and Data Collection - Voltammetric experiments were performed at rotated disk electrodes (RDEs) under control by a Model MSR rotator (Pine Instrument) with potentiometric control of rotating disk electrodes (RDE) by a Model RDE4 potentiostat (Pine Instrument). A threecompartment cell was used to separate the working, auxiliary and reference electrodes. Electrode potentials used in voltammetric experiments were measured and reported $v$ s. the saturated calomel electrode (SCE). Voltammetric data were collected using an IBM-compatible computer equipped with an AT-MIO-16XE-50 data acquisition board (National Instruments) and Labview data acquisition software (National Instruments). Tables 1 and 2 contain summaries of electrode areas and manufacturers. In house preparations were carried out by the Materials Development Processing Center. Prior to data collection, all electrodes were polished with 0.1 micron alumina powder.

Chemicals - All chemicals were Reagent Grade. The electrolyte used in all voltammetric experiments was $1.0 \mathrm{M}$ perchloric acid (Fisher). All water was distilled followed by further purification in a NANO-Pure-II system (SYBRON/Barnstead). Sodium nitrate (Fisher) was used as received to prepare all nitrate solutions used in the experiments. Solutions used in all voltammetric experiments were degassed with $\mathrm{N}_{2}$ for removal of dissolved $\mathrm{O}_{2}$ with constant flow of $\mathrm{N}_{2}$ maintained over the solution. 


\section{Results and Discussion}

Comparison of various pure metal and alloy electrodes - The initial study undertaken in this research was the determination of $\mathrm{H}_{2}(\mathrm{~g})$ evolution (Eqn. 6) potentials at various metal electrodes in $1 \mathrm{M} \mathrm{HClO}_{4}$. The evolution of $\mathrm{H}_{2}(\mathrm{~g})$ requires the formation of adsorbed $\mathrm{H}$-atoms (Eqn. 1). Therefore, it was believed that the potentials at which $\mathrm{H}_{2}$ (g) evolution occurs would reflect the potentials expected for $\mathrm{NO}_{3}{ }^{-}$reduction, based upon the dependence of the reduction on Eqn. 1 as well.

Adsorption of $\mathrm{NO}_{3}{ }^{-}$(Eqn. 3) is also a prerequisite step for $\mathrm{NO}_{3}{ }^{-}$ reduction (Eqn. 5), so the next step in the research was to study the response of $\mathrm{NO}_{3}{ }^{-}$at the same metal electrodes, as used in the $\mathrm{H}_{2}(\mathrm{~g})$ evolution study, to determine $\mathrm{NO}_{3}{ }^{-}$adsorption properties at said electrodes. The data were analyzed to determine values for $\mathrm{NO}_{3}{ }^{-}$reduction current density $\left(\mathrm{mA} \mathrm{cm}^{-2}\right)$ at the metal electrodes which are obtained at the potentials at which a $1 \mathrm{~mA} \mathrm{~cm}-2$ background current $\left(\mathrm{H}_{2}(\mathrm{~g})\right.$ evolution) is seen. The data are plotted in Figure 1 as $\mathrm{NO}_{3}{ }^{-}$reduction current density versus the $\mathrm{H}_{2}(\mathrm{~g})$ evolution potential. Potential values at which a $1 \mathrm{~mA} \mathrm{~cm}-2$ current density for $\mathrm{H}_{2}(\mathrm{~g})$ evolution occurred at the various electrode materials are summarized in Tables 1 and 2 .

The purpose for this initial study was to determine pure metal electrode materials with differing potentials for $\mathrm{H}_{2}(\mathrm{~g})$ evolution and/or the 
capability for $\mathrm{NO}_{3}{ }^{-}$adsorption with the prospect of combining the pure metals into alloy electrodes which exhibited improved electrocatalytic response for $\mathrm{NO}_{3}{ }^{-}$reduction. The belief was that combination of metals with differing $\mathrm{H}_{2}(\mathrm{~g})$ evolution potentials would provide specific sites at the electrode surface for $\mathrm{H}$-atom adsorption (Eqn. 1) to occur allowing for $\mathrm{NO}_{3}{ }^{-}$ adsorption to occur at the other unoccupied sites.

Looking at the data in Figure 1, Pt, Ru and Ag show similar potentials for $\mathrm{H}_{2}(\mathrm{~g})$ evolution with minimal response for nitrate reduction. The $\mathrm{Au}, \mathrm{Ti}$ and $\mathrm{Sb}$ electrodes show minimal response to $\mathrm{NO}_{3}{ }^{-}$reduction in addition to potentials for $\mathrm{H}_{2}(\mathrm{~g})$ evolution greater than $-0.50 \mathrm{~V}$. Adsorbed $\mathrm{H}$-atoms at the electrode surface can block $\mathrm{NO}_{3}{ }^{-}$adsorption which could be the cause of poor response at these electrodes. Additionally, weak adsorption of $\mathrm{NO}_{3}{ }^{-}$ would also hinder the reduction process. A $1.0 \mathrm{~mA} \mathrm{~cm}-2$ current density for $\mathrm{H}_{2}(\mathrm{~g})$ evolution is seen at $-0.90 \mathrm{~V}$ for the $\mathrm{Sn}$ and $\mathrm{Al}$ electrodes. Minimal reduction current is seen at these electrodes. The $\mathrm{Cd}, \mathrm{Cu}, \mathrm{Ni}$ and $\mathrm{Zn}$ electrodes exhibit electrocatalytic activity for $\mathrm{NO}_{3}{ }^{-}$reduction with current densities increasing in the order of $\mathrm{Zn}<\mathrm{Ni}<\mathrm{Cu}<\mathrm{Cd}$. The potential at which a $1.0 \mathrm{~mA} \mathrm{~cm}-2$ background current density occurs decreases in the following order, $\mathrm{Ni}>\mathrm{Cu}>\mathrm{Cd}>\mathrm{Zn}$. Based upon the data obtained, various combinations of the pure metals in alloy form were studied and are discussed in the remainder of this chapter. 
Antimony, Tin, Titanium and Alloy Electrodes - The voltammetric responses at $\mathrm{Sb}, \mathrm{Sn}, \mathrm{Ti}$ and $\mathrm{Sb}_{10} \mathrm{Sn}_{20} \mathrm{Ti}_{70}$ electrodes in the absence $(-)$ and presence (-- - ) of $5.0 \mathrm{mM} \mathrm{NO}_{3}^{-}$in $1 \mathrm{M} \mathrm{HClO}_{4}$ are plotted in Figure 2 as current density $\left(\mathrm{mA} \mathrm{cm}{ }^{-2}\right)$ versus potential $(\mathrm{V})$. The pure component metal electrodes show residual responses which are featureless until the onset of $\mathrm{H}_{2}(\mathrm{~g})$ evolution occurring at approximately $-0.90 \mathrm{~V},-0.75 \mathrm{~V}$ and $-0.30 \mathrm{~V}$ for $\mathrm{Sn}(\mathrm{A}), \mathrm{Sb}(\mathrm{B})$, and $\mathrm{Ti}(\mathrm{C})$, respectively. No response for $\mathrm{NO}_{3}{ }^{-}$ reduction is seen at the $\mathrm{Sn}\left(\mathrm{A}^{\prime}\right)$ and $\mathrm{Sb}\left(\mathrm{B}^{\prime}\right)$ electrodes indicating a lack of $\mathrm{NO}_{3}{ }^{-}$adsorption: Addition of $\mathrm{NO}_{3}{ }^{-}$shows no increase in current at the Ti (C) electrode, however, a negative shift in the $\mathrm{H}_{2}(\mathrm{~g})$ evolution potential is seen which indicates adsorption of $\mathrm{NO}_{3}{ }^{-}$is occurring. Adsorption of $\mathrm{NO}_{3}{ }^{-}$ would hinder $\mathrm{H}_{2}$ (g) evolution (Eqn. 6) by blocking surface sites. An additional driving force would then be required to overcome this blockage and resume Eqn. 6 . This additional driving force is seen by a shift in the overpotential ( $\eta$ ) for $\mathrm{H}_{2}(\mathrm{~g})$ evolution. No shift in the $\eta$ for $\mathrm{H}_{2}(\mathrm{~g})$ evolution, with the addition of nitrate to solution, is seen for the $\mathrm{Sb}$ and $\mathrm{Sn}$ electrodes which supports the initial observation that $\mathrm{NO}_{3}{ }^{-}$does not adsorb at these electrodes.

Combination of the three metals into an alloy $\left(\mathrm{Sb}_{10} \mathrm{Sn}_{20} \mathrm{Ti} \mathrm{i}_{0}\right)$ results in an electrode material that shows onset of $\mathrm{H}_{2}(\mathrm{~g})$ evolution in the residual response (D) at approximately $-0.75 \mathrm{~V}$ with significant improvement in electrocatalytic activity for $\mathrm{NO}_{3}^{-}$reduction (D') as compared to the 
component pure metals. Because the major component in the alloy is $\mathrm{Ti}$, the alloy electrode is expected to exhibit a potential for onset of $\mathrm{H}_{2}(\mathrm{~g})$ evolution similar to that of Ti. However, this is not the case. The residual response (D) of the alloy electrode is closer to that of the Sb and $\mathrm{Sn}$. An explanation for this observation is unknown. Based upon this observation, however, adsorption of hydrogen (Eqn. 1) is believed to occur at the Sb and $\mathrm{Sn}$ sites. The Ti sites are believed to act as $\mathrm{NO}_{3}{ }^{-}$adsorption sites as it was the only metal of the three to exhibit signs for $\mathrm{NO}_{3}{ }^{-}$adsorption.

Nitrate reduction shows no significant rotational velocity dependence (data not shown), however, a concentration dependence is seen. The positive scan for current density $\left(\mathrm{mA} \mathrm{cm}^{-2}\right)$ versus potential $(\mathrm{V})$ at the $\mathrm{Sb}_{10} \mathrm{Sn}_{20} \mathrm{Ti}_{70}$ alloy electrode in the absence (A) and the presence of $2 \mathrm{mM}(\mathrm{B})$, $3 \mathrm{mM}(\mathrm{C}), 4 \mathrm{mM}$ (D) and $5 \mathrm{mM}(\mathrm{E})$ nitrate is shown in Figure 3. The alloy electrode exhibits a nonlinear concentration dependence for $\mathrm{NO}_{3}{ }^{-}$reduction. Reasons for this are uncertain but are believed to involve the nitrate adsorption step (Eqn. 3). Based upon the complications arising from the number of possible alloy combinations with a trinary alloy and also the difficulty in preparation of the varied composition alloys, further study of $\mathrm{Sb}-\mathrm{Sn}$-Ti alloy electrodes was decided against. Binary alloy combinations of various metals were examined for simpler combinations.

Copper, Zinc, and Alloy Electrodes - The positive scans for the voltammetric responses at $\mathrm{Cu}, \mathrm{Zn}$ and $\mathrm{Cu}_{63} \mathrm{Zn}_{37}$ electrodes in the absence (- 
$\longrightarrow$ and presence (-- ) of $5.0 \mathrm{mM} \mathrm{NO}_{3}{ }^{-}$in $1 \mathrm{M} \mathrm{HClO}_{4}$ are plotted in Figure 4 as current density $\left.(\mathrm{mA} \mathrm{cm})^{2}\right)$ versus potential $(V)$. $\mathrm{Zn}$ has a residual response (A) with onset of $\mathrm{H}_{2}(\mathrm{~g})$ evolution occurring at $-1.0 \mathrm{~V}$. The positive scan limit for $\mathrm{Zn}$ was limited to $-1.0 \mathrm{~V}$ due to the anodic dissolution of the electrode at more positive potentiais (data not shown). The lack of a plateau shaped response for $\mathrm{NO}_{3}{ }^{-}$reduction at $\mathrm{Zn}$ (A') indicates a reduction that is not mass transport limited suggesting a kinetic limitation. However, cathodic current for $\mathrm{NO}_{3}{ }^{-}$reduction is seen indicating that $\mathrm{NO}_{3}{ }^{-}$can adsorb at $\mathrm{Zn}$.

The residual response for the $\mathrm{Cu}_{63} \mathrm{Zn}_{37}$ alloy electrode $(\mathrm{C})$ is indistinguishable from the residual response for $\mathrm{Cu}(\mathrm{B})$ with onset of $\mathrm{H}_{2}(\mathrm{~g})$ evolution occurring at approximately $-0.70 \mathrm{~V}$ at both electrodes. Voltammetric data for $\mathrm{NO}_{3}{ }^{-}$reduction at the Cu electrode (B') show a plateau shaped response with rotational velocity dependence (data not shown) and a maximum current density for $5.0 \mathrm{mM} \mathrm{NO}_{3}{ }^{-}$in $1 \mathrm{M} \mathrm{HClO}_{4}$ at 9.4 $\mathrm{rad} \mathrm{s}^{-1}$ of approximately $-6.0 \mathrm{~mA} \mathrm{~cm}^{-2}$. The $\mathrm{Cu}_{63} \mathrm{Zn}_{37}$ alloy electrode shows a maximum current density for $5.0 \mathrm{mM} \mathrm{NO}_{3}{ }^{-}$in $1 \mathrm{M} \mathrm{HClO}_{4}$ at $9.4 \mathrm{rad}$ $\mathrm{s}^{-1}$ of approximately $-23.0 \mathrm{~mA} \mathrm{~cm}-2$. This is a dramatic increase in response for $\mathrm{NO}_{3}{ }^{-}$reduction as compared to the pure component metal electrodes.

The main reason for this increase in cathodic current is believed to involve the adsorption of $\mathrm{NO}_{3}{ }^{-}$and $\mathrm{H}$-atoms at the electrode surface. Because the onset for $\mathrm{H}_{2}(\mathrm{~g})$ evolution occurs at more positive potentials at 
$\mathrm{Cu}(-0.70 \mathrm{~V})$ as compared to $\mathrm{Zn}(-1.0 \mathrm{~V}), \mathrm{Cu}$ surface sites in the $\mathrm{Cu}_{63} \mathrm{Zn}_{37}$ alloy electrode are sites at which adsorption of $\mathrm{H}$-atoms occur. However, at more negative potentials, $\mathrm{NO}_{3}{ }^{-}$adsorption can occur at $\mathrm{Cu}$ sites which is proven by the fact that a cathodic current is seen for $\mathrm{NO}_{3}{ }^{-}$reduction at $\mathrm{Cu}$. The adsorption step is required by Eqn. 3, so therefore we would expect to see limited response if $\mathrm{NO}_{3}{ }^{-}$adsorption was not taking place at $\mathrm{Cu} . \mathrm{Zn}$ exhibits electrocatalytic properties for $\mathrm{NO}_{3}{ }^{-}$reduction which indicates that adsorption of $\mathrm{NO}_{3}{ }^{-}$can occur at $\mathrm{Zn}$ (required by Eqn. 3). Therefore, $\mathrm{Zn}$ sites in the alloy are catalytic sites for $\mathrm{NO}_{3}{ }^{-}$adsorption. Very little hydrogen adsorption is believed to occur at the $\mathrm{Zn}$ sites because the potentials at which reduction is occurring are more positive than the $\eta$ for $\mathrm{H}_{2}(\mathrm{~g})$ evolution to occur at $\mathrm{Zn}$. Additionally, the incorporation of $\mathrm{Zn}$ into the alloy has helped to stabilized the metal in acidic media.

Copper, Nickel, and Alloy Electrode - The final alloy studied for this preliminary research was a combination of $\mathrm{Cu}$ and Ni. Data is shown in Figure 6 for the voltammetric responses of $\mathrm{Cu}\left(\mathrm{A}, \mathrm{A}^{\prime}\right), \mathrm{Ni}\left(\mathrm{B}, \mathrm{B}^{\prime}\right)$ and $\mathrm{Cu}_{25} \mathrm{Ni}_{75}$ alloy $\left(\mathrm{C}, \mathrm{C}^{\prime}\right)$ in the absence $(-)$ and the presence of $5.0 \mathrm{mM} \mathrm{NO}_{3}^{-}(---)$ in $1 \mathrm{M} \mathrm{HClO}_{4}$. The residual responses for the various electrodes are featureless until onset of $\mathrm{H}_{2}(\mathrm{~g})$ evolution which occurs at approximately $-0.45 \mathrm{~V},-0.55 \mathrm{~V}$ and $-0.70 \mathrm{~V}$ at the $\mathrm{Ni}, \mathrm{Cu}_{25} \mathrm{Ni}_{75}$ alloy and $\mathrm{Cu}$ electrodes, respectively. The potential at which $\mathrm{H}_{2}(\mathrm{~g})$ evolution is seen at the alloy 
electrode is expected as the alloy has a larger concentration of nickel versus copper. Hence we would expect the alloy to resemble Ni more than $\mathrm{Cu}$.

The reduction of $5.0 \mathrm{mM} \mathrm{NO}_{3}{ }^{-}$occurs at the $\mathrm{Ni}$ electrode (B') with a maximum current density of approximately $-6 \mathrm{~mA} \mathrm{~cm}^{-2}$ and a non-plateau shaped response. $\mathrm{Cu}\left(\mathrm{A}^{3}\right)$ exhibits a maximum current density for the reduction of $5.0 \mathrm{mM}$ nitrate of approximately $-5 \mathrm{~mA} \mathrm{~cm}^{-2}$ and exhibits a plateau shaped response which is indicative of a mass transport limited reduction response. Although a larger maximum current density is seen at $\mathrm{Ni}$ as compared to $\mathrm{Cu}, \mathrm{Cu}$ exhibits a mass transport limited response which indicates better kinetics for $\mathrm{NO}_{3}{ }^{-}$reduction. Weak $\mathrm{NO}_{3}{ }^{-}$adsorption at $\mathrm{Ni}$ could account for the non-mass transport limited response. Additionally, the formation of adsorbed $\mathrm{H}$-atoms at the electrode surface could hinder the $\mathrm{NO}_{3}{ }^{-}$adsorption capabilities of the nickel electrode which in turn would limit the overall ability for $\mathrm{NO}_{3}{ }^{-}$reduction.

The maximum current density for the reduction of $5.0 \mathrm{mM} \mathrm{NO}_{3}^{-}$at the $\mathrm{Cu}_{25} \mathrm{Ni}_{75}$ alloy electrode is approximately $-25 \mathrm{~mA} \mathrm{~cm}^{-2}$. In addition to a larger maximum current as compared to the pure component metals, the reduction shows a mass transport limited response. Reasons for this are believed to involve the separation of catalytic sites at which reactions 1 and 3 occur. Because the potential at which onset of $\mathrm{H}_{2}(\mathrm{~g})$ evolution begins at the alloy electrode is closer to that of $\mathrm{Ni}$, formation of adsorbed $\mathrm{H}$-atoms at the $\mathrm{Cu}_{25} \mathrm{Ni}_{75}$ alloy is believed to occur at the $\mathrm{Ni}$ sites. Both $\mathrm{Ni}$ and $\mathrm{Cu}$ 
exhibit electrocatalytic activity for $\mathrm{NO}_{3}{ }^{-}$reduction, however, the lack of a mass transport limited response at $\mathrm{Ni}$ suggests weak adsorption of $\mathrm{NO}_{3}{ }^{-}$. Thus, $\mathrm{NO}_{3}{ }^{-}$adsorption (Eqn. 3 ) is believed to occur at the $\mathrm{Cu}$ sites.

Voltammetric data are plotted as current density $\left(\mathrm{mA} \mathrm{cm} \mathrm{cm}^{-2}\right)$ versus potential $(\mathrm{V})$ in Figure 7 for the $\mathrm{Cu}_{25} \mathrm{Ni}_{75}$ alloy electrode in the absence (A) and the presence of $5.0 \mathrm{mM} \mathrm{NO}_{3}{ }^{-}$at rotational velocities of 6.5 (B), 9.7 (C), 12.9 (D), and $16.1(\mathrm{E}) \mathrm{rad} \mathrm{s}^{-1}$. A non-linear increase in current is seen with increasing rotational velocity which is indicative of a kinetic limitation in the reduction process. As rotational velocity increases, the flux of $\mathrm{NO}_{3}{ }^{-}$to the electrode surface increases. The production of $\mathrm{H}$-atoms may be slow enough that reduction of all the available $\mathrm{NO}_{3}{ }^{-}$at higher rotational velocities is not possible which would result in the non-linearity seen.

\section{Conclusions}

Voltammetric data indicate that the limiting current for $\mathrm{NO}_{3}{ }^{-}$ reduction in $1 \mathrm{M} \mathrm{HClO}_{4}$ is greater for the alloy electrodes as compared to their pure component metals. The alloy electrodes allow for $\mathrm{NO}_{3}{ }^{-}$adsorption and cathodic formation of adsorbed $\mathrm{H}$-atoms, both prerequisites for $\mathrm{NO}_{3}{ }^{-}$ reduction, to occur concurrently at different adsorption sites.

In the $\mathrm{Sn}_{10} \mathrm{Sb}_{20} \mathrm{Ti}_{70}$ alloy, individual adsorption sites for the two processes are difficult to distinguish. Titanium is the only pure metal that indicated adsorption of $\mathrm{NO}_{3}{ }^{-}$, which strongly suggests that in the alloy, $\mathrm{Ti}$ 
sites are the $\mathrm{NO}_{3}{ }^{-}$adsorption sites. Based upon the complexity of the ternary alloy, binary alloys of various metals were considered. The $\mathrm{Cu}$ sites in the $\mathrm{Cu}_{63} \mathrm{Zn}_{37}$ alloy are where adsorbed $\mathrm{H}$-atoms were formed with $\mathrm{NO}_{3}{ }^{-}$ adsorption occurring at the $\mathrm{Zn}$ sites. The $\mathrm{Cu}_{25} \mathrm{Ni}_{75}$ alloy showed a reverse role for the $\mathrm{Cu}$ sites. Adsorbed $\mathrm{H}$-atoms were generated by the cathodic discharge of $\mathrm{H}^{+}$at the $\mathrm{Cu}$ sites and $\mathrm{NO}_{3}{ }^{-}$adsorption occurred at the Ni sites.

The voltammetric response for $\mathrm{NO}_{3}{ }^{-}$reduction at the alloy electrodes increased in the order of $\mathrm{Sn}_{10} \mathrm{Sb}_{20} \mathrm{Ti}_{70}<\mathrm{Cu}_{25} \mathrm{Ni}_{75}<\mathrm{Cu}_{63} \mathrm{Zn}_{37}$. Cu and $\mathrm{Ni}$ are miscible with one another at almost all atomic percent ratios allowing formation of numerous combinations in alloys. Although the $\mathrm{Cu}_{63} \mathrm{Zn}_{37}$ alloy electrode showed larger response for nitrate, the alloy was limited by the possible combinations that can be studied. Further study of Cu-Ni alloy electrodes was decided upon and is discussed in the next chapter.

\section{Acknowledgments}

This report has been authored by the Iowa State University of Science and Technology under Contract No. W-7405-ENG-82 with the U.S.

Department of Energy. The U. S. Government retains and the publisher, by accepting the article for publication, acknowledges that the U. S. Government retains a non-exclusive, paid-up, irrevocable, world-wide license to publish or reproduce the published form of this manuscript, or allow others to do so, for U. S. Government purposes. 


\section{References}

1. Inoue, Y., Hisoshima Daigaku Igaku Zasshi, 1972, $20,347$.

2. Bruning-Fann, C.S. and J.B. Kaneene, Vet. Human Toxicol, 1993, 35, 521.

3. Cantor, K.P., Cancer, Causes Control, Pap., 1997, 8, 292.

4. Mirvish, S.S., Cancer Lett., 1995, 93, 17.

5. Li, H., L, J.Q. Chambers, and D.T. Hobbs, J. Appl. Electrochem., $1988,18,454$.

6. Ma, L., et al., J. Electroanal. Chem., 1993, 362, 201.

7. Yang, X., Z. De-Ling, and J.F. Rusling, J. Electroanal. Chem., 1997, $424,1$.

8. Taniguchi, I., et al., J. Electroanal. Chem., 1987, 224, 199.

9. Yu, C.-H. and Y.O. Su, J. Electroanal. Chem., 1994, 368, 323.

10. Cosnier, S., B. Galland, and C. Innocent, J. Electroanal. Chem., 1997, $433,113$.

11. Larsen, L.H., T. Kjær, and N.P. Revsbech, Anal. Chem., 1997, 69, 3527.

12. Khomutov, N.E. and U.S. Stamkulov, Sov. Electrochem., 1971, 7, 312.

13. Vijh, A.K., J. Catal, 1974, 230.

14. Davis, J., et al., Analyst, 2000, 125, 737.

15. Cattarin, S., J. Appl. Electrochem., 1992, 22, 1077.

16. Bouzek, K., et al., J. Appl. Electrochem., 2001, 31, 1185. 
17. Sherwood, J., Glenn A. and D.C. Johnson, Anal. Chim. Acta, 1981, $129,87$.

18. Shibata, M., K. Yoshida, and N. Furuya, J. Electrochem. Soc., 1998, $145,2348$.

19. de Vooys, A.C.A., R.A. van Santen, and J.A.R. van Veen, J. Molec. Catal. A: Chem., 2000, 154, 203.

20. Schlagel, D.L., The reduction of nitrate at copper, cadmium and coppercadmium alloy electrodes. 1997, Thesis: Iowa State University.

21. Sherwood, G.A., A copperized cadmium flow-through detector for the amperometric determination of nitrate in aqueous samples based on electrocatalytic reduction. 1979, Thesis: Iowa State University.

22. Suroso, I., Reduction of nitrate and the effect of anions on nitrate degradation with zero-valent iron, bimetals and trimetals. 2001, Thesis: Iowa State University.

23. Bodini, M.E. and D. Sawyer, Anal. Chem., 1977, 49, 485.

24. Davenport, R.J. and D.C. Johnson, Anal. Chem., 1973, 45, 1979.

25. Genders, J.D., D. Hartsough, and D.T. Hobbs, J. Appl. Electrochem., $1996,26,1$.

26. Fedurco, M., P. Kedzierzawski, and J. Augustynski, J. Electrochem. Soc., 1999, 146, 2569.

27. Bouamrane, F., et al., J. Electroanal. Chem., 1996, 405, 95.

28. Reuben, C., et al., J. Electroanal. Chem., 1995, 396, 233. 
29. Tenne, R., et al., J. Electroanal. Chem., 1993, 347, 409.

30. Bakos, I. and G. Horanyi, J. Electroanal. Chem., 1994, 370, 309.

31. Horanyi, G. and E.M. Rizmayer, J. Electroanal. Chem., 1982, 140, 347.

32. Horanyi, G. and E.M. Rizmayer, J. Electroanal. Chem., 1983, 143, 323.

33. Horanyi, G. and E.M. Rizmayer, J. Electroanal. Chem., 1985, 188, 265.

34. Ohmori, T., M.S. El-Deab, and M. Osawa, J. Electroanal. Chem., $1999,470,46$.

35. Bockris, J.O.M. and J. Kim, J. Electrochem. Soc., 1996, 143, 3801.

36. Gootzen, J.F.E., et al., J. Electroanal. Chem., 1997, 434, 171.

37. Deganello, F., et al., Appl. Catal. B: Environ., 2000, 24, 265.

38. Ilinitch, O.M., et al., J. Mol. Catal. A: Chem., 2000, 158, 237.

39. Ilinitch, O.M., et al., Catal. Today, 2000, 56, 137.

40. Ureta-Zanrtu, S. and C. Yanez, Electrochim. Acta, 1997, 42, 1725. 
Table 1. Summary of various parameters including area, potential at which nitrate reduction current density was measured, reactivity towards nitrate reduction, and manufacturer for various alloy electrodes and the component pure metal electrodes.

\begin{tabular}{|l|c|c|c|c|}
\hline Electrode & $\begin{array}{l}\text { Area } \\
\left(\mathbf{c m}^{\mathbf{2}}\right)\end{array}$ & $\begin{array}{l}\text { Potential } \\
\text { (V vs SCE) }\end{array}$ & Reactivity & Manufacturer \\
\hline Antimony & 0.205 & -0.75 & poor & In house \\
\hline Antimony-Tin- & 1.23 & -0.806 & good & In house \\
(Sitanium Alloy & & & & \\
\hline Copper & & & & \\
\hline Copper-Nickel Alloy & 0.177 & -0.55 & excellent & In house \\
(Cu, & & & & \\
\hline Copper-Zinc Alloy & 0.785 & -0.655 & excellent & Goodfellow \\
(Cu632n & & & & In house \\
\hline Nickel & 0.154 & -0.70 & & good \\
\hline Tin & 0.177 & -0.45 & good & In house \\
\hline Titanium & 0.152 & -0.90 & poor & In house \\
\hline Zinc & 0.311 & -0.402 & poor & In house \\
\hline
\end{tabular}


Table 2. Summary of various parameters including area, potential at which nitrate reduction current was measured, reactivity towards nitrate reduction, and manufacturer for various pure metal electrodes.

\begin{tabular}{|c|c|c|c|c|}
\hline Electrode & $\begin{array}{l}\text { Area } \\
\left(\mathrm{cm}^{2}\right)\end{array}$ & $\begin{array}{l}\text { Potential } \\
\text { (V vs SCE) }\end{array}$ & Reactivity & Manufacturer \\
\hline Aluminum & 0.292 & -0.893 & fair & In house \\
\hline Cadmium & 0.196 & -0.979 & excellent & $\begin{array}{c}\text { Pine } \\
\text { Instruments }\end{array}$ \\
\hline Gold & 0.198 & -0.504 & poor & $\begin{array}{c}\text { Pine } \\
\text { Instruments }\end{array}$ \\
\hline Platinum & 0.185 & -0.255 & poor & $\begin{array}{c}\text { Pine } \\
\text { Instruments }\end{array}$ \\
\hline Ruthenium & 0.198 & -0.256 & poor & $\begin{array}{c}\text { Pine } \\
\text { Instruments }\end{array}$ \\
\hline Silver & 0.130 & -0.256 & poor & In house \\
\hline
\end{tabular}




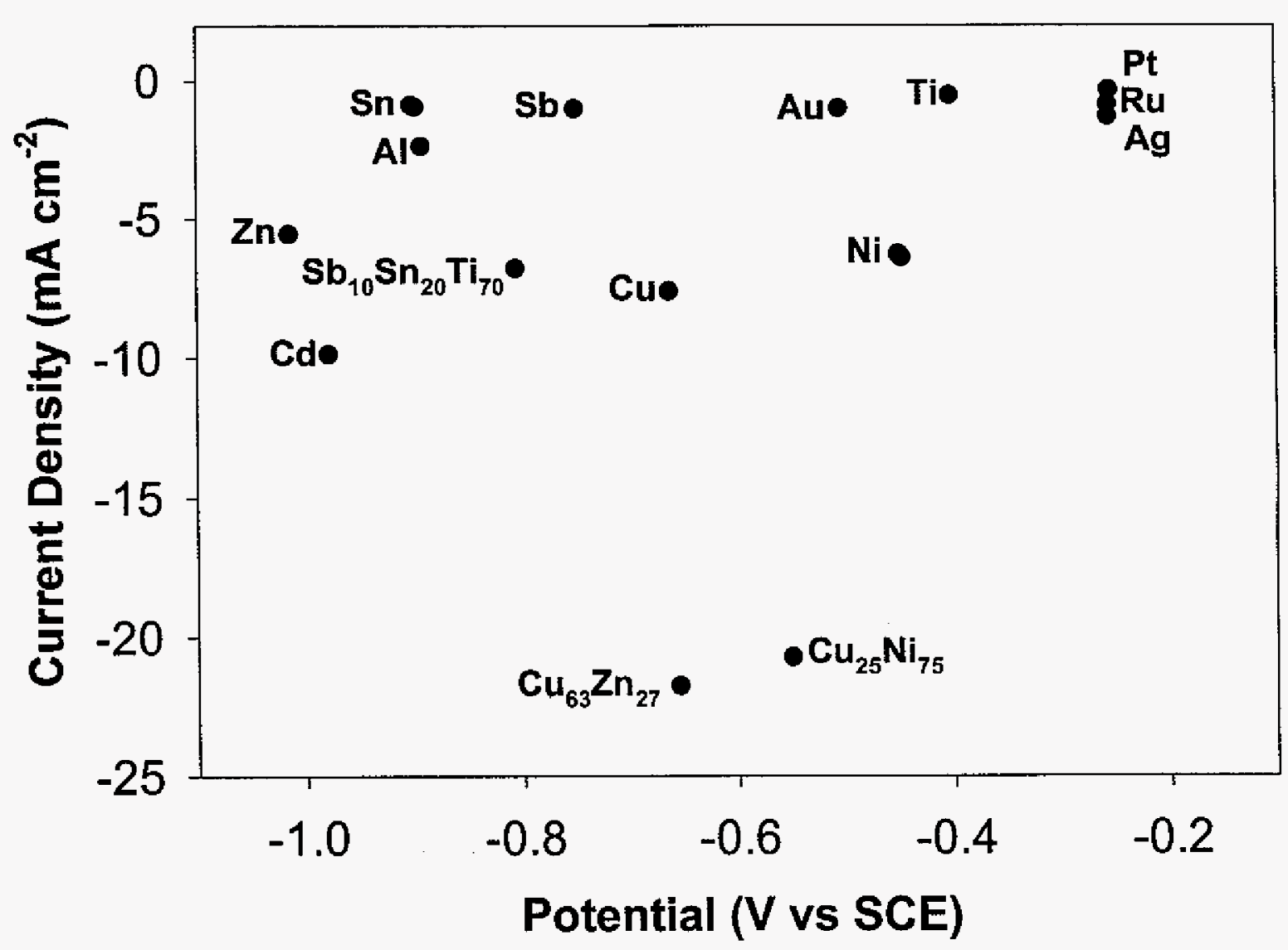

Figure 1. Comparison of nitrate reduction at various electrode materials plotted as nitrate reduction current density $\left(\mathrm{mA} \mathrm{cm}^{-2}\right)$ versus potential at which a $1.0 \mathrm{~mA} \mathrm{~cm}^{-2}$ current density for hydrogen evolution occurs at the electrode. Nitrate concentration (mM): $5 \mathrm{mM}$ Electrolyte: $1.0 \mathrm{M} \mathrm{HClO}_{4}$. Scan rate: $40 \mathrm{mV} \mathrm{s}^{-1}$. Rotational velocity: $9.7 \mathrm{rad} \mathrm{s}^{-1}$. 


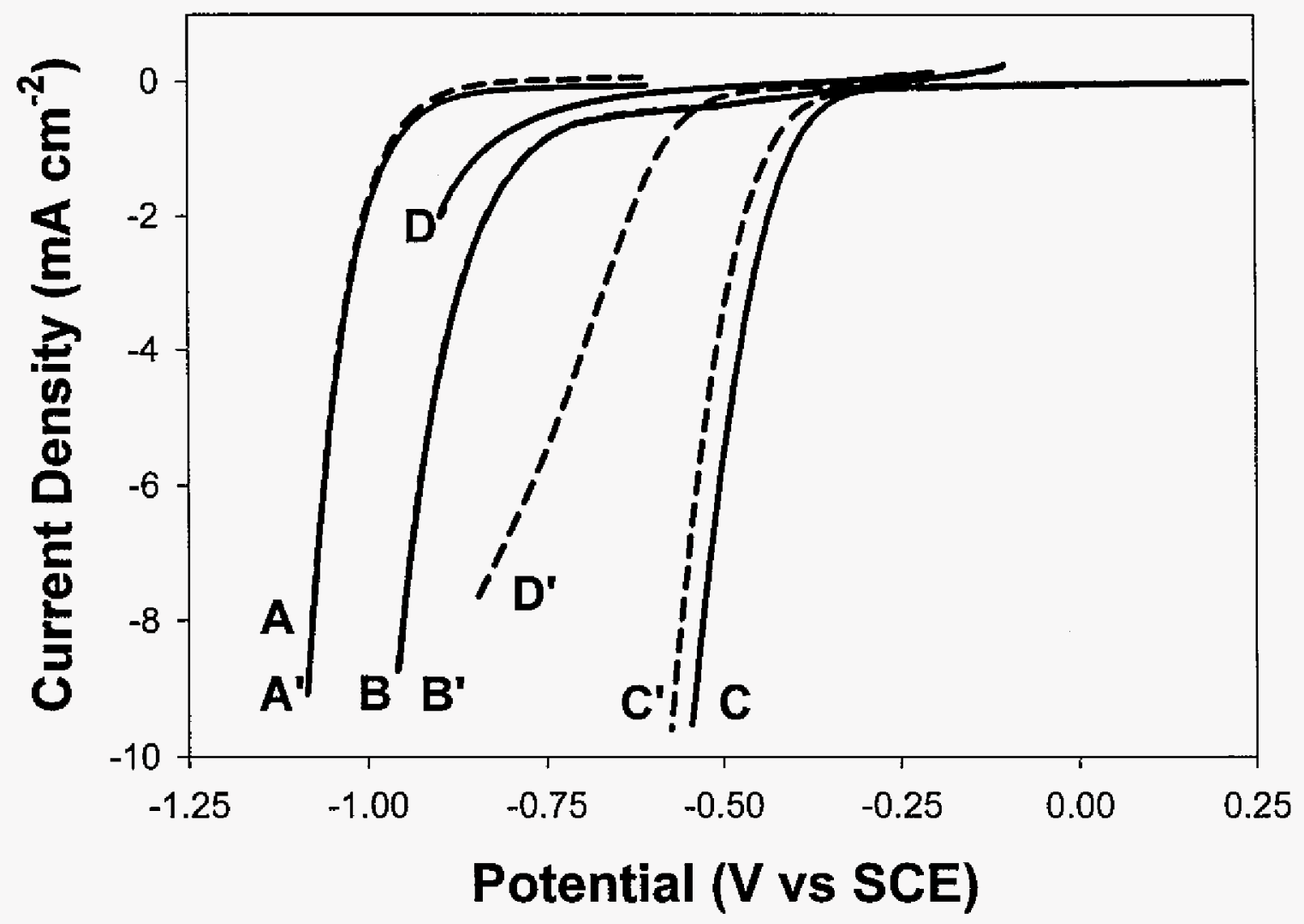

Figure 2. Comparison of nitrate reduction at antimony, tin, titanium and antimony-tin-titanium alloy electrodes. Electrolyte: $1.0 \mathrm{M} \mathrm{HClO}_{4}$. Scan rate: $40 \mathrm{mV} \mathrm{s}^{-1}$. Rotational velocity: $9.7 \mathrm{rad} \mathrm{s}^{-1}$. Electrode: $\mathrm{Sn}\left(\mathrm{A}, \mathrm{A}^{\prime}\right), \mathrm{Sb}$

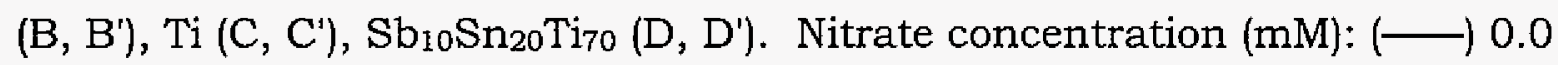
,$(---) 5.0$. 


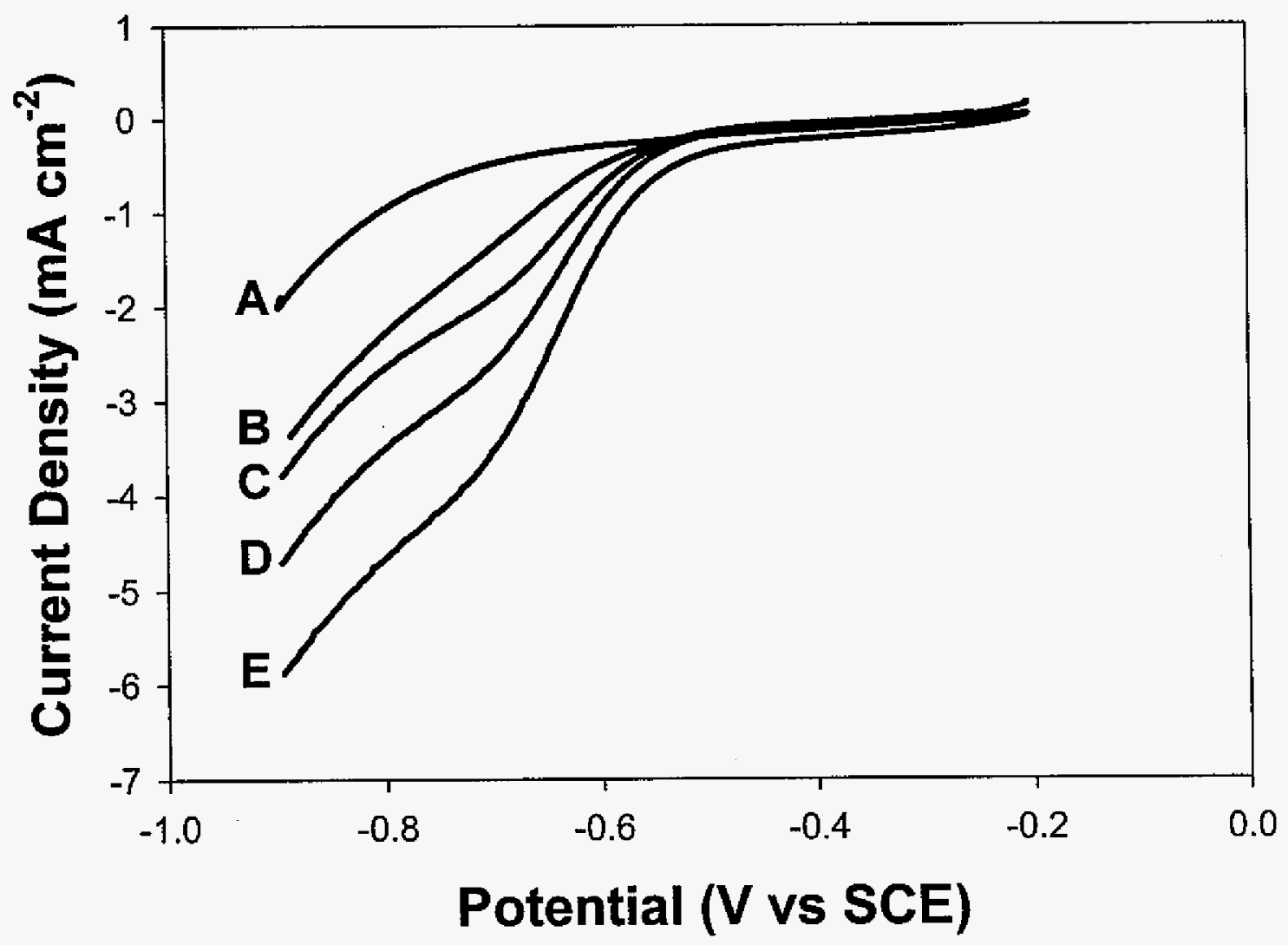

Figure 3. Response of nitrate reduction at $\mathrm{Sb}_{10} \mathrm{Sn}_{20} \mathrm{Ti}_{70}$ electrode. Nitrate concentration (mM): (A) 0, (B) 1.0, (C) 2.0, (D) 3.0, (E) 4.0. Electrolyte: 1.0 M $\mathrm{HClO}_{4}$. Scan rate: $40 \mathrm{mV} \mathrm{s}^{-1}$. Rotational velocity: $9.7 \mathrm{rad} \mathrm{s}^{-1}$. 


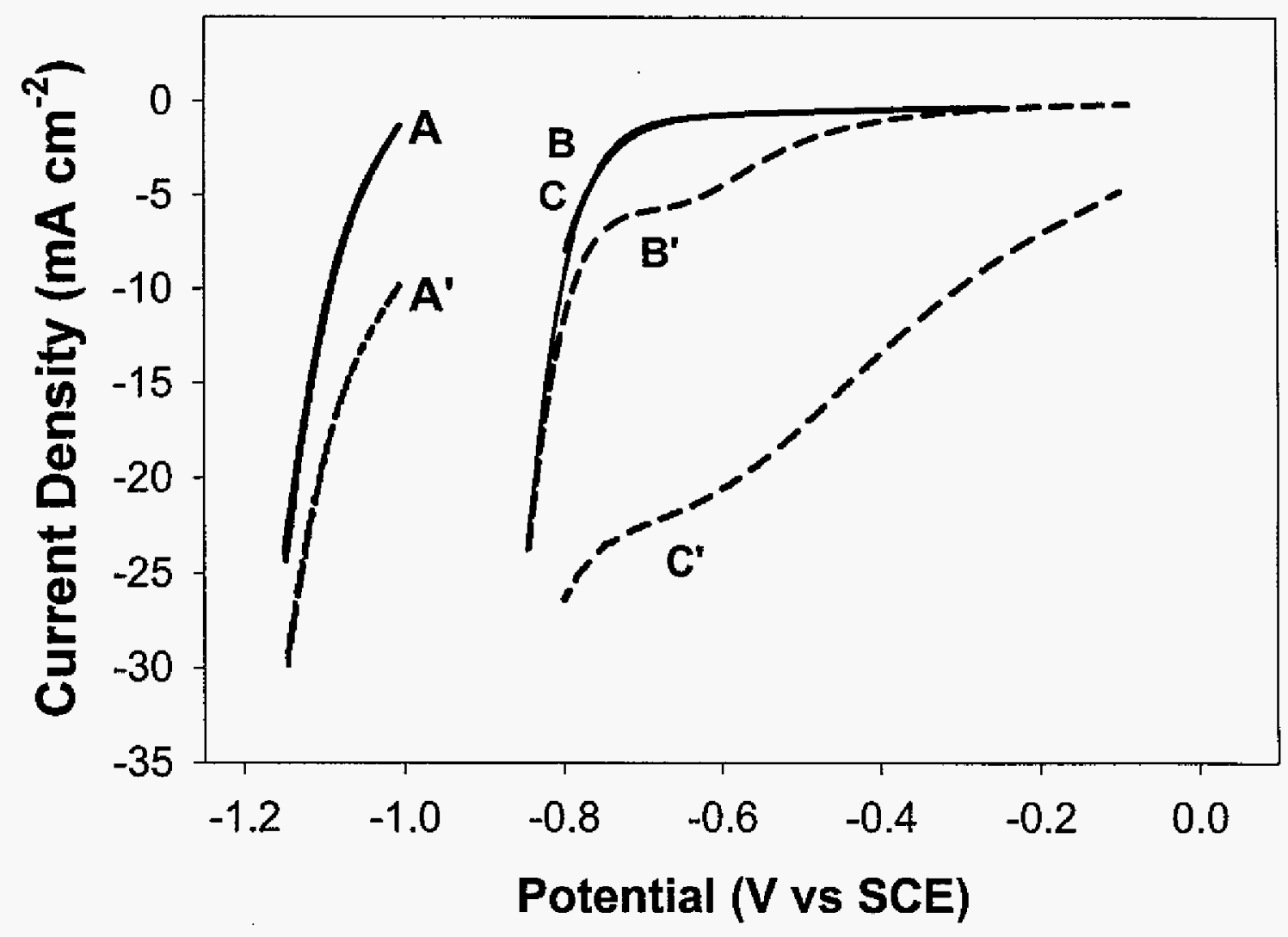

Figure 4. Comparison of nitrate reduction at copper, zinc and copper-zinc alloy electrodes. Electrolyte: $1.0 \mathrm{M} \mathrm{HClO}_{4}$. Scan rate: $40 \mathrm{mV} \mathrm{s}{ }^{-1}$. Rotational velocity: $9.7 \mathrm{rad} \mathrm{s}^{-1}$. Electrode: $\mathrm{Zn}\left(\mathrm{A}, \mathrm{A}^{\prime}\right), \mathrm{Cu}\left(\mathrm{B}, \mathrm{B}^{\prime}\right), \mathrm{Cu}_{63} \mathrm{Zn}_{37}$ (C, C'). Nitrate concentration (mM): $(\longrightarrow 0.0,(---) 5.0$. 


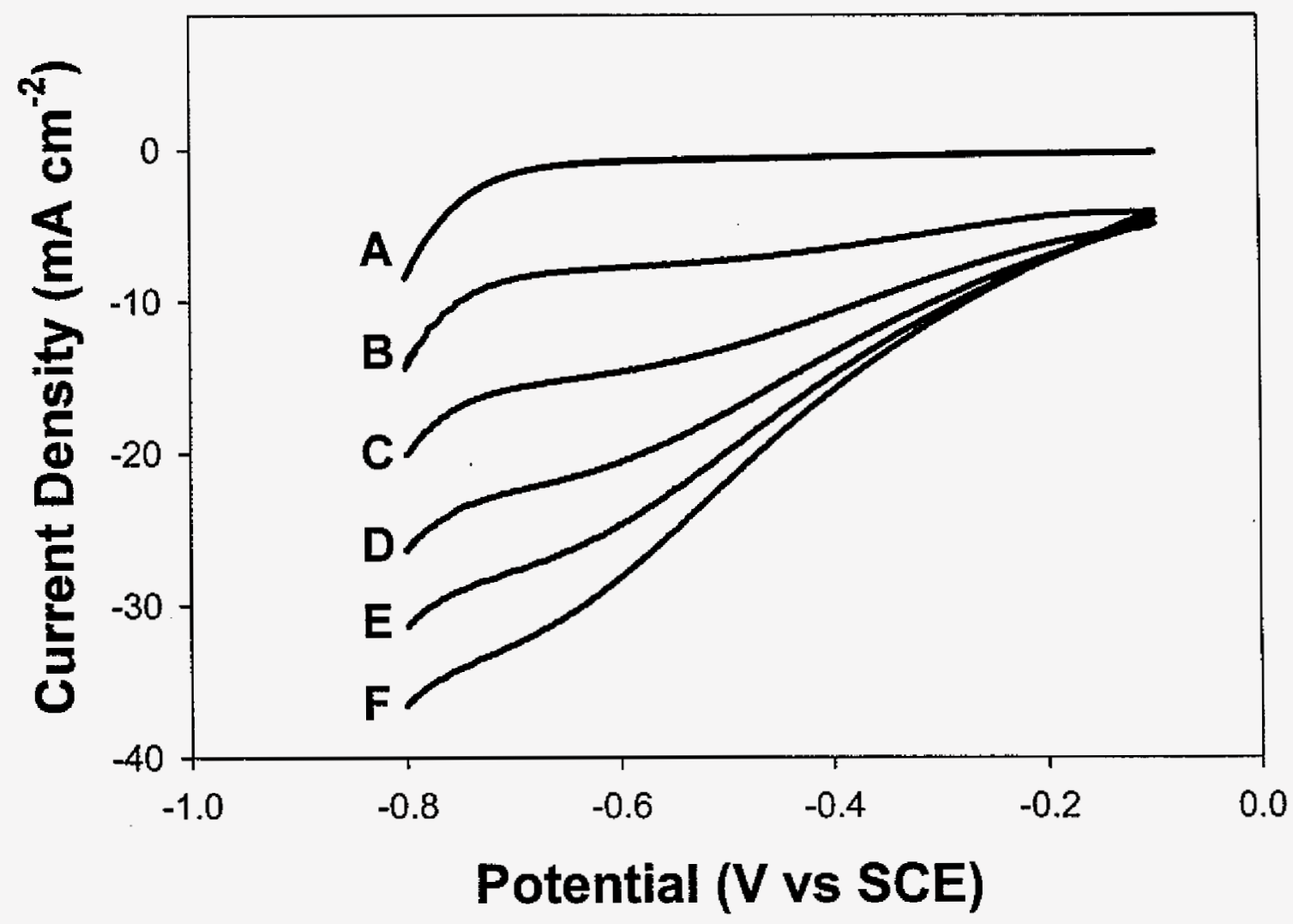

Figure 5. Response of nitrate reduction at $\mathrm{Cu}_{63} \mathrm{Zn}_{37}$ electrode. Nitrate concentration: $5.0 \mathrm{mM}$ Electrolyte: $1.0 \mathrm{M} \mathrm{HClO}_{4}$. Scan rate: $40 \mathrm{mV} \mathrm{s}^{-1}$. Rotational velocity ( $\mathrm{rad} \mathrm{s}^{-1}$ ): (A) Residual, (B) 3.2, (C) 6.5, (D) 9.7, (E) 12.9, (F) 16.1 . 


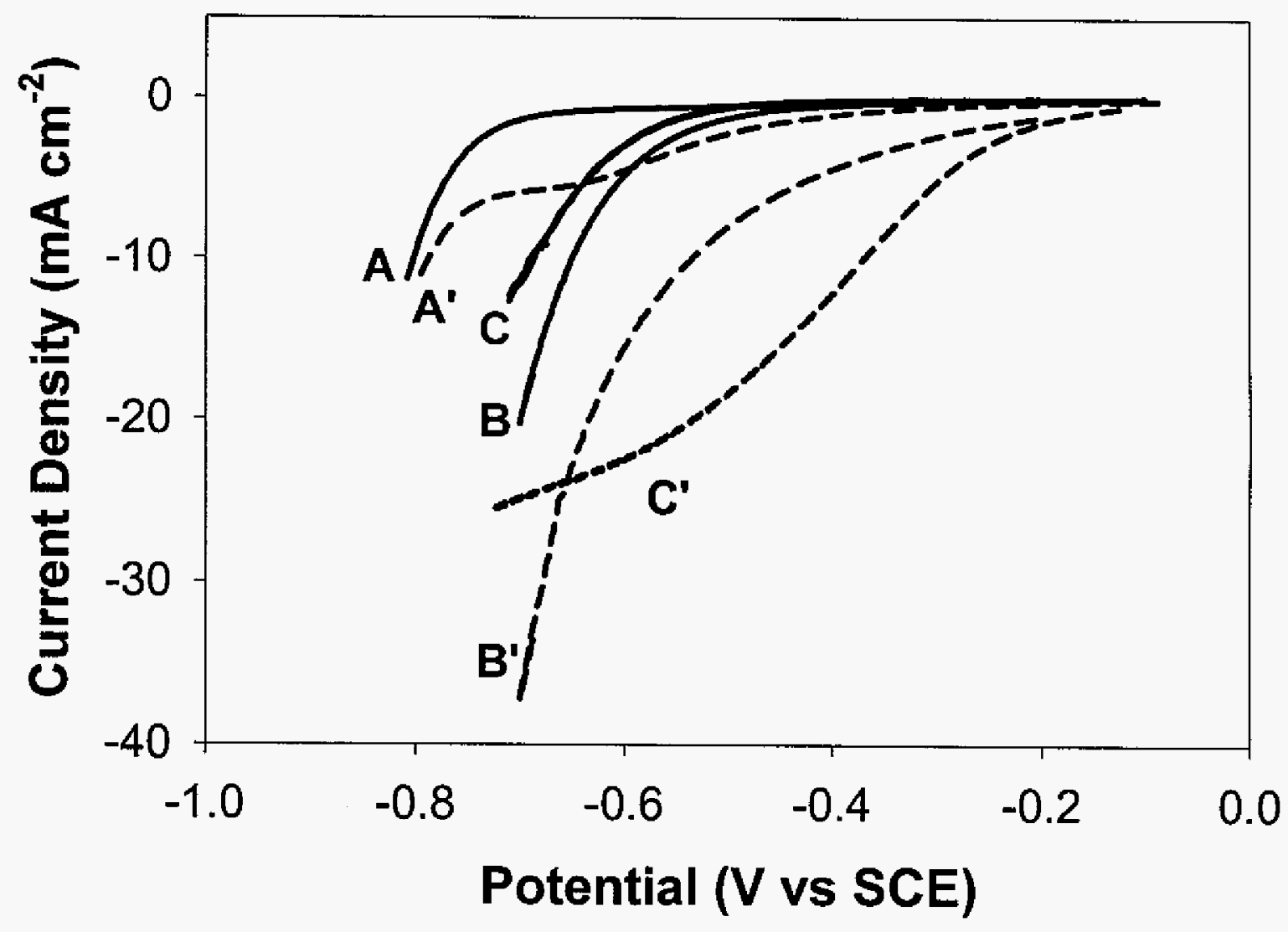

Figure 6. Comparison of nitrate reduction at copper, nickel, and coppernickel alloy electrodes. Electrolyte: $1.0 \mathrm{M} \mathrm{HClO}_{4}$. Scari rate: $40 \mathrm{mV} \mathrm{s}{ }^{-1}$. Rotational velocity: $9.7 \mathrm{rad} \mathrm{s}^{-1}$. Electrode: $\mathrm{Ni}\left(\mathrm{A}, \mathrm{A}^{\prime}\right), \mathrm{Cu}\left(\mathrm{B}, \mathrm{B}^{\prime}\right), \mathrm{Cu}_{25} \mathrm{Ni}_{75}$ $\left(C, C^{\prime}\right)$. Nitrate concentration $(\mathrm{mM}):(-) 0.0,(---) 5.0$. 


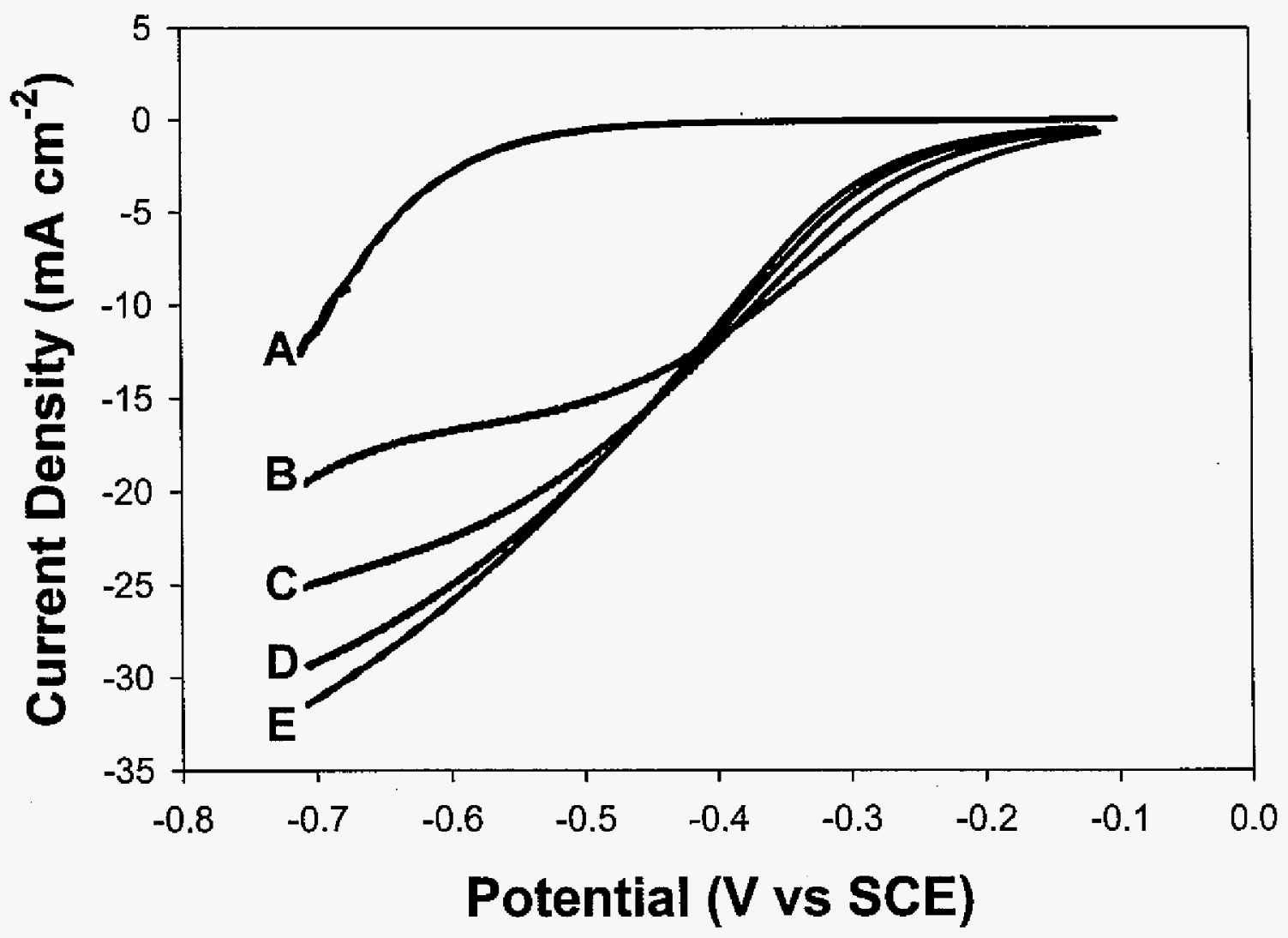

Figure 7. Response of nitrate reduction at $\mathrm{Cu}_{25} \mathrm{Ni}_{75}$ electrode. Nitrate concentration: $5.0 \mathrm{mM}$ Electrolyte: $1.0 \mathrm{M} \mathrm{HClO}_{4}$. Scan rate: $40 \mathrm{mV} \mathrm{s}^{-1}$. Rotational velocity ( $\mathrm{rad} \mathrm{s}^{-1}$ ): (A) Residual, (B) 6.5, (C) 9.7, (D) 12.9, (E) 16.1. 


\title{
CHAPTER 5. ELECTROCATALYSIS OF NITRATE
}

\section{REDUCTION REACTIONS IN ACIDIC MEDIA AT}

\section{COPPER-NICKEL ALLOY ELECTRODES}

\author{
Submitted to Electroanalysis \\ Brett K. Simpson and Dennis C. Johnson
}

\begin{abstract}
\end{abstract}
The cathodic reduction of $\mathrm{NO}_{3}{ }^{-}$in $1.0 \mathrm{M} \mathrm{HClO}_{4}$ is investigated by voltammetry at pure $\mathrm{Ni}$ and $\mathrm{Cu}$ electrodes, and three $\mathrm{Cu}-\mathrm{Ni}$ alloy electrodes of varying composition. A general mechanism for the cathodic response is proposed that has the requirements of co-adsorption of $\mathrm{NO}_{3}{ }^{-}$and $\mathrm{H}$-atoms generated by cathodic discharge of $\mathrm{H}^{+}$. Voltammetric data demonstrate the significantly improved activity for $\mathrm{NO}_{3}{ }^{-}$reduction at $\mathrm{Cu}-\mathrm{Ni}$ alloy electrodes as compared to pure $\mathrm{Ni}$ and $\mathrm{Cu}$ electrodes. This observation is explained on the basis of the synergistic benefit of different surface sites for adsorption of $\mathrm{H}$-atoms (Ni-sites) and adsorption of $\mathrm{NO}_{3}{ }^{-}$(Cu-sites) at these binary alloy electrodes. Koutecky-Levich plots indicate that the $\mathrm{NO}_{3}{ }^{-}$response at a $\mathrm{Cu}_{75} \mathrm{Ni}_{25}$ electrode corresponds to an 8 -electron reduction, In comparison, the response at $\mathrm{Cu}_{50} \mathrm{Ni}_{50}$ and $\mathrm{Cu}_{25} \mathrm{Ni}_{75}$ electrodes corresponds to a 6 -electron reduction. Flow injection data obtained using $\mathrm{Cu}_{50} \mathrm{Ni}_{50}$ and $\mathrm{Cu}_{25} \mathrm{Ni}_{75}$ electrodes with $100-\mu \mathrm{L}$ injections exhibit detection limits for $\mathrm{NO}_{3}{ }^{-}$of ca. 0.95 $\mu \mathrm{M}$ (ca. $95 \mathrm{pmol}$ ) and $0.60 \mu \mathrm{M}$ (ca. $60 \mathrm{pmol}$ ), respectively. 


\section{Introduction}

The electrochemical reduction of $\mathrm{NO}_{3}{ }^{-}$has been examined at numerous electrode materials. Khomutov and Stamkulov studied this reduction at various transition metals and determined that the reduction overpotential corresponding to a specified current density varied as a function of the atomic number of the cathode material [1]. Vijh reinterpreted the data on the basis of metal-hydrogen (M-H) and metaloxygen $(\mathrm{M}-\mathrm{O})$ bond energies. The transition metal cathodes exhibited volcano-shaped plots with respect to activity for $\mathrm{NO}_{3}{ }^{-}$reduction as a function of $\mathrm{M}-\mathrm{H}$ and $\mathrm{M}-\mathrm{O}$ bond energies with optimal activity corresponding to intermediate bond energies [2]. Studies of $\mathrm{NO}_{3}{ }^{-}$reduction also have been performed at $\mathrm{Cu}[3-12], \mathrm{Cd}[7,13,14], \mathrm{Pb}[15,16]$ and $\mathrm{Ag}[4,17]$ electrodes, and at B-doped diamond electrodes [18-20].

The reduction of $\mathrm{NO}_{3}{ }^{-}$also has been studied at Pt electrodes [21-24]. Horanyi et al. reported that this reduction was adversely affected by increasingly negative values of applied potential with complete truncation at approximately $0.0 \mathrm{~V}$ vs. RHE [24]. This loss of electrocatalytic activity was attributed to blockage of $\mathrm{NO}_{3}{ }^{-}$adsorption by the adsorbed $\mathrm{H}$-atoms generated by cathodic discharge of $\mathrm{H}^{+}$corresponding to onset of $\mathrm{H}_{2}(g)$ generation. Ohmori et al. came to a similar conclusion from their study of $\mathrm{NO}_{3}{ }^{-}$reduction at a polycrystalline $\mathrm{Au}$ electrode in solutions of varying $\mathrm{pH}$ [25]. Bockris and Kim compared the activities of $\mathrm{Ni}, \mathrm{Fe}$ and $\mathrm{Pb}$ electrodes 
for $\mathrm{NO}_{3}{ }^{-}$reduction and also observed suppression of activity at potentials corresponding to onset of cathodic generation of $\mathrm{H}_{2}(g)$ [26].

Various bimetallic electrode surfaces have been identified to exhibit improved activity for $\mathrm{NO}_{3}{ }^{-}$reduction in comparison to electrodes prepared from the pure component metals. Examples include Cu-Pd electrodes [9, 27-29], Cs-doped Au electrodes [25], Cu electrodeposited on a variety of substrates $[5,7,11]$, and Ge deposited on Pt electrodes [30]. A variety of deposition techniques were used to form these binary metallic electrodes. We contend that a simpler approach is the use of binary alloys as electrode materials. Ureta-Zanartu reported that the binary Pt-Ir alloy exhibited improved catalytic response for $\mathrm{NO}_{3}{ }^{-}$reduction in comparison to the pure component metals [31]. Furthermore, Moorcroft et al. reported that the cathodic response for $\mathrm{NO}_{3}{ }^{-}$at an electrode consisting of $70 \% \mathrm{Cu}$ and $30 \% \mathrm{Ni}$ (" $\mathrm{Cu}_{70} \mathrm{Ni}_{30}$ ") was improved in comparison to the pure component metals [32].

A general mechanism proposed for the initial steps in nitrate reduction at a bimetallic catalyst in acidic media is summarized in the following equations:

$$
\begin{aligned}
\mathrm{NO}_{3}^{-} & \rightarrow \mathrm{NO}_{3}^{-} \text {ads } \\
2 \mathrm{H}^{+}+2 \mathrm{e}^{-} & \rightarrow 2 \mathrm{H}_{\text {ads }} \\
2 \mathrm{H}_{\text {ads }}+\mathrm{NO}_{3}^{-} \text {ads } & \rightarrow \mathrm{NO}_{2}^{-} \text {ads }+\mathrm{H}_{2} \mathrm{O}
\end{aligned}
$$

net: $\mathrm{NO}_{3}^{-}+2 \mathrm{H}^{+}+2 \mathrm{e}^{-} \rightarrow \mathrm{NO}_{2}^{-}$ads $+\mathrm{H}_{2} \mathrm{O}$ 
This mechanism specifies co-adsorption of $\mathrm{NO}_{3}{ }^{-}$from the bulk solution (Eqn. 1) and $\mathrm{H}$-atoms generated by cathodic discharge of $\mathrm{H}^{+}$(Eqn. 2). Adsorption of $\mathrm{NO}_{3}{ }^{-}$in the above mechanism is expected to occur through the O-moieties of the anion [2]. Subsequently, the transfer of $\mathrm{H}_{\text {ads }}$ to the Omoiety of $\mathrm{NO}_{3}{ }^{-}$ads results in cathodic elimination of $\mathrm{H}_{2} \mathrm{O}$ with production of $\mathrm{NO}_{2}{ }^{-}$ads (Eqn. 3). The standard reduction potential $\left(E^{\mathrm{o}}\right)$ for the $\mathrm{NO}_{3}{ }^{-}-\mathrm{HNO}_{2}$ reduction half-reaction is $+0.94 \mathrm{~V}$ vs. NHE. However, because reduction of $\mathrm{NO}_{3}{ }^{-}$, according to the proposed mechanism, requires cathodic discharge of $\mathrm{H}^{+}$, the onset of voltammetric response for $\mathrm{NO}_{3}{ }^{-}$can be expected to be under control of the overpotential for $\mathrm{H}^{+}$discharge at the surface sites capable of adsorbing $\mathrm{H}$-atoms. Reactions similar to that above can be written for sequential reduction of $\mathrm{NO}_{2}^{-}$ads and its reduction product(s).

At large negative potentials, adsorbed $\mathrm{H}$-atoms can be rapidly harvested in the cathodic production of $\mathrm{H}_{2}(g)$, as represented by:

$$
\mathrm{H}^{+}+\mathrm{H}_{\mathrm{ads}}+\mathrm{e}^{-} \rightarrow \mathrm{H}_{2}(g)
$$

Attenuation of the cathodic response for $\mathrm{NO}_{3}{ }^{-}$in the potential region of $\mathrm{H}_{2}(g)$ evolution has been explained on the basis of competitive adsorption of $\mathrm{H}$ atoms at sites otherwise occupied by adsorbed $\mathrm{NO}_{3}^{-}[24,26]$. Alternatively, we suggest the possibility that rapid consumption of $\mathrm{H}$-atoms in the $\mathrm{H}_{2}(g)$ evolution process (Eqn. 5) is a kinetically more favorable fate for the $\mathrm{H}$ atoms in comparison to consumption within the $\mathrm{NO}_{3}{ }^{-}$reduction mechanism. Regardless of the explanation for attenuation of $\mathrm{NO}_{3}{ }^{-}$reduction by $\mathrm{H}_{2}(g)$ 
evolution, we anticipate that the optimal electrocatalytic surface for $\mathrm{NO}_{3}{ }^{-}$ reduction will be a bi-functional surface consisting of two different adsorption sites that exhibit a substantial difference in overpotential for the cathodic discharge of $\mathrm{H}^{+}$(Eqn. 2) and subsequent evolution of $\mathrm{H}_{2}(g)$ (Eqn. 5). Furthermore, single-phase binary alloys represent a homogeneous mixture of two types of adsorption sites so that sites for $\mathrm{NO}_{3}{ }^{-}$adsorbed are surrounded by sites carrying adsorbed $\mathrm{H}$-atoms. A single report was located describing $\mathrm{NO}_{3}{ }^{-}$reduction at a Cu-Ni alloy electrode containing $70 \% \mathrm{Cu}$ and $30 \% \mathrm{Ni}$ ("Cu${ }_{70} \mathrm{Ni} 30$ ") [32]. Pure $\mathrm{Cu}$ and $\mathrm{Ni}$ electrodes are observed to exhibit significant differences in their overpotential for cathodic discharge of $\mathrm{H}^{+}$with evolution of $\mathrm{H}_{2}(g)$. Therefore, we have chosen to examine further the voltammetric response for $\mathrm{NO}_{3}{ }^{-}$reduction at $\mathrm{Cu}-\mathrm{Ni}$ alloy electrodes.

\section{Experimental}

Instrumentation and data collection - Voltammetric experiments were performed at rotated disk electrodes (RDEs) under control by a Model MSR rotator (Pine Instrument) with potentiometric control of RDEs by a Model RDE4 potentiostat (Pine Instrument). A three-compartment cell was used to separate the working, auxiliary and reference electrodes. Electrode potentials used in voltammetric experiments were measured and reported vs. the saturated calomel electrode (SCE). Voltammetric data were collected using an IBM-compatible computer equipped with an AT-MIO-16XE-50 data 
acquisition board (National Instruments) and Labview data acquisition software (National Instruments).

Flow injection data were performed using a FIA-2500 system (FIAlab Instruments), a Flexcell flow-through electrochemical cell (ANTEC Leyden) and an ED40 electrochemical detector (Dionex). Constant flow rate was maintained by application of constant He pressure to the container of carrier phase. All electrode potentials applied in the flow cell were controlled vs. a silver-silver chloride electrode (SSCE); however, these potential values are reported here vs. SCE. Flow injection data were collected using an IBM-compatible computer equipped with Peaknet data acquisition software (Dionex).

All data were obtained at ambient temperature $\left(24 \pm 2{ }^{\circ} \mathrm{C}\right)$. Statistical analyses of linear segments of Koutecky-Levich and calibration plots were performed using Sigmaplot for Windows (SPSS).

Preparation of electrodes - Preparation of electrodes was carried out in house by the Metals Development Processing Center. The Cu electrodes were constructed with areas of 0.154 and $0.448 \mathrm{~cm}^{2}$ for use in voltammetric and flow injection experiments, respectively. The pure Ni and Cu-Ni alloy electrodes were constructed with areas of 0.177 and $0.448 \mathrm{~cm}^{2}$ for use in voltammetric and flow injection experiments, respectively. Prior to data collection, electrodes were polished with $0.1-\mu \mathrm{m}$ alumina powder 
suspended in water. Compositions indicated for the $\mathrm{Cu}-\mathrm{Ni}$ alloys correspond to atomic percentages.

Chemicals - All chemicals were Reagent Grade. The electrolyte used in all voltammetric and flow-injection experiments was $1.0 \mathrm{M} \mathrm{HClO}_{4}$ (Fisher). All water had been distilled followed by further purification in a NANO-Pure-II system (SYBRON/Barnstead). Sodium nitrate (Fisher) was used as received to prepare all nitrate solutions. Solutions used in voltammetric experiments were rigorously deaerated by dispersed $\mathrm{N}_{2}(\mathrm{~g})$ and a constant flow of $\mathrm{N}_{2}(\mathrm{~g})$ was maintained over solutions during voltammetric testing. Solutions used in all flow-injection experiments were rigorously deaerated with dispersed $\mathrm{He}(g)$ and maintained under a constant pressure of He.

\section{Results and Discussion}

Voltammetric response at Ni electrodes - Typical voltammetric data, plotted as current density $\left(\mathrm{mA} \mathrm{cm}^{-2}\right)$ vs. potential (V), are shown in Figure 1 for the positive potential scan at a $\mathrm{Ni} \mathrm{RDE}$ in $1.0 \mathrm{M} \mathrm{HClO}_{4}$ for the absence (A) and presence of $\mathrm{NO}_{3}^{-}$at $1.0 \mathrm{mM}(\mathrm{B}), 1.5 \mathrm{mM}(\mathrm{C})$, and $2.0 \mathrm{mM}$ (D) concentrations. The residual response (A) for the $\mathrm{Ni}$ electrode is featureless in the region of $-0.3 \mathrm{~V}$ to $-0.5 \mathrm{~V}$; however, for increasing negative potential below ca. $-0.5 \mathrm{~V}$ the residual current increases as a result of the rapid cathodic discharge of $\mathrm{H}^{+}$with concomitant evolution of $\mathrm{H}_{2}(g)$. Continuation 
of the potential positive from $-0.3 \mathrm{~V}$ to $0.0 \mathrm{~V}$ (data not included) shows an anodic current speculated to result primarily from anodic dissolution of the Ni electrode. Shifting the negative scan limit from $-0.5 \mathrm{~V}$ to $-0.3 \mathrm{~V}$ results in a slight decrease in the anodic current in the region $-0.3 \mathrm{~V}$ to $0.0 \mathrm{~V}$ and oxidation of adsorbed $\mathrm{H}$-atoms is speculated to contribute to the anodic current in this potential region. The positive potential scans were limited to $-0.3 \mathrm{~V}$ in these studies to avoid dissolution of the $\mathrm{Ni}$ electrode.

Whereas a small cathodic response is evident in Figure 1 resulting from additions of $\mathrm{NO}_{3}{ }^{-}$, there is no evidence of a limiting-current plateau. This is evidence of slow heterogeneous kinetics for the cathodic reduction of $\mathrm{NO}_{3}{ }^{-}$at the Ni electrode. Furthermore, voltammetric data obtained as a function of changes in rotational velocity of the electrode (data not shown) indicated the virtual absence of any dependence of the cathodic response on rotational velocity. This observation confirms the diagnosis of slow heterogeneous kinetics. It is also observed in Figure 1 that the small $\mathrm{NO}_{3}{ }^{-}$ response is attenuated in the potential region for $\mathrm{H}_{2}(g)$ evolution, i.e., see the difference between Curves $A$ and $D$ for change in potential from $-0.5 \mathrm{~V}$ to $-0.6 \mathrm{~V}$.

Voltammetric response at Cu electrodes - Typical voltammetric response, plotted as current density $\left(\mathrm{mA} \mathrm{cm}^{-2}\right)$ vs. applied potential (V), for the positive potential scan is shown in Figure 2 for a Cu RDE in $1.0 \mathrm{M}$ $\mathrm{HClO}_{4}$ as a function of increasing rotational velocity in the absence (A) and 
presence $(\mathrm{B}-\mathrm{E})$ of $1.0 \mathrm{mM} \mathrm{NO}_{3}{ }^{-}$. The residual response at the $\mathrm{Cu}$ electrode (Curve A) is without feature in the range of $-0.2 \mathrm{~V}$ to $-0.65 \mathrm{~V}$; however, for increasing negative potential below $-0.65 \mathrm{~V}$, the residual cathodic current increases as a result of cathodic discharge of $\mathrm{H}^{+}$with concomitant evolution of $\mathrm{H}_{2}(g)$. The positive scan limit was maintained at $-0.2 \mathrm{~V}$ to avoid anodic dissolution of the $\mathrm{Cu}$ electrode observed to occur at more positive potentials (data not shown). It is important to recognize that the overpotential for $\mathrm{H}_{2}(g)$ evolution at the $\mathrm{Cu}$ electrode in Figure 2 (ca. $-0.8 \mathrm{~V}$ at $-6 \mathrm{~mA} \mathrm{~cm}-2$ ) is significantly larger than at the $\mathrm{Ni}$ electrode in Figure 1 (ca. $-0.6 \mathrm{~V}$ at $-6 \mathrm{~mA}$ $\left.\mathrm{cm}^{-2}\right)$.

As represented in Figure 2 by Curves $\mathrm{B}-\mathrm{E}, \mathrm{NO}_{3}{ }^{-}$reduction at the $\mathrm{Cu}$ electrode exhibits a strong dependence on rotational velocity in the potential region ca. $-0.6 \mathrm{~V}$ to $-0.7 \mathrm{~V}$. This is evidence of faster heterogeneous kinetics for $\mathrm{NO}_{3}{ }^{-}$reduction at the $\mathrm{Cu}$ electrode in comparison to the $\mathrm{Ni}$ electrode. It is also apparent, in the potential region ca. $-0.5 \mathrm{~V}$ to $-0.6 \mathrm{~V}$, that dependence on rotational velocity is diminished as the velocity increases. This can be explained on the basis of the mechanistic requirement of adsorbed $\mathrm{H}$-atoms. Accordingly, for increasingly flux of $\mathrm{NO}_{3}{ }^{-}$at the electrode surface, mechanistic control shifts from the rate of mass transport of $\mathrm{NO}_{3}{ }^{-}$to the electrode (low flux of $\mathrm{NO}_{3}{ }^{-}$) to the rate of generation of $\mathrm{H}-$ atoms (high flux of $\mathrm{NO}_{3}{ }^{-}$). An explanation for the inverse dependence on rotational velocity in the region ca. $-0.3 \mathrm{~V}$ to $-0.45 \mathrm{~V}$, resulting in a so- 
called isopotential point $(\mathrm{F})$ at $-0.45 \mathrm{~V}$, is not known at the present time. Again, as in the case of the $\mathrm{Ni}$ electrode, the $\mathrm{NO}_{3}{ }^{-}$response is observed to be attenuated for increasingly negative values of potential in the region of $\mathrm{H}_{2}(g)$ evolution (ca. $-0.7 \mathrm{~V}$ to $-0.8 \mathrm{~V}$ ).

Voltammetric response at $\mathrm{Cu}-\mathrm{Ni}$ alloy electrodes - The mechanism proposed above for cathodic reduction of $\mathrm{NO}_{3}{ }^{-}$is based on the co-requisites of the adsorption of both $\mathrm{NO}_{3}{ }^{-}$, from the bulk solution (Eqn. 1), and $\mathrm{H}-$ atoms, generated by cathodic discharge of $\mathrm{H}^{+}$(Eqn. 2). Based on the observation of a smaller overpotential for $\mathrm{H}_{2}(g)$ at the Ni electrode (see Figure 1) in comparison to the $\mathrm{Cu}$ electrode (see Figures 2), we concluded that $\mathrm{H}$-atoms are more strongly adsorbed at $\mathrm{Ni}$-sites in comparison to $\mathrm{Cu}-$ sites. In contrast, voltammetric data for $\mathrm{NO}_{3}{ }^{-}$were interpreted as indicating that $\mathrm{NO}_{3}{ }^{-}$is more strongly adsorbed at $\mathrm{Cu}$-sites in comparison to Ni-sites. Therefore, we expect that the voltammetric response for $\mathrm{NO}_{3}{ }^{-}$will exhibit the existence of an electrocatalytic benefit of the presence of both Ni-sites and $\mathrm{Cu}$-sites in the surfaces of $\mathrm{Cu}-\mathrm{Ni}$ alloy electrodes.

Figure 3 shows a comparison of the voltammetric responses obtained at $\mathrm{Cu}(\mathrm{A}), \mathrm{Ni}(\mathrm{B})$ and $\mathrm{Cu}_{50} \mathrm{Ni}_{50}$ (C) electrodes in $1.0 \mathrm{M} \mathrm{HClO}_{4}$, plotted as current density $\left(\mathrm{mA} \mathrm{cm}^{-2}\right)$ vs. potential $(\mathrm{V})$, for the absence (-) and presence $(--)$ of $1.0 \mathrm{mM} \mathrm{NO}_{3}{ }^{-}$. The voltammetric responses at pure $\mathrm{Cu}$ and Ni electrodes were discussed in previous sections. The $\mathrm{Cu}_{50} \mathrm{Ni}_{50}$ electrode exhibits a residual response (C) that is featureless in the region of 
ca. $-0.10 \mathrm{~V}$ to $-0.55 \mathrm{~V}$; however, the cathodic current increases sharply for potentials more negative than $-0.55 \mathrm{~V}$ as a result of $\mathrm{H}_{2}(g)$ evolution. It is apparent that the overpotential for $\mathrm{H}_{2}(g)$ evolution for the $\mathrm{Cu}_{50} \mathrm{Ni}_{50}$ electrode (C) is approximately the average of the two overpotentials for $\mathrm{H}_{2}(g)$ evolution at the $\mathrm{Cu}(\mathrm{A})$ and $\mathrm{Ni}(\mathrm{B})$ electrodes. This is to be expected for an electrode surface comprised of both $\mathrm{Cu}$-sites and Ni-sites.

Of greatest significance in Figure 3 is the appearance of a well-defined plateau current for $\mathrm{NO}_{3}{ }^{-}$reduction at the $\mathrm{Cu}_{50} \mathrm{Ni}_{50}$ electrode $\left(\mathrm{C}^{\prime}\right)$ in the potential region ca. $-0.4 \mathrm{~V}$ to $-0.6 \mathrm{~V}$. The overpotential for $\mathrm{NO}_{3}{ }^{-}$reduction corresponding to the half-wave potential $\left(E_{1 / 2}\right)$ at $\mathrm{Cu}_{50 \mathrm{Ni}}$ ( ca. $-0.2 \mathrm{~V}$ at $-2.5 \mathrm{~mA} \mathrm{~cm}{ }^{-2}$ ) is substantially less than the overpotentials for the same current density at the $\mathrm{Cu}($ ca. $-0.5 \mathrm{~V}$ ) and $\mathrm{Ni}(\mathrm{ca} .-0.6 \mathrm{~V})$ electrodes. The small value of overpotential and the existence of a extensive limiting current plateau at the $\mathrm{Cu}_{50} \mathrm{Ni}_{50}$ electrode $\left(\mathrm{C}^{\prime}\right)$ are evidence for more favorable heterogeneous kinetics for $\mathrm{NO}_{3}{ }^{-}$reduction in comparison to the $\mathrm{Ni}\left(\mathrm{B}^{\prime}\right)$ and $\mathrm{Cu}$ (A') electrodes. We attribute the improved electrocatalytic response at the alloy electrode to be the result of the synergism of the two types of adsorption sites at the binary alloy surface.

Also significant in Figure 3 is evidence that the cathodic response for $\mathrm{NO}_{3}{ }^{-}$at the CusoNiso electrode $\left(\mathrm{C}^{7}\right)$ is terminated at ca. $-0.7 \mathrm{~V}$ corresponding to extensive cathodic evolution of $\mathrm{H}_{2}(g)$ at Ni-sites. There is no evidence of significant $\mathrm{H}_{2}(g)$ generation at this potential at the $\mathrm{Cu}$ electrode. Therefore, 
attenuation of the $\mathrm{NO}_{3}{ }^{-}$reduction at the $\mathrm{Cu}_{50} \mathrm{Ni}_{50}$ electrode cannot possibly result from competitive adsorption by $\mathrm{H}$-atoms at the Cu-sites where $\mathrm{NO}_{3}{ }^{-}$is adsorbed at this $\mathrm{Cu}-\mathrm{Ni}$ alloy electrode. We speculate as an alternate explanation that attenuation of $\mathrm{NO}_{3}{ }^{-}$reduction at the $\mathrm{Cu}_{50} \mathrm{Ni}_{50}$ electrode results because $\mathrm{H}_{2}(g)$ evolution from the $\mathrm{Ni}$-sites at $-0.7 \mathrm{~V}$ is a kinetically more favorable fate for the adsorbed $\mathrm{H}$-atoms. Accordingly, the average lifetime of adsorbed $\mathrm{H}$-atoms on $\mathrm{Ni}$-sites is made sufficiently short, by the fast heterogeneous kinetics of $\mathrm{H}_{2}(\mathrm{~g})$ evolution, to negate the probability of their consumption within the $\mathrm{NO}_{3}{ }^{-}$reduction mechanism.

Figure 4 compares the voltammetric responses obtained in the absence $(-)$ and presence $(--)$ of $1.0 \mathrm{mM} \mathrm{NO}_{3}{ }^{-}$at the $\mathrm{Cu}_{75} \mathrm{Ni}_{25}\left(\mathrm{~A}, \mathrm{~A}^{\prime}\right)$, $\mathrm{Cu}_{50} \mathrm{Ni}_{50}\left(\mathrm{~B}, \mathrm{~B}^{\prime}\right)$, and $\mathrm{Cu}_{25} \mathrm{Ni}_{75}\left(\mathrm{C}, \mathrm{C}^{\prime}\right)$ electrodes. As expected, the residual responses for the three electrodes indicate a positive shift in the overpotential for $\mathrm{H}_{2}(g)$ evolution as the $\mathrm{Ni}$ : $\mathrm{Cu}$ ratio is increased in the alloy electrodes. Of greatest significance is the observation that the overpotential for $\mathrm{NO}_{3}{ }^{-}$reduction is the smallest, i.e., least negative half-wave potential $\left(\mathrm{E}_{1 / 2}\right)$, for the CusoNiso electrode $\left(\mathrm{C}^{\prime}\right)$ in comparison to that for the $\mathrm{Cu}(\mathrm{A})$ and Ni (B') electrodes. Furthermore, for the $\mathrm{Cu}_{50} \mathrm{Ni}_{50}$ electrode $\left(\mathrm{C}^{\prime}\right)$, the plateau current is the most well developed. This observation is consistent with expectations based on our view of the synergistic importance of both the $\mathrm{Cu}$-sites and $\mathrm{Ni}$-sites in the $\mathrm{NO}_{3}{ }^{-}$reduction mechanism. It is a curiosity that the maximum current density of ca. $-6 \mathrm{~mA} \mathrm{~cm}^{-2}$ for $\mathrm{NO}_{3}{ }^{-}$reduction at 
the $\mathrm{Cu}_{25} \mathrm{Ni}_{75}$ electrode (C') is larger than the current density of ca. $-5 \mathrm{~mA}$ $\mathrm{cm}^{-2}$ at the Cu${ }_{50} N_{50}$ electrode (B'). Perhaps the value of $n$ for $\mathrm{NO}_{3}{ }^{-}$ reduction is larger at the $\mathrm{Cu}_{25} \mathrm{Ni}_{75}$ electrode in comparison to the $\mathrm{Cu}_{50} \mathrm{Ni}_{50}$ electrode.

The voltammetric response for $\mathrm{NO}_{3}{ }^{-}$at all three $\mathrm{Cu}-\mathrm{Ni}$ alloy electrodes exhibited strong dependence on changes in rotational velocity and $\mathrm{NO}_{3}{ }^{-}$ concentration. Typical voltammetric data obtained at the $\mathrm{Cu}_{50} \mathrm{Ni}_{50}$ electrode are shown in Figure 5 as a function of rotational velocity and in Figure 6 as a function of $\mathrm{NO}_{3}{ }^{-}$concentration. It is apparent from these data that the $\mathrm{E}_{1 / 2}$ for $\mathrm{NO}_{3}{ }^{-}$reduction shifts to more negative potential values as the flux of $\mathrm{NO}_{3}{ }^{-}$is increased at the electrode surface by increases in rotational velocity and concentration. This shift in $\mathrm{E}_{1 / 2}$ can be explained on the basis of the necessity of increasing the flux of $\mathrm{H}$-atoms to support the increased current for $\mathrm{NO}_{3}{ }^{-}$reduction.

Koutecky-Levich analysis of cathodic currents for $\mathrm{NO}_{3}{ }^{-}$- Construction of so-called Levich plots of current $\left(i, \mathrm{C} \mathrm{s}^{-1}\right)$ at RDEs vs. square root of rotational velocity $\left(\omega^{1 / 2}, \mathrm{~s}^{-1 / 2}\right)$ is frequently used in the characterization of amperometric response mechanisms. For mass transport-limited current response, i.e., fast heterogeneous kinetics, the Levich plot is predicted to be linear with a zero intercept [33]. The slope of a linear Levich plot corresponds to $0.62 n \mathrm{FAD}^{2 / 3} \mathrm{v}^{-1 / 6} \mathrm{C}^{\mathrm{b}}$ where $n$ is the apparent number of electrons transferred in the electrode reaction (eq $\mathrm{mol}^{-1}$ ), $\mathrm{F}$ is the Faraday 
constant $\left(9.65 \times 10^{4} \mathrm{C} \mathrm{eq}^{-1}\right), A$ is the geometric electrode area $\left(\mathrm{cm}^{2}\right), D$ is the diffusion coefficient $\left(\mathrm{cm}^{2} \mathrm{~s}^{-1}\right), v$ is the kinematic viscosity of the solution $\left(\mathrm{cm}^{2} \mathrm{~s}^{-1}\right)$ and $\mathrm{C}^{\mathrm{b}}$ is the bulk concentration of reactant $\left(\mathrm{mol} \mathrm{cm} \mathrm{cm}^{-3}\right)$. Negative curvature from linearity in a Levich plot is characteristic of slow heterogeneous kinetics resulting in an electrode response that is under mixed kinetic-mass transport control. Data under mixed control can be plotted according to the so-called Koutecky-Levich equation as reciprocal current $\left(1 / \mathrm{i}, \mathrm{C}^{-1}\right.$ s) vs. reciprocal square root of rotational velocity $\left(1 / \omega^{1 / 2}\right.$, $\operatorname{rad}^{-1 / 2} \mathrm{~s}^{1 / 2}$ ) [34]. The slope of a linear Koutecky-Levich plot is $1 / 0.62 n \mathrm{FA} D^{2 / 3} \bar{\nu}^{-1 / 6} \mathrm{C}^{\mathrm{b}}$ and the intercept is $1 / n \mathrm{FA} k_{\mathrm{app}} C^{b}$, where $k_{\text {app }}$ is the apparent heterogeneous rate constant $\left(\mathrm{cm} \mathrm{s}^{-1}\right)$.

The response for $\mathrm{NO}_{3}{ }^{-}$at all $\mathrm{Cu}$ and $\mathrm{Cu}-\mathrm{Ni}$ alloy electrodes tested in this study exhibited negative deviation from a linear Levich response and, therefore, the data were plotted according to the Koutecky-Levich equation for the current response obtained for $1.0 \mathrm{mM} \mathrm{NO}_{3}{ }^{-}$. Typical of the Koutecky-Levich plots are those shown in Figure 7 for the $\mathrm{Cu}(\mathrm{A})$ and $\mathrm{Cu}_{50} \mathrm{Ni}_{50}(\mathrm{~B})$ electrodes. Table 1 contains a summary of the data obtained from the Koutecky-Levich plots for the $\mathrm{Cu}, \mathrm{Cu}_{25} \mathrm{Ni}_{75}, \mathrm{Cu}_{50} \mathrm{Ni}_{50}$ and $\mathrm{Cu}_{75} \mathrm{Ni}_{25}$ electrodes. Koutecky-Levich plots for the Ni electrode exhibited no dependence on $\mathrm{NO}_{3}{ }^{-}$concentration and rotational velocity and, therefore, these data are omitted from Table 1. 
Values of $n$ shown in Table 1 were calculated from the slopes of the Koutecky-Levich plots using the values $D=1.9 \times 10^{-5} \mathrm{~cm}^{2} \mathrm{~s}^{-1}[35]$ and $v=$ $8.8 \times 10^{-3} \mathrm{~cm}^{2} \mathrm{~s}^{-1}$. For electrodes with a high $\mathrm{Cu}$ content, i.e., $\mathrm{Cu}$ and $\mathrm{Cu}_{75} \mathrm{Ni}_{25}$, values of $n$ are $7.8 \mathrm{eq} \mathrm{mol}^{-1}$ and $8.0 \mathrm{eq} \mathrm{mol}{ }^{-1}$, respectively. These values are consistent with the speculation that the product of $\mathrm{NO}_{3}{ }^{-}$ reduction at these electrodes is $\mathrm{NH}_{3}\left(n=8 \mathrm{eq} \mathrm{mol}^{-1}\right)$. This result is in agreement with results reported elsewhere [6]. The values of $k_{\text {app }}$ for these electrodes were calculated from the intercepts of the respective KouteckyLevich plots using $n=8 \mathrm{eq} \mathrm{mol}^{-1}$. Values of $n=6.0 \mathrm{eq} \mathrm{mol}^{-1}$ were calculated from the slopes of the Koutecky-Levich plots for the electrodes with a lower Cu content, i.e., $\mathrm{Cu}_{50} \mathrm{Ni}_{50}$ and $\mathrm{Cu}_{25} \mathrm{Ni75}$, using the values $D=1.9 \times 10^{-5} \mathrm{~cm}^{2}$ $\mathrm{s}^{-1}[35]$ and $v=8.8 \times 10^{-3} \mathrm{~cm}^{2} \mathrm{~s}^{-1}$. These values for $n$ are consistent with reduction of $\mathrm{NO}_{3}{ }^{-}$to $\mathrm{NH}_{2} \mathrm{OH}\left(n=6 \mathrm{eq} \mathrm{mol}^{-1}\right)$. An explanation for the difference in $n$ values obtained in this comparison is not known at this time.

It is interesting to note that values of $\mathrm{k}_{\mathrm{app}}$ shown in Table 1 for the $\mathrm{Cu}_{25} \mathrm{Ni}_{75}\left(4.2 \times 10^{-2} \mathrm{~cm} \mathrm{~s}^{-1}\right)$ and $\mathrm{Cu}_{50} \mathrm{Ni}_{50}\left(3.9 \times 10^{-2} \mathrm{~cm} \mathrm{~s}^{-1}\right)$ electrodes are significantly larger for the $\mathrm{Cu}\left(1.4 \times 10^{-2} \mathrm{~cm} \mathrm{~s}^{-1}\right)$ and $\mathrm{Cu}_{75} \mathrm{Ni}_{25}\left(1.0 \times 10^{-2} \mathrm{~cm}\right.$ $\left.\mathrm{s}^{-1}\right)$ electrodes. However, in contrast, the values of $n$ shown in Table 1 for the $\mathrm{Cu}_{25} \mathrm{Ni}_{75}\left(6.0 \mathrm{eq} \mathrm{mol}^{-1}\right)$ and $\mathrm{Cu}_{50} \mathrm{Ni}_{50}\left(6.0 \mathrm{eq} \mathrm{mol}^{-1}\right)$ electrodes are smaller than for the $\mathrm{Cu}\left(7.80 \mathrm{eq} \mathrm{mol}^{-1}\right)$ and $\mathrm{Cu}_{75} \mathrm{Ni}_{25}\left(8.0 \mathrm{eq} \mathrm{mol}^{-1}\right)$ electrodes. Clearly, the $n$ value benefits primarily from availability of a high density of $\mathrm{Cu}$-sites for adsorption of $\mathrm{NO}_{3}{ }^{-}$whereas the $\mathrm{k}_{\text {app }}$ value benefits primarily 
from a high density of Ni-sites for generation of adsorbed H-atoms. Perhaps the $\mathrm{NH}_{2} \mathrm{OH}$ produced by the six-electron process must be desorbed with subsequent readsorption in a different configuration at an adjacent Cu-site to achieve the subsequent two-electron reduction to $\mathrm{NH}_{3}$. As a consequence, chances for readsorption are expected to be greatly diminished when $\mathrm{Cu}$-sites are completely surrounded by Ni-sites in the surfaces of the $\mathrm{Cu}_{50} \mathrm{Ni}_{50}$ and $\mathrm{Cu}_{25} \mathrm{Ni}_{75}$ electrodes.

Flow Injection Analysis of nitrate reduction - FIA peaks for $\mathrm{NO}_{3}{ }^{-}$, obtained using the flow-injection system with detection at the $\mathrm{Cu}_{25} \mathrm{Ni}_{75}$ electrodes in the flow-through detection cell, are shown in Figure 8. Shown are the first five and the last five peaks obtained for a series of 50 injections of $(100 \mu \mathrm{L})$ of $1.0 \mathrm{mM} \mathrm{NO}_{3}{ }^{-}$in $1.0 \mathrm{M} \mathrm{HClO}_{4}$. The detection potential used was $-0.50 \mathrm{~V}$ and the flow rate of the solvent was $1.0 \mathrm{~mL} \mathrm{~min}{ }^{-1}$. The injections were made at intervals of $1.5 \mathrm{~min}$. Minor peak variations can be seen in the chromatogram in Figure 8. For the first five injections, the average deviation of peak heights was $1.3 \%$ while that for the last five injections was $0.6 \%$. Peak height showed a loss of $11.1 \%$ between the average of the first five injections and the last five injections. Some loss in electrode response is seen over the period of 50 injections. Therefore, use of the alloy electrodes in electrochemical detection is expected to require repolishing of the electrode surface with frequent recalibrations. 
Figure 9 shows calibration data, based on peak-height data, for nitrate using a flow-injection system with the $\mathrm{Cu}_{50} \mathrm{Ni}_{50}(\mathrm{~A})$ and $\mathrm{Cu}_{25} \mathrm{Ni}_{75}(\mathrm{~B})$ electrodes. The error bars shown represent the standard deviation for all injections. The straight lines shown in Figure 9 correspond to the linear regressions for nitrate. A linear response at the $\mathrm{Cu}_{25} \mathrm{Ni}_{75}(\mathrm{~B})$ electrode is observed for nitrate over the concentration range studied with a slope of -

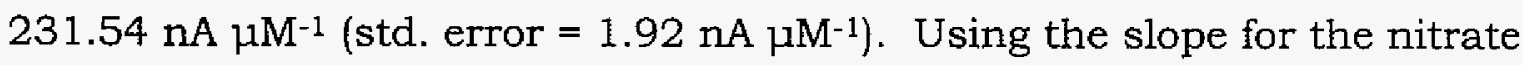
response and $3 \mathrm{X}$ the average peak-to-peak variation in baseline signal ( 46 $\mathrm{nA})$, the limit of detection is estimated by:

$$
\frac{3(46 \mathrm{nA})}{\left(\mid-231.54 \mathrm{nA} \mu \mathrm{M}^{-1}\right)}=0.60 \mu \mathrm{M}
$$

This estimated detection limit corresponds to $60 \mathrm{pmol}$ in a $100-\mu \mathrm{L}$ injection. A linear response at the CusoNiso (B) is observed for nitrate over the concentration range of $10-30 \mu \mathrm{M}$ with a slope of $-144.7 \mathrm{nA} \mu \mathrm{M}^{-1}$ (std. error $=$ $\left.3.92 \mathrm{nA} \mu \mathrm{M}^{-1}\right)$. Using the slope for the nitrate response and $3 \mathrm{X}$ the average peak-to-peak variation in baseline signal represented $(46 \mathrm{nA})$, the limit of detection is estimated by:

$$
\frac{3(46 \mathrm{nA})}{\left(\mid-144.7 \mathrm{nA} \mu \mathrm{M}^{-1}\right)}=0.95 \mu \mathrm{M}
$$

This estimated detection limit corresponds to $95 \mathrm{pmol}$ in a $100-\mu \mathrm{L}$ injection.

\section{Conclusions}

Voltammetric response for $\mathrm{NO}_{3}{ }^{-}$at the $\mathrm{Cu}-\mathrm{Ni}$ alloy electrode is 
superior to the response at the pure $\mathrm{Cu}$ and $\mathrm{Ni}$ electrodes. This is explained on the basis of the synergism of the two different metal sites at these binary alloy electrodes acting within the proposed response mechanism.

Accordingly, adsorbed $\mathrm{H}$-atoms are generated by cathodic discharge of $\mathrm{H}^{+}$at the Ni-sites whereas adsorption of $\mathrm{NO}_{3}{ }^{-}$occurs at the Cu-sites. The voltammetric response for $\mathrm{NO}_{3}{ }^{-}$at the $\mathrm{Cu}_{50} \mathrm{Ni}_{50}$ electrode exhibits a limitingcurrent plateau over a more extensive potential range (ca. $-0.35 \mathrm{~V}$ to $-0.6 \mathrm{~V}$ ) in comparison to that the $\mathrm{Cu}_{25} \mathrm{Ni}_{75}$ electrode (ca. $-0.45 \mathrm{~V}$ to $-0.6 \mathrm{~V}$ ). However, the sensitivity is larger at the $\mathrm{Cu}_{25} \mathrm{Ni}_{75}$ electrode with a larger linear range of response. Therefore, we recommend use of the $\mathrm{Cu}_{25} \mathrm{Ni}_{75}$ electrode.

It was observed that $\mathrm{NO}_{3}{ }^{-}$reduction at $\mathrm{Cu}-\mathrm{Ni}$ alloy electrode (see Figure 3 ) is attenuated by $\mathrm{H}_{2}(g)$ evolution at Ni-sites in the binary surface. This observation refutes speculation that the attenuation might be a consequence of competitive adsorption by $\mathrm{H}$-atoms at Cu-sites where $\mathrm{NO}_{3}{ }^{-}$ is adsorbed. Instead, we conclude that the fast kinetics for $\mathrm{H}_{2}(g)$ evolution decrease the average lifetime of adsorbed $\mathrm{H}$-atoms at $\mathrm{N}$ - -sites to the extent that there is no probability they will be harvested within the $\mathrm{NO}_{3}{ }^{-}$reduction mechanism. 


\section{Acknowledgments}

This report has been authored by the Iowa State University of Science and Technology under Contract No. W-7405-ENG-82 with the U.S.

Department of Energy. The U. S. Government retains and the publisher, by accepting the article for publication, acknowledges that the U. S.

Government retains a non-exclusive, paid-up, irrevocable, world-wide license to publish or reproduce the published form of this manuscript, or allow others to do so, for U. S. Government purposes.

\section{References}

1. N. E. Khomutov and U.S. Stamkulov, Sov. Electrochem., 1971, 7, 312.

2. A. K. Vijh, J. Catal., 1974, 230.

3. K. Bouzek, et al., J. Appl. Electrochem., 2001, 31, 1185.

4. S. Cattarin, J. Appl. Electrochem., 1992, 22, 1077.

5. J. Davis, et al., Analyst, 2000, 125, 737 .

6. D. Pletcher and Z. Poorabedi, Electrochimica Acta, 1979, 24, 1253.

7. J. Sherwood and D. C. Johnson, Anal. Chim. Acta, 1981, 129, 87.

8. M. Shibata, K. Yoshida and N. Furuya, J. Electrochem. Soc., 1998, $145,2348$.

9. A. C. A. de Vooys, R. A. van Santen and J. A. R. van Veen, J. Molec. Catal. A: Chem., 2000, 154, 203. 
10. D. L. Schlagel, The reduction of nitrate at copper, cadmium and coppercadmium alloy electrodes, Dissertation: Iowa State University, Ames, Iowa, 1997.

11. G. A. Sherwood, A copperized cadmium flow-through detector for the amperometric determination of nitrate in aqueous samples based on electrocatalytic reduction. Dissertation: Iowa State University, Ames, Iowa, 1979.

12. I. Suroso, Reduction of nitrate and the effect of anions on nitrate degradation with zero-valent iron, bimetals and trimetals, Dissertation: Iowa State University, Ames, Iowa, 2001.

13. M. E. Bodini and D. Sawyer, Anal. Chem., 1977, 49, 485.

14. R. J. Davenport and D. C. Johnson, Anal. Chem., 1973, 45, 1979.

15. J. D. Genders, D. Hartsough and D.T. Hobbs, J. Appl. Electrochem., $1996,26,1$.

16. H. L. Li, J. Q. Chambers and D. T. Hobbs, J. Appl. Electrochem., 1988, $18,454$.

17. M. Fedurco, P. Kedzierzawski and J. Augustynski, J. Electrochem. Soc., 1999, 146, 2569.

18. F. Bouamrane, et al., J. Electroanal. Chem., 1996, 405, 95.

19. C. Reuben, et al., J. Electroanal. Chem., 1995, 396, 233.

20. R. Tenne, et al., J. Electroanal. Chem., 1993, 347, 409.

21. I. Bakos and G. Horanyi, J. Electroanal. Chem., 1994, 370, 309. 
22. G. Horanyi and E. M. Rizmayer, J. Electroanal. Chem., 1982, 140, 347.

23. G. Horanyi and E. M. Rizmayer, J. Electroanal. Chem., 1983, 143, 323.

24. G. Horanyi and E. M. Rizmayer, J. Electroanal. Chem., 1985, 188, 265.

25. T. Ohmori, M. S. El-Deab and M. Osawa, J. Electroanal. Chem., 1999, $470,46$.

26. J. O. M. Bockris and J. Kim, J. Electrochem. Soc., 1996, 143, 3801.

27. F. Deganello, et al., Appl. Catal. B: Environ., 2000, 24, 265.

28. O. M. Ilinitch, et al., Catal. Today, 2000, 56, 137.

29. O. M. Ilinitch, et al., J. Mol. Catal. A: Chem., 2000, 158, 237.

30. J. F. E. Gootzen, et al., J. Electroanal. Chem., 1997, 434, 171.

31. S. Ureta-Zanrtu and C. Yanez, Electrochimica Acta, 1997, 42, 1725.

32. M. J. Moorcroft, et al., Anal. Lett., 2000, 33, 3127.

33. V. G. Levich, Physicochemical Hydrodynamics, Englewood Cliffs, NJ: Prentice-Hall, 1962, 345.

34. J. Koutecky and V. G. Levich, Zh. Fiz. Khim., 1958, 32, 1565.

35. V. M. Vdovenko, V.M., Y.V. Gurikov, and E.K. Legin, Radiokhimiya, 1966, 8, 323 . 
Table 1. Data obtained from Koutecky-Levich plots for $1.0 \mathrm{mM}$ nitrate in 1.0 M $\mathrm{HClO}_{4}$ at copper and copper-nickel alloy electrodes.

\begin{tabular}{|c|c|c|c|c|}
\hline Electrode & $\mathrm{Cu}$ & $\mathrm{Cu}_{75} \mathrm{Ni}_{25}$ & $\mathrm{Cu}_{50} \mathrm{Ni}_{50}$ & $\mathrm{Cu}_{25} \mathrm{Ni} 75$ \\
\hline $\begin{array}{l}\text { Detection Potential } \\
\text { (V vs SCE) }\end{array}$ & -0.65 & -0.60 & -0.55 & -0.50 \\
\hline 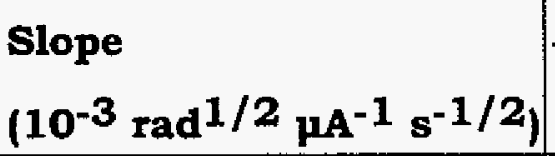 & $-8.87 \pm 0.03$ & $-7.5 \pm 0.2$ & $-10.0 \pm 0.2$ & $-10.1 \pm 0.2$ \\
\hline $\begin{array}{l}\mathbf{n}_{\text {eff }} \\
\left(\mathrm{eq} \mathrm{mol}^{-1}\right)\end{array}$ & $7.80 \pm 0.03$ & $8.0 \pm 0.2$ & $6.0 \pm 0.1$ & $6.0 \pm 0.1$ \\
\hline $\begin{array}{l}\text { intercept } \\
\left(10^{-4} \mathbf{p A}^{-1}\right)\end{array}$ & $-5.96 \pm 0.04$ & $-7.1 \pm 0.3$ & $-2.5 \pm 0.2$ & $-2.3 \pm 0.1$ \\
\hline $\begin{array}{l}k_{\text {app }} \\
\left(10^{-2} \mathrm{~cm} \mathrm{~s}^{-1}\right)\end{array}$ & $1.43 \pm 0.01$ & $1.02 \pm 0.04$ & $3.9 \pm 0.3$ & $4.2 \pm 0.2$ \\
\hline $\mathbf{r}^{2}$ & $0.999_{8}$ & $0.999_{7}$ & $0.999_{2}$ & $0.998_{6}$ \\
\hline
\end{tabular}




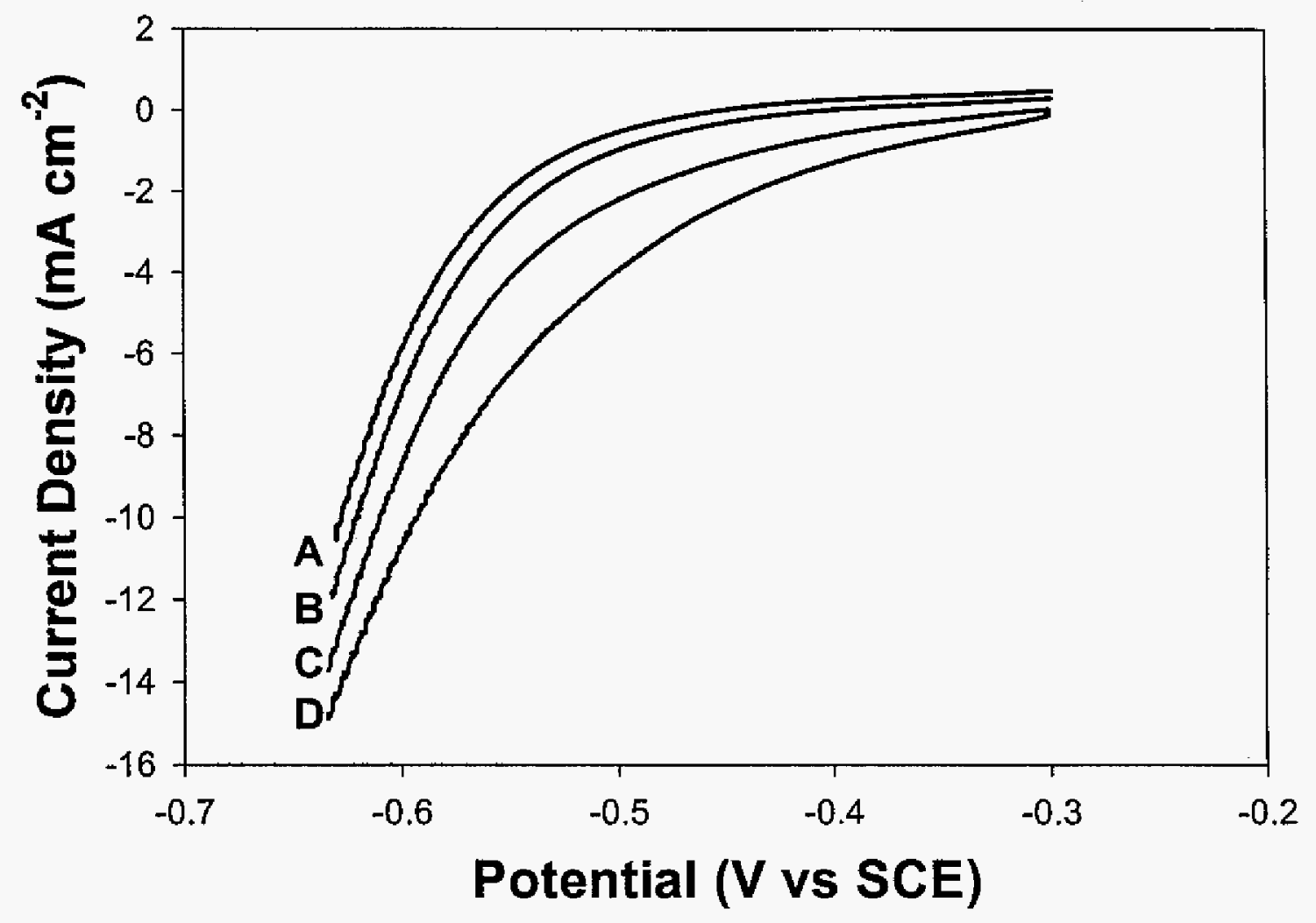

Figure 1. Response of nitrate reduction at pure nickel electrode. Nitrate concentration (mM): (A) 0, (B) 0.5, (C) 1.0, (D) 1.5, (E) 2.0. Electrolyte: $1.0 \mathrm{M}$ $\mathrm{HClO}_{4}$. Scan rate: $40 \mathrm{mV} \mathrm{s}^{-1}$. Rotational velocity: $9.7 \mathrm{rad} \mathrm{s}^{-1}$. 


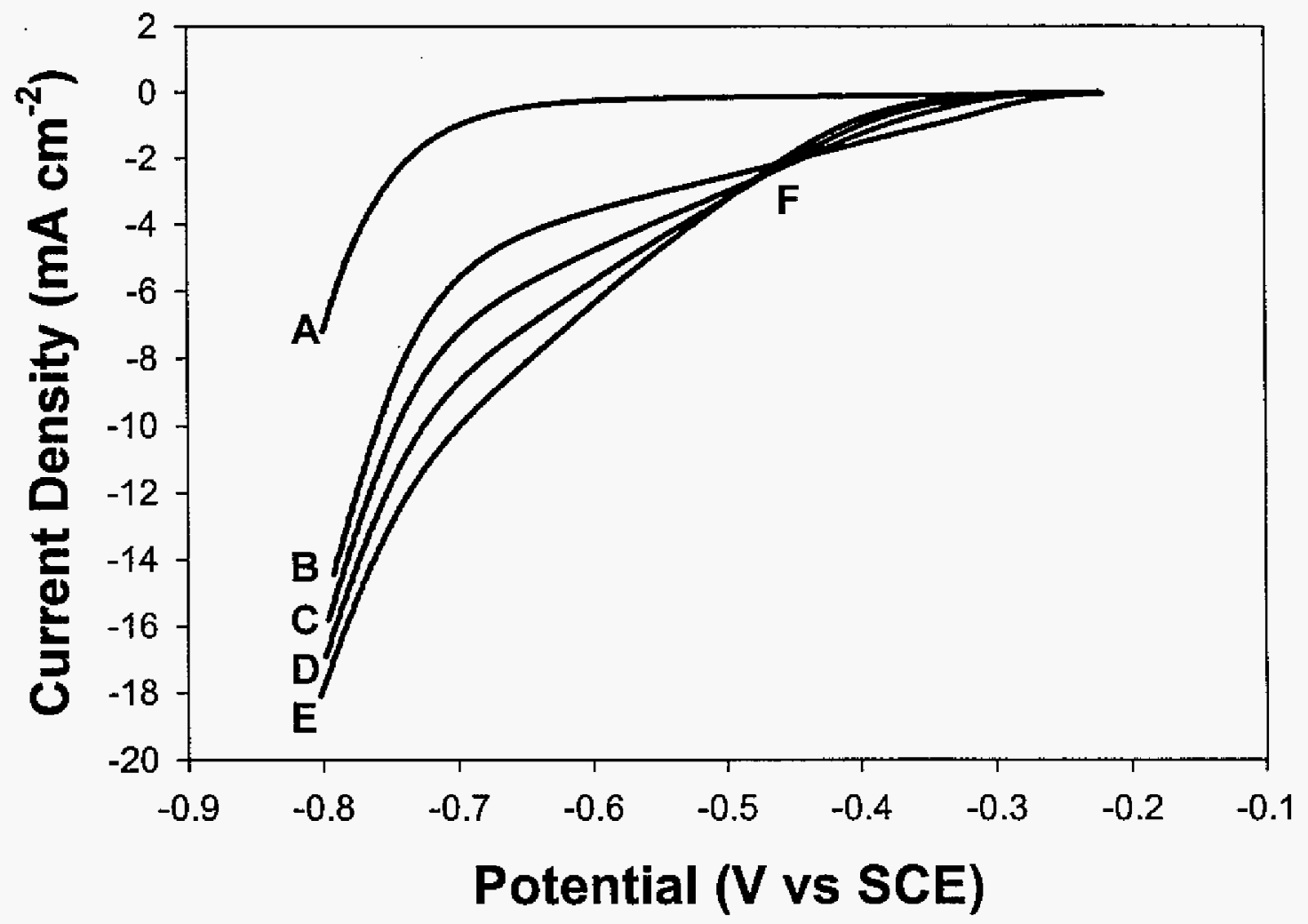

Figure 2. Response of nitrate reduction at pure copper electrode. Nitrate concentration: $1.0 \mathrm{mM}$ Electrolyte: $1.0 \mathrm{M} \mathrm{HClO}_{4}$. Scan rate: $40 \mathrm{mV} \mathrm{s}^{-1}$. Rotational velocity (rad s-1): (A) Residual, (B) 6.5, (C) 9.7, (D) 12.9, (E) 16.1. 


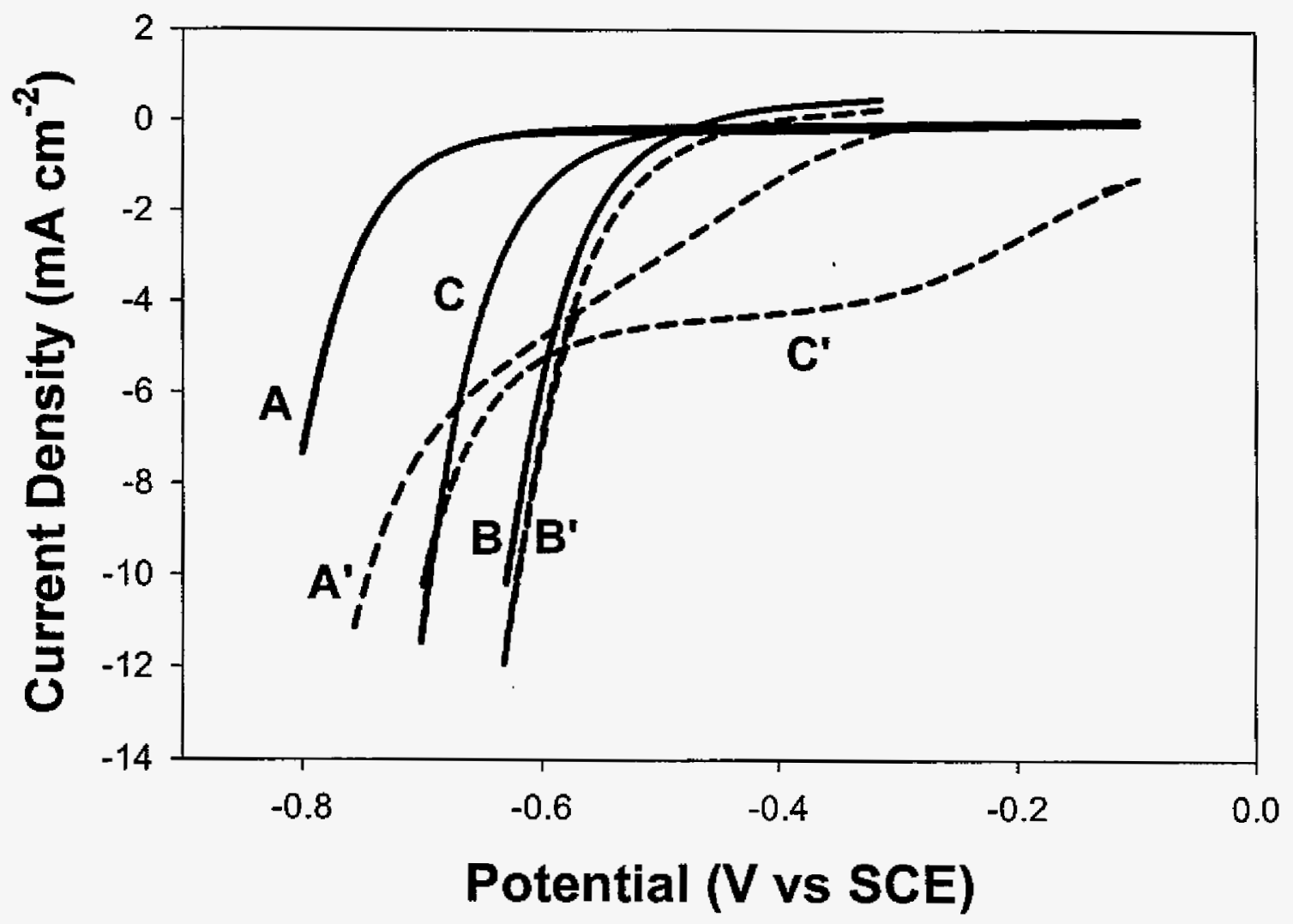

Figure 3. Comparison of nitrate reduction at pure copper, pure nickel, and $\mathrm{Cu}_{50} \mathrm{Ni}_{50}$ electrodes. Electrolyte: $1.0 \mathrm{M} \mathrm{HClO}_{4}$. Scan rate: $40 \mathrm{mV} \mathrm{s}^{-1}$. Rotational velocity: $9.7 \mathrm{rad} \mathrm{s}^{-1}$. Electrode: $\mathrm{Cu}\left(\mathrm{A}, \mathrm{A}^{\prime}\right), \mathrm{Ni}\left(\mathrm{B}, \mathrm{B}^{\prime}\right), \mathrm{Cu}_{50} \mathrm{Ni}_{50}$ $\left(C, C^{\prime}\right)$. Nitrate concentration $(\mathrm{mM}):(-0.0,(---) 1.0 \mathrm{mM}$. 


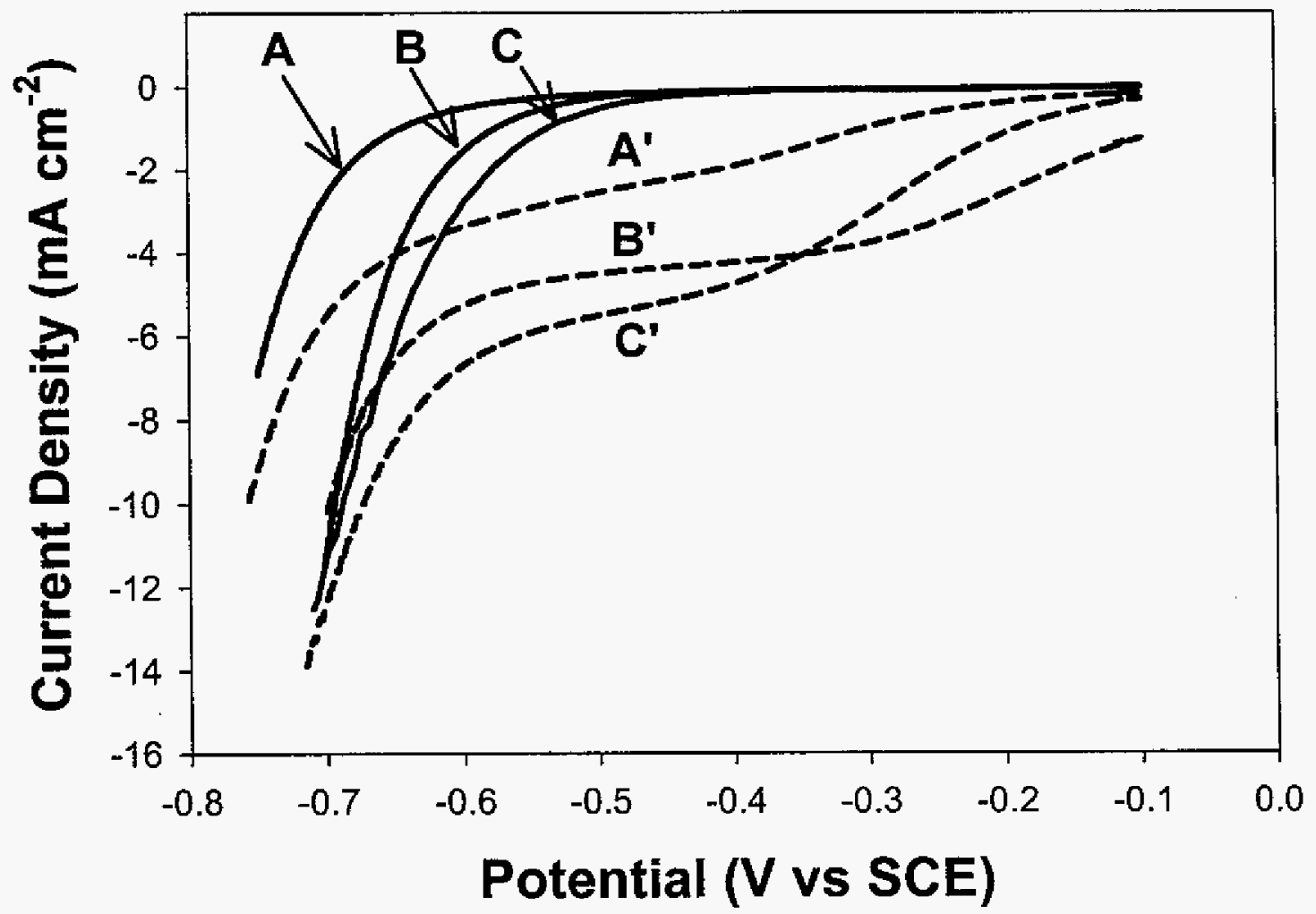

Figure 4. Comparison of nitrate reduction at copper-nickel alloy electrodes of various composition. Electrolyte: $1.0 \mathrm{M} \mathrm{HClO}_{4}$. Scan rate: $40 \mathrm{mV} \mathrm{s} \mathrm{m}^{-1}$. Rotational velocity: $9.7 \mathrm{rad} \mathrm{s}^{-1}$. Electrode: $\mathrm{Cu}_{75} \mathrm{Ni}_{25}\left(\mathrm{~A}, \mathrm{~A}^{\prime}\right), \mathrm{Cu}_{50} \mathrm{Ni}_{50}$ (B, $\left.\mathrm{B}^{\prime}\right), \mathrm{Cu}_{25} \mathrm{Ni75}\left(\mathrm{C}, \mathrm{C}^{\prime}\right)$. Nitrate concentration $(\mathrm{mM}):(-) 0.0,(---) 1.0$ $\mathrm{mM}$. 


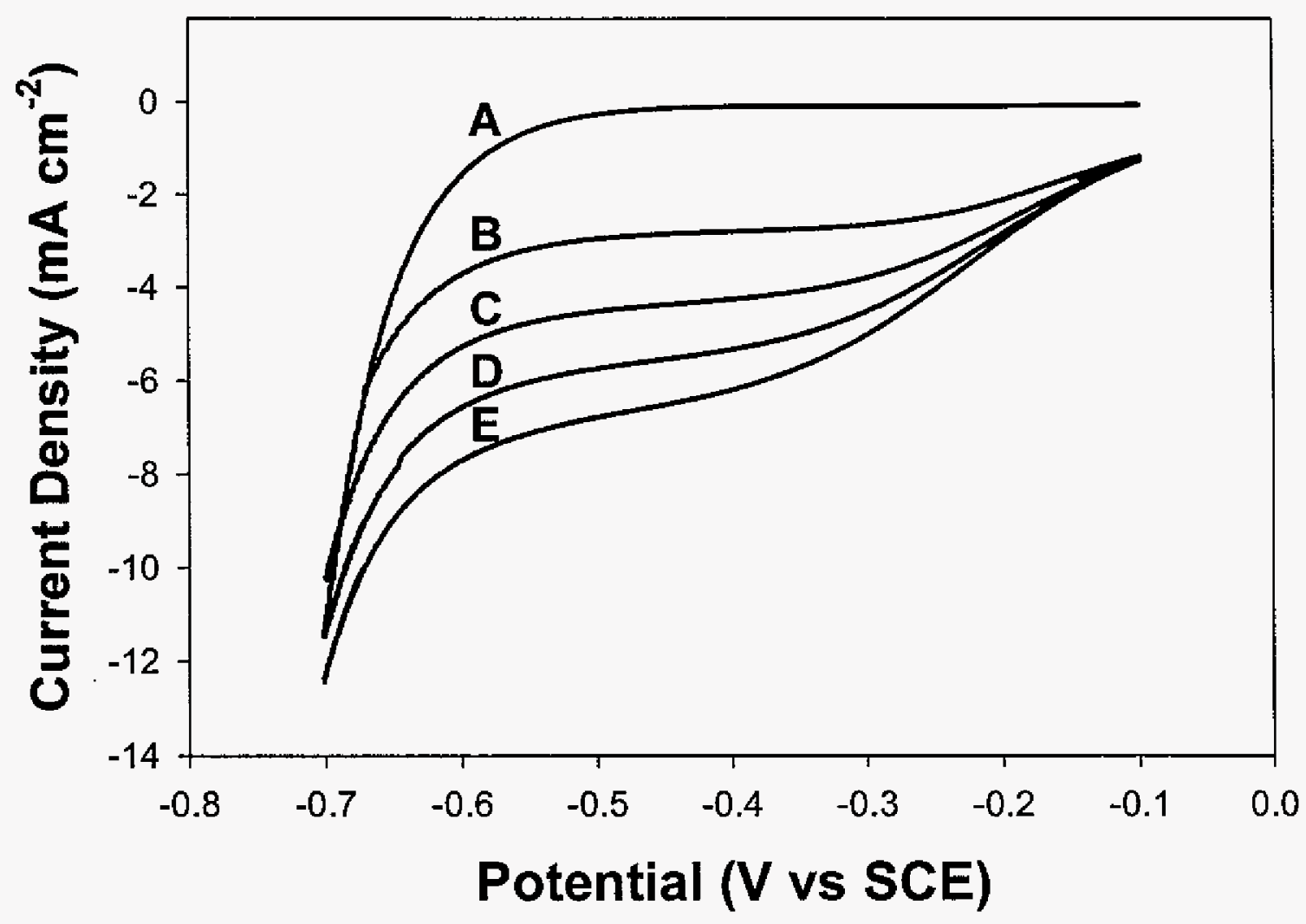

Figure 5. Response of nitrate reduction at $\mathrm{Cu}_{50} \mathrm{Ni}_{50}$ electrode. Nitrate concentration: $1.0 \mathrm{mM}$. Electrolyte: $1.0 \mathrm{M} \mathrm{HClO}_{4}$. Scan rate: $40 \mathrm{mV} \mathrm{s}^{-1}$. Rotational velocity (rad s-1): (A) Residual, (B) 6.5, (C) 9.7, (D) 12.9, (E) 16.1. 


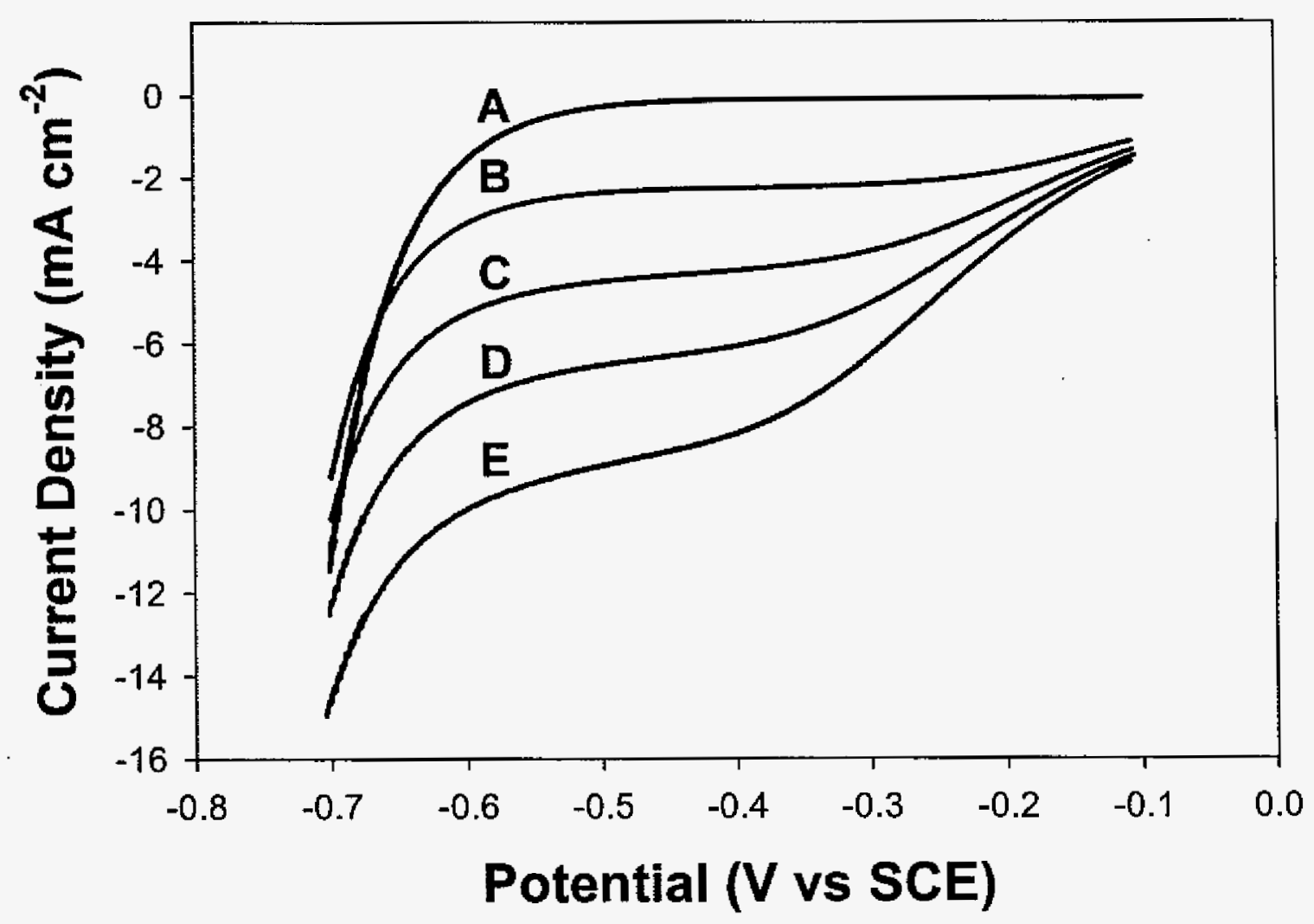

Figure 6. Response of nitrate reduction at $\mathrm{Cu}_{50} \mathrm{Ni}_{50}$ electrode. Nitrate concentration $(\mathrm{mM}):(\mathrm{A}) 0,(\mathrm{~B}) 0.5,(\mathrm{C}) 1.0$, (D) 1.5 , (E) 2.0 . Electrolyte: $1.0 \mathrm{M}$ $\mathrm{HClO}_{4}$. Scan rate: $40 \mathrm{mV} \mathrm{s}^{-1}$. Rotational velocity: $9.7 \mathrm{rad} \mathrm{s}^{-1}$. 


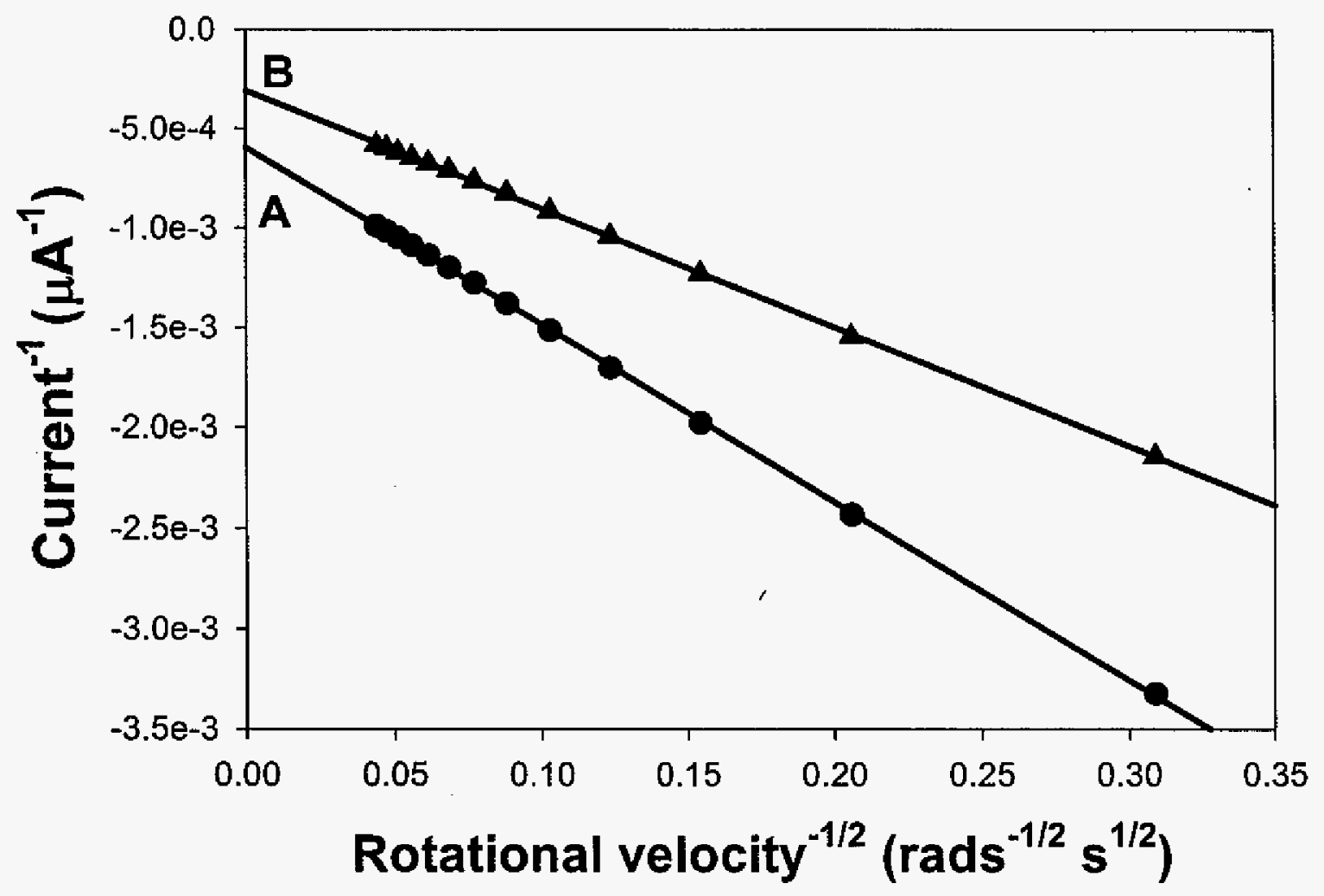

Figure 7. Koutecky-Levich plots for $1.0 \mathrm{mM}$ nitrate in $1.0 \mathrm{M} \mathrm{HClO}_{4}$.

Electrode: $\mathrm{Cu}(\bullet)$, Cu${ }_{50} \mathrm{Ni}_{50}(\Delta)$ Detection potential: $\mathrm{Cu}(-0.65 \mathrm{~V}), \mathrm{Cu}_{50} \mathrm{Ni}_{50}$ $(-0.55 V)$ 


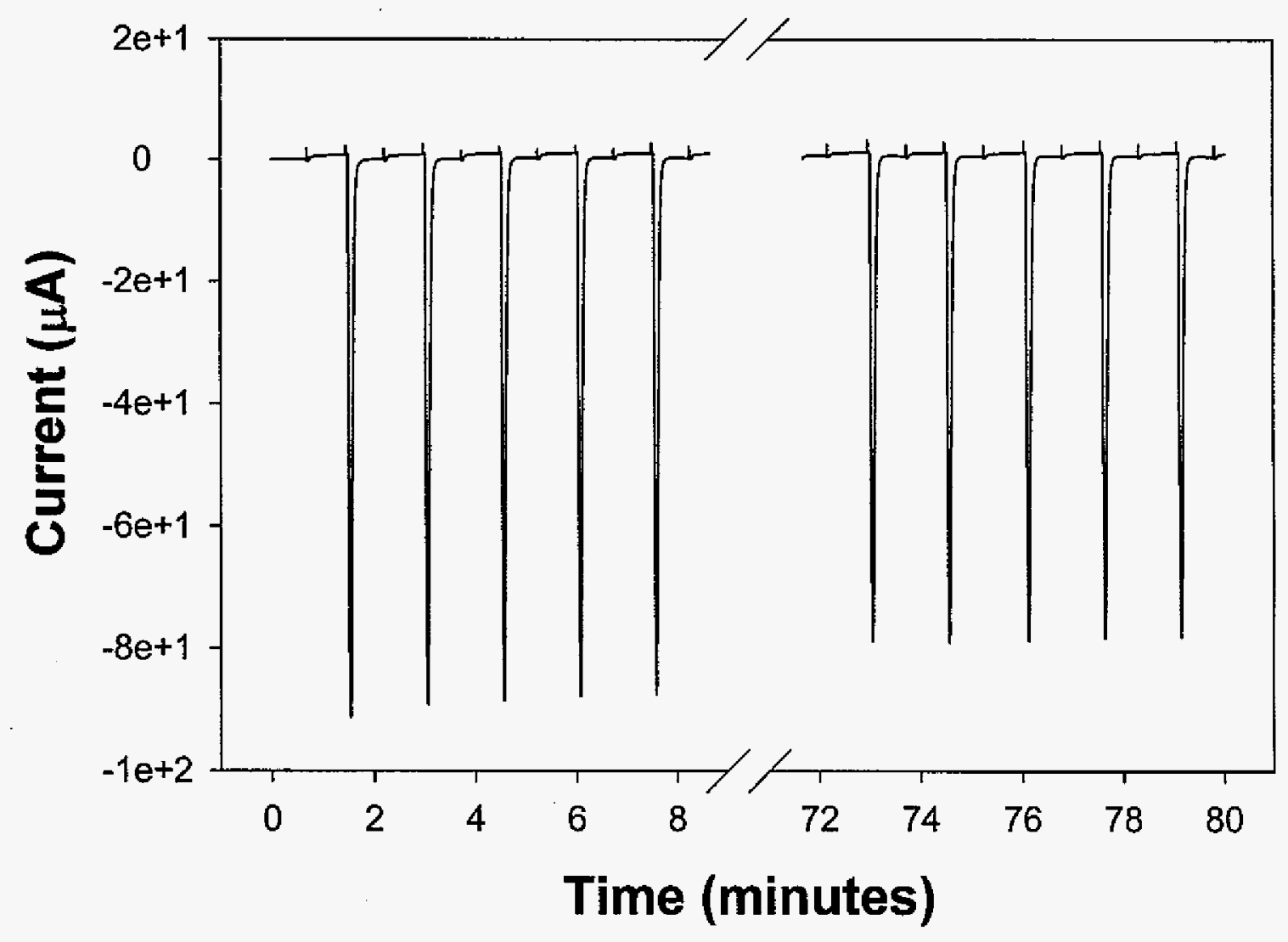

Figure 8. Stability of response for injections of $100-\mu \mathrm{L}$ samples of $1.0 \mathrm{mM}$ nitrate in $1.0 \mathrm{M} \mathrm{HClO}_{4}$ at 1.5 -minute intervals in a flow-injection system with detection at the $\mathrm{Cu}_{25} \mathrm{Ni} 75$ electrode. Peaks shown correspond to the first five and last five of 50 injections. Detection potential: $-0.50 \mathrm{~V}$ vs. SCE. Flow rate: $1.0 \mathrm{~mL} \min ^{-1}$. 


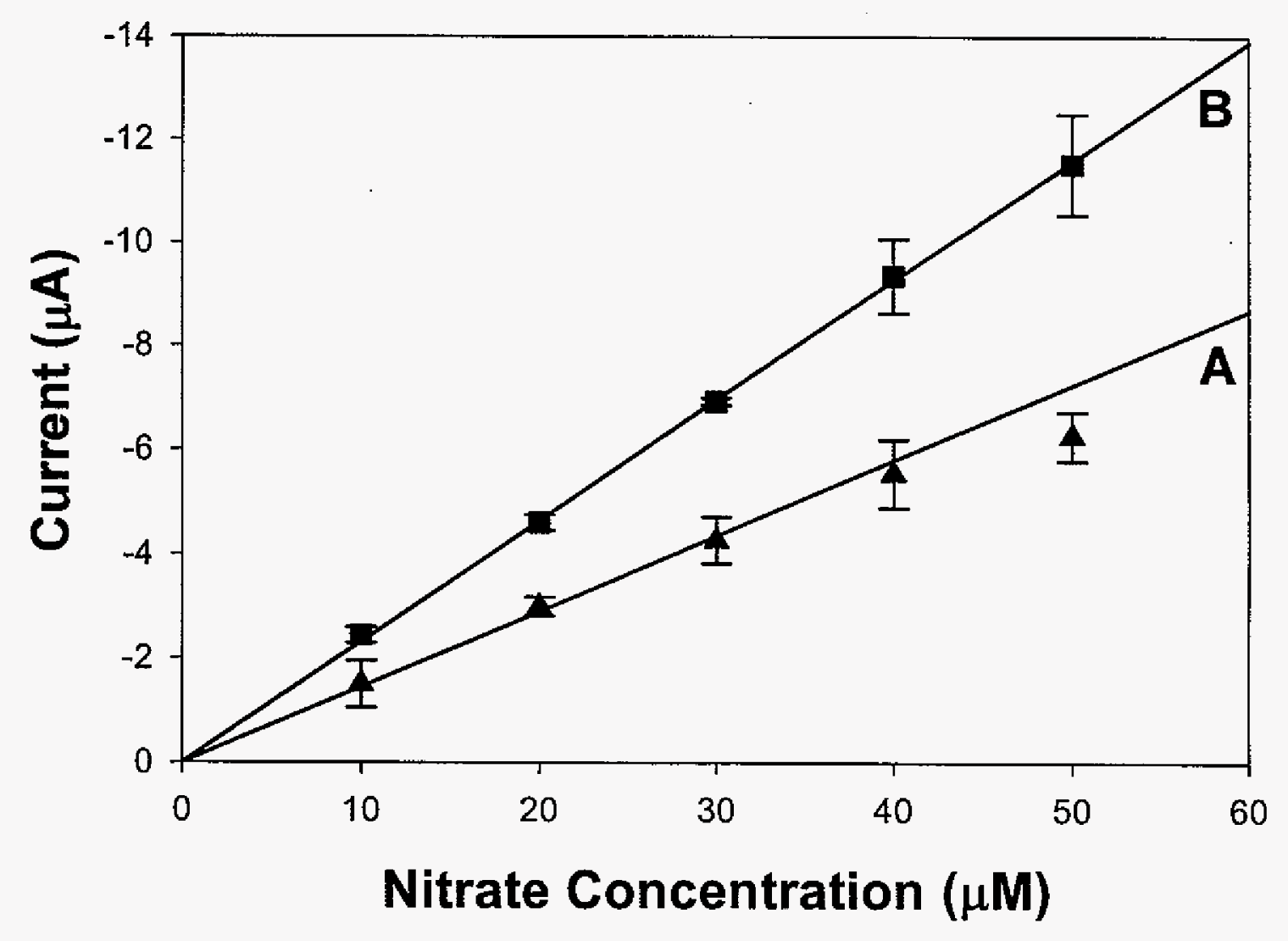

Figure 9. Peak currents by flow injection detection vs. concentration of nitrate in $1.0 \mathrm{M} \mathrm{HClO}_{4}$ using copper-nickel alloy electrodes. All points include a minimum of 10 injection peaks with standard deviation shown.

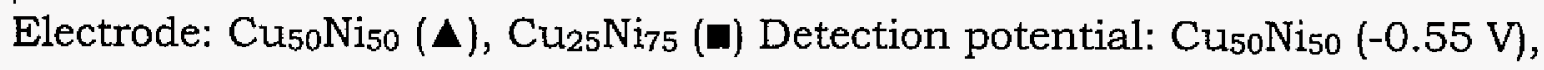
$\mathrm{Cu}_{25} \mathrm{Ni}_{75}(-0.50 \mathrm{~V}) .(-)$ linear regression line data. 


\section{CHAPTER 6. CONCLUSIONS}

\section{General Conclusions}

Throughout this thesis, the fundamental aspects involved in the electrocatalysis of anodic $\mathrm{O}$-transfer reactions and cathodic $\mathrm{H}$-transfer reactions have been studied.

The investigation into anodic O-transfer reactions at undoped and Fe(III)-doped $\mathrm{MnO}_{2}$ films revealed that $\mathrm{MnO}_{2}$ film electrodes prepared by a cycling voltammetry deposition show improved response for DMSO oxidation at the film electrodes vs. the Au substrate. Doping of the $\mathrm{MnO}_{2}$ films with Fe(III) further enhanced electrode activity. Reasons for this increase are believed to involve the adsorption of DMSO by the Fe(III) sites.

The investigation into anodic $\mathrm{O}$-transfer reactions at undoped and $\mathrm{Fe}$ (III)-doped $\mathrm{RuO}_{2}$ films showed that the $\mathrm{Fe}$ (III)-doped $\mathrm{RuO}_{2}$-film electrodes are applicable for anodic detection of sulfur compounds. The Fe(III) sites in the $\mathrm{Fe}-\mathrm{RuO}_{2}$ films are speculated to act as adsorption sites for the sulfur species while the Ru(IV) sites function for anodic discharge of $\mathrm{H}_{2} \mathrm{O}$ to generate the adsorbed $\mathrm{OH}$ species.

The investigation into cathodic $\mathrm{H}$-transfer reactions, specifically nitrate reduction, at various pure metals and their alloys demonstrated that the incorporation of metals into alloy materials can create a material that exhibits bifunctional properties for the various steps involved in the overall nitrate reduction reaction. The $\mathrm{Sb}_{10} \mathrm{Sn}_{20} \mathrm{Ti}_{70}, \mathrm{Cu}_{63} \mathrm{Ni}_{37}$ and $\mathrm{Cu}_{25} \mathrm{Ni}_{75}$ alloy 
electrodes exhibited improved activity for nitrate reduction as compared to their pure component metals. The $\mathrm{Cu}_{63} \mathrm{Ni}_{37}$ alloy displayed the highest activity for nitrate reduction.

The final investigation was a detailed study of the electrocatalytic activity of cathodic $\mathrm{H}$-transfer reactions (nitrate reduction) at various compositions of $\mathrm{Cu}-\mathrm{Ni}$ alloy electrodes. Voltammetric response for $\mathrm{NO}_{3}{ }^{-}$at the $\mathrm{Cu}-\mathrm{Ni}$ alloy electrode is superior to the response at the pure $\mathrm{Cu}$ and $\mathrm{Ni}$ electrodes. This is explained on the basis of the synergism of the two different metal sites at these binary alloy electrodes acting within the proposed response mechanism. Accordingly, adsorbed $\mathrm{H}$-atoms are generated by cathodic discharge of $\mathrm{H}^{+}$at the Ni-sites whereas adsorption of $\mathrm{NO}_{3}{ }^{-}$occurs at the Cu-sites.

\section{Future Research}

As indicated in Chapters 4 and 5, alloy electrodes can show improved electrocatalytic response for cathodic $\mathrm{H}$-transfer reactions. Binary (and ternary) alloys are a rich source for new electrode materials capable of not only cathodic $\mathrm{H}$-transfer reactions but anodic $\mathrm{O}$-transfer reactions as well. Initial studies would be in the combination of pure metals previously tested (Chapter 4) to gain further knowledge in the understanding of cathodic $\mathrm{H}$ transfer reactions. 


\section{ACKNOWLEDGEMENTS}

This work was performed at Ames Laboratory under Contract No. W7405-Eng-82 with the U.S. Department of Energy. The United States government has assigned the DOE Report number IS-T 1970 to this thesis.

I would like to thank my mother and father for being sources of constant love, support and understanding throughout my life. My brother and sister have always been there for their "little" brother and in addition, have provided me with seven nieces and nephews who have been a constant source of joy in my life for which I am forever grateful. I am also grateful to my extended family of friends back home: Jon Eck (who has been a source of goofiness I could always rely on), Eric Dalseide, and Brian Vollmer. They all have been true friends that I consider myself blessed to have.

Next on the list of acknowledgements are friends I have met during my years in graduate school. I wish to thank Tony Layson, Viken Djerdjian, Michael Klem and Rich and Crista Walsh (and of course Benny and Gus) for the friendship they have provided me. They provided much needed support during my graduate school years and I am forever in their debt. I wish to also thank, Matt and Sally Johll, who have been a second family to me, and Natasha Popovich, the Serbian sister I never had, who has provided me with so much laughter (sometimes at her own expense) that I could never thank her enough. 
The last people I wish to acknowledge are those in academia who helped me get where I am today. Mr. Gary Healy, my high school chemistry instructor, taught me the joy of bad puns and bad jokes along with some useful chemistry. Dr. Duane Weisshaar and Dr. Gary Earl, my undergraduate chemistry professors, taught me a lot about chemistry and inspired me to go into academia. And finally, I need to acknowledge Dr. Dennis C. Johnson, my Ph.D. advisor, who has been a large inspiration for me. He taught me the belief that life does exist beyond chemistry and one should take as much advantage of it as one can. 